\title{
Enhanced recovery after surgery fact or fiction?
}

Citation for published version (APA):

Maessen, J. (2009). Enhanced recovery after surgery fact or fiction? [Doctoral Thesis, Maastricht University]. Datawyse / Universitaire Pers Maastricht. https://doi.org/10.26481/dis.20091106jm

Document status and date:

Published: 01/01/2009

DOI:

10.26481/dis.20091106jm

Document Version:

Publisher's PDF, also known as Version of record

\section{Please check the document version of this publication:}

- A submitted manuscript is the version of the article upon submission and before peer-review. There can be important differences between the submitted version and the official published version of record.

People interested in the research are advised to contact the author for the final version of the publication, or visit the DOI to the publisher's website.

- The final author version and the galley proof are versions of the publication after peer review.

- The final published version features the final layout of the paper including the volume, issue and page numbers.

Link to publication

\footnotetext{
General rights rights.

- You may freely distribute the URL identifying the publication in the public portal. please follow below link for the End User Agreement:

www.umlib.nl/taverne-license

Take down policy

If you believe that this document breaches copyright please contact us at:

repository@maastrichtuniversity.nl

providing details and we will investigate your claim.
}

Copyright and moral rights for the publications made accessible in the public portal are retained by the authors and/or other copyright owners and it is a condition of accessing publications that users recognise and abide by the legal requirements associated with these

- Users may download and print one copy of any publication from the public portal for the purpose of private study or research.

- You may not further distribute the material or use it for any profit-making activity or commercial gain

If the publication is distributed under the terms of Article $25 \mathrm{fa}$ of the Dutch Copyright Act, indicated by the "Taverne" license above, 
Enhanced Recovery After Surgery

Fact or Fiction? 


\section{Funding}

Nutricia was the main funding source of the initial ERAS collaboration and sponsored the execution of the studies underlying this thesis. Part of the studies were also supported by a grant of the Netherlands Organisation for Health Research and Development (ZonMw)
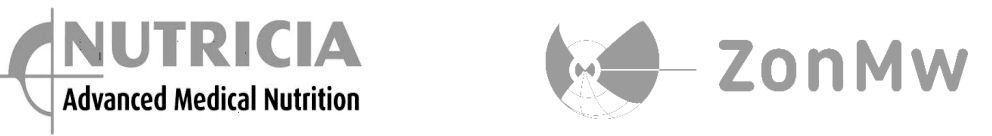

\section{Publication}

Financial support for publication of this thesis has kindly been provided by Nutricia.

\section{Layout and cover design}

Cover: Pieter Ritzen

Layout: José Maessen

\section{Production}

Datawyse | Universitaire Pers Maastricht

ISBN: 9789052788715

(C) Copyright, José Maessen, Maastricht 2009 


\title{
Enhanced Recovery After Surgery Fact or Fiction?
}

\author{
Proefschrift
}

ter verkrijging van de graad van doctor aan de Universiteit Maastricht, op gezag van de Rector Magnificus, Prof. mr. G.P.M.F. Mols

volgens het besluit van het College van Decanen, in het openbaar te verdedigen op vrijdag 6 november 2009 om 16:00 uur

door

José Maessen

$\underbrace{\underbrace{\top}_{1}}_{\substack{\text { UNIVERSITAIRE } \\ \text { PERS MAASTRICHT }}}$ 


\section{Promotores}

Prof. dr. M.F. von Meyenfeldt

Prof. dr. C.H.C. Dejong

\section{Copromotor}

Dr. T. van der Weijden

\section{Beoordelingscommissie}

Prof. dr. M. van Kleef, voorzitter

Dr. M.A.E. van Bokhorst - de van der Schueren, VU Medisch Centrum

Prof. Dr. C.J.H.M. van Laarhoven, UMC St. Radboud

Dr. H. Tange

Prof. Dr. R. de Wit 


\section{Table of Contents}

$\begin{array}{lll}\text { Chapter } 1 & \text { General Introduction } & 7\end{array}$

\section{Part $1 \quad$ Initial international experiences}

Chapter 2 Fast track perioperative care programmes in colonic surgery 21

Chapter 3 A protocol is not enough to implement an enhanced 35 recovery programme for colorectal resection

\section{Part 2 Experiences at Maastricht University Medical Centre}

Chapter 4 Length of stay: an inappropriate readout of the success of enhanced recovery programmes

Chapter 5 Enhanced recovery after surgery: fact or fiction?

Chapter 6 Reasons for poor adoption of evidence based recommendations for postoperative recovery in colonic surgery

\section{Part 3 Experiences in the Netherlands}

Chapter 7 Perioperative care in elective colonic surgery in the Netherlands in the new millennium: are we doing what we should do?

Chapter 8 Life and death of the nasogastric tube in elective colonic surgery in the Netherlands

Chapter 9 To eat or not to eat: facilitating early oral intake after colonic surgery in the Netherlands 



\section{Chapter 1}

General introduction 


\section{Postoperative recovery}

In order to structure the perioperative care process of ambulatory surgery, postoperative recovery is conveniently divided in three distinct phases.

The early recovery phase lasts from discontinuation of anaesthetic agents until the patient is awake and vital protective reflexes and motor function have recovered. This phase requires close monitoring and supervision and normally takes place in the post anaesthesia care unit (PACU).

The intermediate recovery phase is the phase of clinical recovery that takes place in the surgical unit and lasts from when the patient has regained stable vital functions until he is ready to go home.

The late recovery phase lasts from discharge from the hospital until the patient reaches complete functional, physiological and psychological recovery ${ }^{1,2}$.

\section{Accelerating postoperative recovery: the concept of fast track surgery}

In the early 1990's surgery underwent revolutionary changes due to the introduction of ultra short acting anaesthetics, the development of regional anaesthetic techniques to control pain and the use of minimally invasive open or laparoscopic techniques in surgery. Combining these new anaesthetic and analgesic methods with these new surgical techniques in a treatment pathway shortened the time required for the early and intermediate postoperative recovery considerably.

In ambulatory surgery, patients regained vital reflexes in the operating room and could directly be transferred to the day surgery unit, thereby bypassing the post anaesthesia care unit (PACU). This so termed "fast tracking" treatment path was aimed to streamline ambulatory surgery.

Recovery times of patients who were fast tracked were significantly shorter compared to those for patients who were not fast tracked ${ }^{3}$ and patients that were able to bypass the PACU were discharged home earlier than patients who were not ${ }^{4,5}$. Other arguments brought up to justify the "fast tracking" concept were reduced nursing workload, reduced costs and improved quality of care by focussing attention on getting patients back to their preoperative status as quickly as possible ${ }^{6,7,8}$ The expansion of the fast track concept to more major surgical procedures resulted in an increasing number of surgical procedures being performed as short stay surgery. Prostatectomies, pneumonectomies, total hip and knee replacements and peripheral vascular reconstructions are procedures that are nowadays performed in a short stay setting ${ }^{9}$. 


\section{Fast track colonic surgery}

The expansion of the fast track concept to colonic surgery has been pioneered by Henrik Kehlet, a surgeon of the Hvidovre University Hospital in Denmark. He reported on a median postoperative hospital stay of two days in 60 consecutive colectomy patients who were treated in a fast track surgery programme ${ }^{10}$, whereas colonic surgery usually requires a postoperative hospital stay of 5-10 days ${ }^{11}$.

The median age of the patients was 74 years and most of the patients had comorbidity; only 18 patients were considered to have no significant concomitant illnesses and had normal preoperative mobility. Within two days, patients tolerated early nutrition, all but three of the patients had defecation and patients were spending between five and six hours out of bed.

Kehlet emphasized that major improvements in recovery may require a multifaceted approach (Figure 1$)^{12}$.Stress induced organ dysfunction, pain, nausea and vomiting, ileus, hypoxemia and sleep disturbances, fatigue, immobilisation and semi-starvation and traditional perioperative care principles such as the use of drains, nasogastric tubes, fasting regimes and bed rest were identified as key factors that contribute to the postoperative functional deterioration.

Staff training/reorganisation and procedure specific care plans

Preoperative patient information and optimisation of organ function
Stress reduction

- Regional anaesthesia

- Minimal invasive operations

- Normothermia

- Pharmacological modifiers
Effective pain relief and prophylaxis for nausea and vomiting
Modification of postoperative care

- Early mobilisation

- Minimal use of tubes and drains

Figure 1. Multimodal Interventions required for major improvement in surgical outcome

Kehlet developed a multimodal rehabilitation programme that combined a number of interventions to reduce the stress of the surgical procedure, risk of organ dysfunction and loss of functional capacity. This multimodal programme involved the cancellation of traditional perioperative care principles such as immobilisation, drains, nasogastric tubes and fasting, while introducing innovations such as carbohydrate loaded liquids before surgery, regional anaesthetic techniques, minimally invasive open or laparoscopic surgical techniques, maintenance of normal tem- 
perature during surgery, optimal treatment of postoperative pain and prophylaxis for nausea and vomiting ${ }^{13,14}$.

The application of this multimodal rehabilitation programme after colonic resections significantly reduced length of hospitalisation ${ }^{10-15}$ and significantly improved postoperative recovery, physical performance, pulmonary function, body composition $^{16}$, and convalescence ${ }^{17}$.

Other single centre groups have subsequently confirmed that the application of such fast track multimodal perioperative care programmes in colorectal surgery patients results in a reduced length of hospital stay, less morbidity, reduced postoperative ileus, improved pulmonary function, less pain, and less fatigue ${ }^{18-19}$

\section{Enhanced Recovery After Surgery}

In 2001 the Enhanced Recovery After Surgery (ERAS) group was established as a collaboration of university or specialised departments of surgery from five northern European centres: Kehlet's group of the Hvidovre University Hospital, Hvidovre, Denmark, practicing fast track surgery and four centres practicing a more traditional pattern of care: the Royal Infirmary, Edinburgh, UK, the Karolinska Institutet at Ersta Hospital, Stockholm, Sweden, the University Hospital of Northern Norway, Troms $\varnothing$, Norway and Maastricht University Medical Centre, Maastricht, the Netherlands.

The ERAS group reviewed the case-mix, clinical management and clinical outcomes of colorectal surgery patients in these five participating centres ${ }^{20}$. A retrospective chart review was undertaken over a one year period between 1998 and 2001 and 451 consecutive patients undergoing an open colorectal resection above the peritoneal reflection were evaluated.

As expected, length of stay was significantly shorter in the "fast track" centre of Denmark compared to the centres practicing traditional care (a median of 2 days versus a median of 7-9 days). Based on patient demographics such as age, BMI, gender and P-Possum scores it was concluded that the surgical populations were comparable between the five centres and that case-mix did not account for the reduced length of hospitalisation. The reduction in length of stay in Denmark had no significant influence on morbidity and 30-day mortality, but was associated with increased readmission rates. The elements of perioperative care applied in each hospital varied widely, both within the traditional care centres and in comparison with the centre performing fast track surgery.

With the Danish experience as a starting point, the ERAS group considered the evidence base for individual components of perioperative care and developed a new evidence based programme (the ERAS protocol) that presented recommendations on how surgical patients undergoing a colonic resection should be cared for ${ }^{21}$. 
Using a multidisciplinary team approach, with a focus on stress reduction and early return of function, the ERAS protocol aims to allow patients to recover more quickly from major surgery.

The key recommendations of the ERAS guideline comprise preoperative patient information and counselling, no oral bowel preparation, no preoperative fasting, preoperative carbohydrate loading, no pre-anaesthetic medication, single dose antibiotic prophylaxis half an hour before surgery, short incisions, avoidance of long acting opioids, mid-thoracic epidural anaesthesia, paracetamol as baseline analgesic, avoidance of fluid overload, use of an upper-body forced-air heating cover, no drains, no nasogastric decompression tubes, prevention of postoperative nausea and vomiting in risk patients, standard laxatives, early removal of urinary bladder catheters, early oral nutrition and nutritional supplements and early mobilisation (Figure 2).

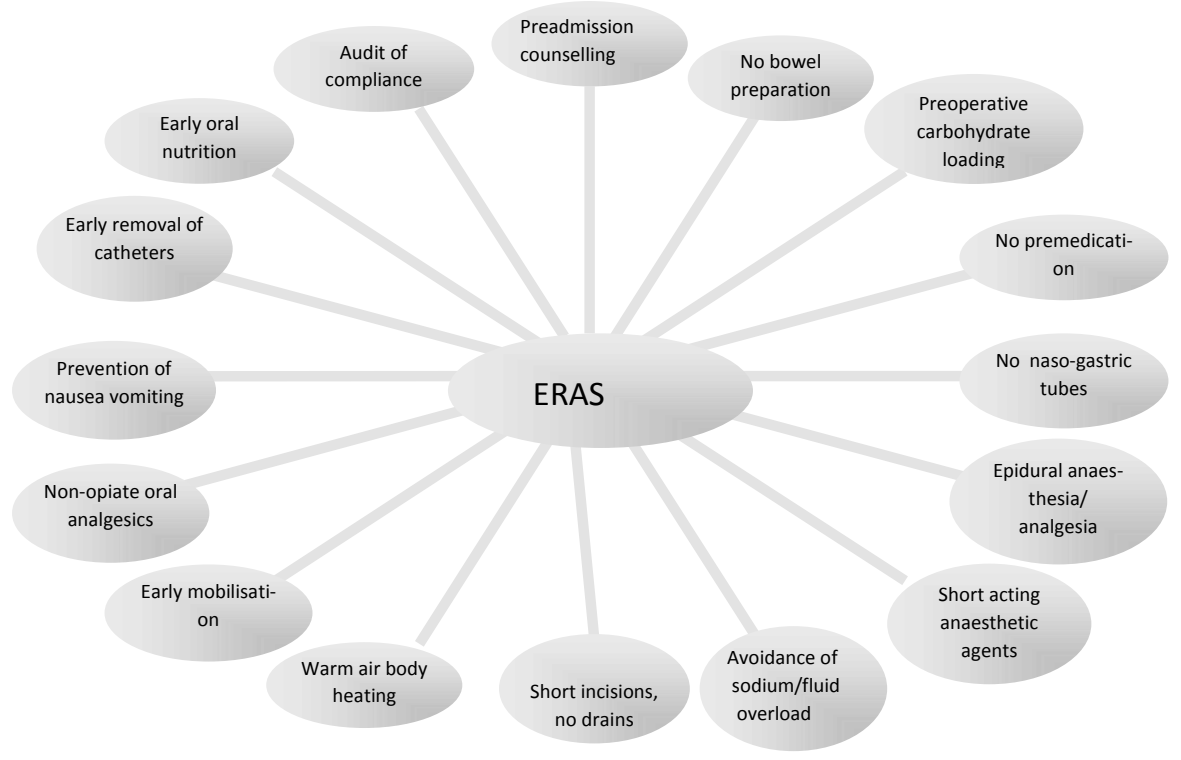

Figure 2. The essential elements of the Enhanced Recovery After Surgery programme

\section{The gap between evidence and practice}

One of the most consistent findings in health services research is the gap between best practice (what should be done according to scientific evidence) on the one hand and actual clinical practice (what is done) on the other hand ${ }^{22}$. Studies suggest that at least $30-40 \%$ of the patients do not receive care according to current 
scientific evidence, while more than $20 \%$ of the care provided is not needed or potentially harmful to patients ${ }^{23,24,25}$.

In 2003 the ERAS group studied perioperative care in the five countries belonging to the ERAS group ${ }^{26}$. A questionnaire, especially designed to obtain information on surgical routines, was mailed to the head surgeons of all digestive surgical centres.

The study revealed that perioperative care in colorectal cancer treatment in northern Europe varied widely and differed substantially from evidence based practice. Lassen stated that "in spite of a large evidence base for perioperative care, surgical patients remain exposed to unnecessary starvation, suboptimal stress reduction and fluid overload". The results of this postal survey were later confirmed by actual measurements in a study by Kehlet et $\mathrm{al}^{27}$.

In the Netherlands also a broad variation existed in the provision of care for colorectal surgery patients. Clinicians did not adhere to the best scientific evidence. Oral bowel preparation and a nasogastric decompression tube were widely used. There were no restrictions on routine intravenous fluid and sodium administration and a nil by mouth regimen postoperatively was still the rule. Postoperative epidural anaesthesia/analgesia was well implemented but although patients were thus optimally prepared to tolerate a normal diet soon after surgery, more than half of the Dutch centres did not allow patients to eat solid food until they moved bowels, passed gas or passed stool.

\section{Closing the gap between evidence and practice.}

An important reason for the gap between guideline and practice is the accumulation of an enormous amount of information about what works and what does not work to produce good outcomes in health care. Data from the Medline database illustrate the rise of published randomised clinical trials from just over 100 per year in 1966 to nearly 10.000 annually in $1995^{28}$, which has 10 years later risen to 16.000 in 2005 . It is literally impossible for any clinician to read all of the relevant literature and to keep knowledge up to date.

The development of evidence based clinical practice guidelines has been embraced as one of the most promising and effective tools for improving the uptake of research findings in every day practice. Guidelines combine reviews of the scientific literature with insights from clinical practice to generate concrete recommendations that may help clinicians and patients to decide on appropriate care for specific clinical circumstances ${ }^{29}$.

In 2001 the ERAS group searched the literature, weighted the strength of the evidence from trials and defined concrete recommendations about the management of patients undergoing elective colorectal resections. In the beginning of 2002 the new guideline was disseminated to the locally involved professionals by means of 
presentations and discussion, and practitioners of the four traditional care ERAS centres started to treat patients in accordance with the ERAS guideline. In 2005 the ERAS guideline was published in a scientific clinical journal ${ }^{21}$, the protocol was presented at several national and international conferences and was used as basis for the module on Perioperative Nutrition of the ESPEN (the European Society for Clinical Nutrition and Metabolism) Life Long Learning educational programme.

\section{The Breakthrough Series}

The Institute for Healthcare Improvement (IHI) is an American non profit organisation created in 1991 to help lead the improvement of health care in the U.S.A. In its initial years, $\mathrm{IHI}$ activities were focused on providing courses on a wide range of improvement topics. In 1995 the IHI studied the impact of these efforts on national health care performance and demonstrated that standard educational methods such as lecture style conferences did not improve health care.

Seeking to have a greater and more immediate impact on health care outcomes, $\mathrm{IHI}$ constructed the Breakthrough Series, a model for achieving breakthrough improvements $^{30}$. The Breakthrough Series approach differs in important ways from earlier approaches to quality improvement cycles. Such improvements may involve long periods of auditing outcome and/or performance data, baseline data collection, prioritizing opportunities, identifying changes required and finally implementing changes. The Breakthrough Series is a short term learning system (6-15 months). The time of analysing the sources of the problem and possible solutions is reduced through increased reliance on existing scientific knowledge and experience.

Key features of the methodology are plan-do-study-act cycles, cycles of improvements, that involves planning of improvements, carrying out the plans, measuring the results and acting on what is learned. These cycles continue serially over time and refinement is added with each cycle. The implementation activities are guided by an expert team: subject matter experts in a specific clinical area combined with implementation experts. This expert team helps organisations to select, test and implement changes of care within a short time frame.

In 2006 a nationwide breakthrough project concerning the implementation of the ERAS protocol was initiated by the Dutch Institute for Healthcare Improvements (CBO). All Dutch hospitals were invited to participate and within a short timeframe 26 Dutch hospitals (one quarter of all Dutch hospitals) signed up for the Breakthrough Series "Perioperative Care", wich was conducted in two series of 12 and 14 hospitals each. At present, a third series of nine hospitals is progressing through the implementation of the ERAS guideline. 


\section{Aims of the thesis}

Evidence that a multimodal rehabilitation programme was superior to traditional perioperative care was already generated in various randomised controlled trials. However, there was no evidence that these effects were reproducible in real life clinical practice. Most case series are from single surgeons or single surgical wards and are thus strongly influenced by the interests and expertise of the surgeon as well as the case load that is seen in the respective institutions.

The aim of the present thesis was to evaluate the implementation of the evidence based perioperative care guideline of the Enhanced Recovery After Surgery group in every day practice, including all patients that are scheduled for a colon resection and all practitioners in the department involved in colonic surgery, with varying experience and acceptance of the principles of the multimodal program.

The following sub-aims were defined:

Process evaluation:

- to evaluate to what level the ERAS guideline can be implemented in daily practice

- to evaluate what difficulties arise when introducing an ERAS programme in daily care

Effect evaluation

- to evaluate whether the anticipated effects of the multimodal approach on clinical recovery and length of stay can be reproduced in an every day setting

\section{Outline of the thesis}

\section{Part 1: Initial international experiences}

In chapter 2 the perioperative care elements of a fast track programme in colonic surgery are discussed and results of randomised clinical controlled trials that have been published on fast track colonic surgery are reviewed.

In chapter 3 the initial experiences of the application of the ERAS protocol in the five European centres of the ERAS collaboration are described. The study evaluated the influence of changing perioperative routines to the ERAS programme on recovery and length of stay. Elements that contribute to length of stay and recovery were examined. 


\section{Part 2: Experiences at Maastricht University Medical}

\section{Centre}

Initial experience has demonstrated that the influence of the ERAS programme on length of stay was partly frustrated by an additional stay of a median of two days after patients were recovered. In chapter 4 this discrepancy between fulfilling discharge criteria and actual discharge is evaluated.

The overall aim of an enhanced recovery after surgery programme is "to allow patients to recover more quickly from major surgery". Chapter 5 evaluates whether the implementation of the ERAS programme in every day practice resulted in a faster recovery of colorectal surgery patients.

Initial experience has also demonstrated that adherence to the protocol was troublesome, especially in the postoperative phase. In chapter 6 the reasons for poor adoption of the recommendations of the ERAS protocol are described. These reasons are translated in barriers and incentives to change practice.

\section{Part 3: Experiences in the Netherlands}

In chapter 7, 8 and 9 results of the Breakthrough project "Perioperative Care" that concerned the synchronous implementation of the ERAS programme in 26 hospitals in the Netherlands are described. As the third series of 9 hospitals is still ongoing, these results have not been included. In chapter 7, results of a baseline measurement of processes and outcomes of perioperative care in the 26 hospitals that participated to the Breakthrough Series are described. In chapter 8 the effect of the ERAS programme on the elimination of the inappropriate use of nasogastric decompression tubes is reported. Chapter 9 describes the results of the implementation of early oral nutrition postoperatively.

In chapter 10 all findings are discussed and recommendations for clinical patient care and future reseach are given. In chapter 11 the findings of the different studies are summarized and the general concusion of this thesis is presented. 


\section{References}

1. Steward DJ, Volgyesi G. Stabilometry: a new tool for the measurement of recovery following general anaesthesia for out-patients. Can Anaesth Soc J 1978;25(1):4-6.

2. Marshall $\mathrm{SI}$, Chung F. Discharge criteria and complications after ambulatory surgery. Anesth Analg 1999;88(3):508-17.

3. Apfelbaum JL, Walawander CA, Grasela TH, Wise P, McLeskey C, Roizen MF, et al.Eliminating intensive postoperative care in same-day surgery patients using short-acting anesthetics. Anesthesiology 2002;97(1):66-74.

4. Williams BA, Kentor ML, Williams JP, Figallo CM, Sigl JC, Anders JW, et al. Process analysis in outpatient knee surgery: effects of regional and general anesthesia on anesthesia-controlled time.[see comment]. Anesthesiology 2000;93(2):529-38.

5. Duncan PG, Shandro J, Bachand R, Ainsworth L, Duncan PG, Shandro J, et al. A pilot study of recovery room bypass ("fast-track protocol") in a community hospital. Canadian Journal of Anaesthesia 2001;48(7):630-6.

6. Watkins AC, White PF, Watkins AC, White PF. Fast-tracking after ambulatory surgery. Journal of PeriAnesthesia Nursing 2001;16(6):379-87.

7. Awad I, Chung F. Discharge criteria and recovery in ambulatory surgery. Day Surgery. Development and Practice 2006:241-255.

8. Deutsch N, Wu CL. Patient outcomes following ambulatory anesthesia. Anesthesiol Clin North America 2003;21(2):403-15.

9. Wilmore DW, Kehlet H. Management of patients in fast track surgery. BMJ 2001;322(7284):473-6.

10. Basse L, Hjort Jakobsen D, Billesbolle P, Werner M, Kehlet H. A clinical pathway to accelerate recovery after colonic resection. Ann Surg 2000;232(1):51-7.

11. Schoetz DJ, Jr., Bockler M, Rosenblatt MS, Malhotra S, Roberts PL, Murray JJ,et al. "Ideal” length of stay after colectomy: whose ideal?Dis Colon Rectum 1997;40(7):806-10.

12. Kehlet $\mathrm{H}$. Multimodal approach to control postoperative pathophysiology and rehabilitation. $\mathrm{Br} \mathrm{J}$ Anaesth 1997;78(5):606-17.

13. Kehlet $\mathrm{H}$, Wilmore DW. Multimodal strategies to improve surgical outcome.Am J Surg 2002;183(6):630-41.

14. Kehlet H, Dahl JB, Kehlet H, Dahl JB. Anaesthesia, surgery, and challenges inpostoperative recovery. Lancet 2003;362(9399):1921-8.

15. Kehlet $\mathrm{H}$, Mogensen $\mathrm{T}$. Hospital stay of 2 days after open sigmoidectomy with a multimodal rehabilitation programme. Br J Surg 1999;86(2):227-30.

16. Basse L, Raskov HH, Hjort Jakobsen D, Sonne E, Billesbolle P, Hendel HW, et al.Accelerated postoperative recovery programme after colonic resection improves physical performance, pulmonary function and body composition. Br J Surg 2002;89(4):446-53.

17. Jakobsen DH, Sonne E, Andreasen J, Kehlet H, Jakobsen DH, Sonne E, et al. Convalescence after colonic surgery with fast-track vs conventional care. Colorectal Disease 2006;8(8):683-7.

18. Bradshaw BG, Liu SS, Thirlby RC. Standardized perioperative care protocols and reduced length of stay after colon surgery. J Am Coll Surg 1998;186(5):501-6.

19. Gatt M, Anderson AD, Reddy BS, Hayward-Sampson P, Tring IC, MacFie J, et al.Randomized clinical trial of multimodal optimization of surgical care in patients undergoing major colonic resection.[see comment]. Br.J.Surg 2005;92(11):1354-62.

20. Nygren J, Hausel J, Kehlet H, Revhaug A, Lassen K, Dejong C, et al. A comparison in five European Centres of case mix, clinical management and outcomes following either conventional or fasttrack perioperative care in colorectal surgery. Clin Nutr 2005;24(3):455-61.

21. Fearon KC, Ljungqvist $\mathrm{O}$, Von Meyenfeldt $\mathrm{M}$, Revhaug $\mathrm{A}$, Dejong $\mathrm{CH}$, Lassen $\mathrm{K}$, et al. Enhanced recovery after surgery: a consensus review of clinical care for patients undergoing colonic resection. Clin Nutr 2005;24(3):466-77. 
22. Bodenheimer T, Bodenheimer T. The American health care system-the movement for improved quality in health care.[see comment]. N Engl J Med 1999;340(6):488-92.

23. Schuster MA, McGlynn EA, Brook RH, Schuster MA, McGlynn EA, Brook RH. How good is the quality of health care in the United States? 1998.Milbank Quarterly 2005;83(4):843-95.

24. Grol R, Grimshaw J. From best evidence to best practice: effective implementation of change in patients' care. Lancet 2003;362(9391):1225-30.

25. Grol R, Wensing M, Grol R, Wensing M. What drives change? Barriers to and incentives for achieving evidence-based practice. Medical Journal of Australia 2004;180:S57-60.

26. Lassen K, Hannemann P, Ljungqvist O, Fearon K, Dejong CH, von Meyenfeldt MF,et al. Patterns in current perioperative practice: survey of colorectal surgeons in five northern European countries. BMJ 2005;330(7505):1420-1.

27. Kehlet $\mathrm{H}$, Williamson R, Buchler MW, Beart RW, Kehlet $\mathrm{H}$, Williamson R, et al. A survey of perceptions and attitudes among European surgeons towards the clinical impact and management of postoperative ileus. Colorectal Disease 2005;7(3):245-50.

28. Chassin MR. Is health care ready for Six Sigma quality? Milbank Q 1998;76(4):565-91, 510.

29. Field M, Lohr K. Clinical practice guidelines: directions for a new agency.Washington DC: National Academy Press 1990.

30. Kilo CM. A framework for collaborative improvement: lessons from the Institute for Healthcare Improvement's Breakthrough Series.Qual Manag Health Care 1998;6(4):1-13. 



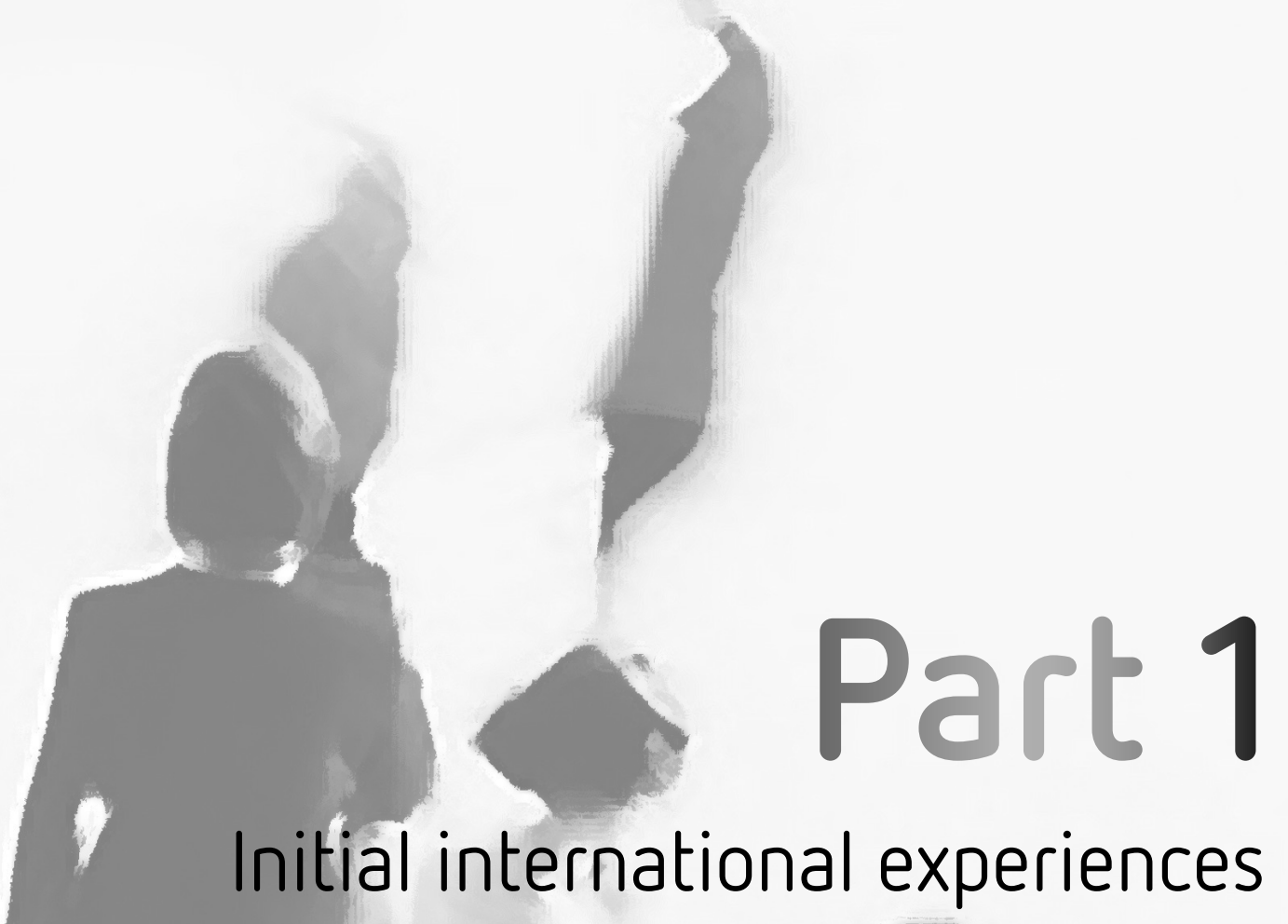





\section{Chapter 2}

\section{Fast track perioperative care programmes in colonic surgery}

J. Wind, J.Maessen, S.W. Polle W.A. Bemelman, M.F. von Meyenfeldt,C.H.C. Dejong, on behalf of the LAFA and Enhanced Recovery After Surgery group

Nederlands Tijdschrift voor Geneeskunde 2006; 150: 229-304

"Ik heb gisteren en vandaag al buiten gewandeld."

Patient P, 4 dagen na operatie 


\section{Abstract}

Fast track perioperative care programmes are intensive multimodal programmes, combining a number of perioperative care elements with the goal to preserve normal preoperative body composition, organ functions, and to actively enhance postoperative recovery. Fast track perioperative care programmes have been introduced into the perioperative protocol of several surgical procedures. This article reviews the use of fast track perioperative care in colonic surgery.

The essence of fast track perioperative care in colonic surgery consists of extensive preoperative counselling, no preoperative fasting but adequate nutrition, reducing surgical trauma, abstaining routine use of drains and nasogastric tubes, tailored anaesthesiology encompassing thoracic epidural, early and enhanced postoperative feeding and mobilisation, and medical support with prokinetics and laxatives. A systematic review demonstrates that fast track perioperative care programmes, in colonic surgery, enhance recovery and shorten primary and overall hospital stay. 


\section{Introduction}

In the previous decades, there has been a tendency to aim for a shorter hospital stay following several surgical procedures, including colorectal surgery. There are many reasons for this; firstly, increasing knowledge has improved the understanding of how the postoperative convalescence of a patient can be accelerated. Secondly, the aim to reduce hospital stay is based on economic efficiency. Furthermore, several technical developments play an important role, including the introduction of minimally invasive (laparoscopic) surgery, and the introduction of fast track perioperative care programmes also referred to as Enhanced Recovery After Surgery (ERAS ${ }^{\circ}$ ).

Fast track programmes combine a number of perioperative elements (Figure1), in order to preserve normal preoperative body composition and organ functions, and to actively enhance postoperative recovery. This results in a faster recovery, less morbidity and a shorter hospital stay ${ }^{1-11}$.

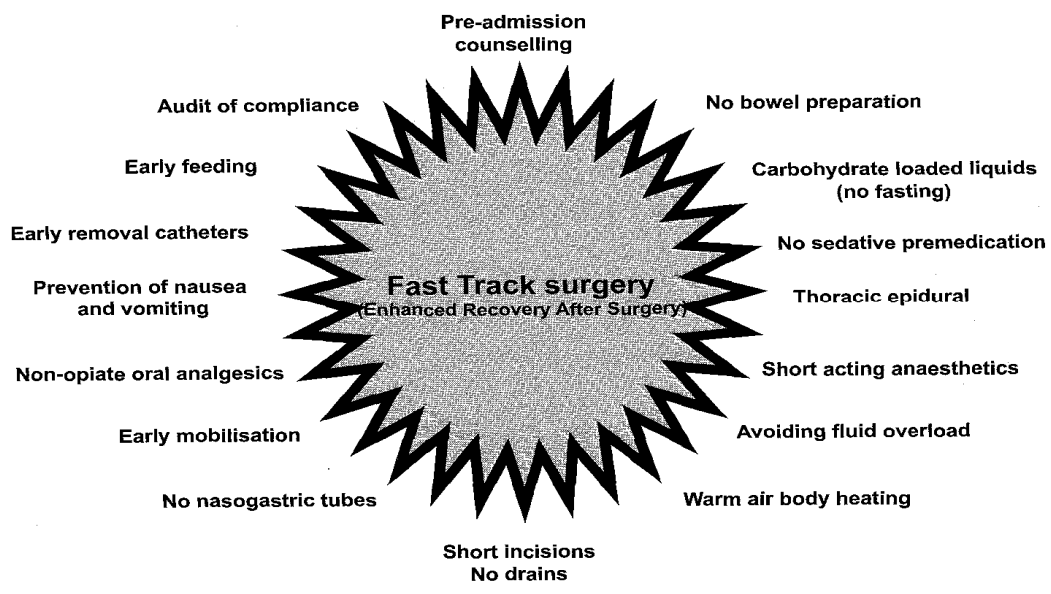

Figure 1. The essential elements of the fast track perioperative care programme.

Kehlet et al. developed a multimodal fast track perioperative care programme specifically for elective large bowel surgery. This programme is aimed to enhance postoperative recovery and to avoid common reasons that interfere with early hospital discharge, such as the need for parenteral analgesics or fluids, inadequate oral intake, delayed patient mobilisation, complications, and lack of home care $^{1-6}$. The essence of Kehlet's and other fast track programmes in colonic surgery, comprises of extensive preoperative counselling, adequate preoperative nutrition including no preoperative fasting but carbohydrate loaded liquids until two hours 
prior to surgery, no bowel preparation, and no sedative pre-medication. Furthermore, the fast track programme includes tailored anaesthesiology encompassing thoracic epidural anaesthesia and short acting anaesthetics, non-opioid pain management, avoiding perioperative fluid overload, minimal invasive surgery, no routine use of drains and nasogastric tubes, early removal of bladder catheters, standard laxatives and prokinetics, and early and enhanced postoperative feeding and mobilisation. A reduction in hospital stay of up to two or three days after elective open segmental colectomy has been reported, in a fast track care programme ${ }^{1-6}$.

Although many surgeons currently apply some of the fast track elements which are not incorporated in a complete fast track perioperative care programme, such as the omission of oral bowel preparation and drains, and early removal of the nasogastric tube, considerable variation still exists throughout Europe in the degree into which these elements are applied into daily practice ${ }^{12-15}$.

Apart from elective large bowel surgery, fast track programmes have been successfully applied in several fields of elective surgery, e.g. for aortic aneurysm repair, pulmonary lobectomy, and laparoscopic gastro-oesophageal reflux surgery ${ }^{16-18}$. In this paper, the individual elements of fast track perioperative care will be discussed, followed by a systematic review of prospective clinical controlled trials that have been published on fast track perioperative care programmes used in elective segmental colorectal resections.

\section{Fast track perioperative care elements}

\section{Preoperative fast track care elements}

In fast track perioperative care, preoperative counselling is more extensive compared to traditional care. Patients are informed on the important elements of fast track perioperative care, such as the importance of early mobilisation and diet resumption to reduce starvation and muscle loss, which is facilitated by tailored loco-regional analgesia and medicinal support. Furthermore, at this first meeting, the patient is informed on his/ her active role with specific tasks in the early postoperative period. These tasks include targets for oral intake and mobilisation. It is also important to discuss when discharge can be expected ${ }^{19-22}$.

Patients included in the fast track programme do not receive oral bowel preparation. Patients only receive two enemas before surgery (evening before and preoperatively). In recent meta-analyses on bowel preparation it has been shown that there are no advantages of oral bowel preparation in colonic surgery ${ }^{23-25}$. On the contrary, it is suggested that after bowel preparation more anastomotic leaks might occur and there is also a trend towards more wound infections, peritonitis and mortality. Other drawbacks of oral bowel preparation include longer preoperative hospitalisation, induction of stress-response, and disturbance of the physio- 
logical bowel motility and bacterial flora. Furthermore, bowel preparation can result in dehydration and electrolyte abnormalities.

Besides the patients' own medication, patients who are treated in a fast track perioperative care programme do not receive sedative pre-medication. Premedication, most often consisting of benzodiazepines, might result in a somnolent/sedated patient both pre- and postoperatively. As a consequence, provided information is not interpreted adequately and active mobilisation is reduced ${ }^{26}$. As the patient starts with oral intake and mobilisation directly after surgery, sedation is undesirable.

The Dutch Anaesthesia Society states that intake of dear fluids up to 2-4 hours before initiation of anaesthesia is safe. However, in daily practice this implies that a patient has to fast from the evening before the operation. This is unnecessary because dear liquids or carbohydrate loaded beverages are out of the stomach within 90 minutes and thereafter there is no increased risk of aspiration ${ }^{15,27-29}$. Another advantage of offering dear carbohydrate loaded beverages two hours before surgery is that it reduces preoperative thirst, hunger, anxiety, and glycogen depletion. Finally, postoperatively insulin resistance is reduced with less risk of hyperglycae$\operatorname{mia}^{15,29}$.

\section{Perioperative fast track care elements}

An important element of anaesthesiologic care in the fast track programme is thoracic epidural analgesia which is commenced preoperatively and continued until two days postoperatively. This thoracic epidural catheter provides optimal pain relief, with the preservation of the patients' normal capability of mobilisation (i.e. no motor function loss of the legs). Furthermore, the use of epidural analgesia results in a reduction of systemic opioid usage. Finally, afferent nerves from the surgical field are blocked (symphatic block) resulting in a reduced stress-response, less gut paralysis, and a decreased risk of pulmonary complications ${ }^{15,30-32}$.

General anaesthesia is accomplished by agents with short pharmaco-dynamic duration resulting in a shorter stay in the recovery department. As a result pro-active recovery is possible on the day of surgery. Postoperative nausea and vomiting are treated with a combination of anti-emetic drugs ${ }^{15,32,33}$.

The surgical "access trauma" is reduced by using small incisions resulting in a reduction of the inflammatory- and neuro-endocrine stressrespons ${ }^{14,34-36}$. A further reduction might be accomplished with a laparoscopic approach. In a meta-analysis on the safety and effectiveness of elective laparoscopic segmental colorectal resections for malignancy it has been demonstrated that laparoscopy, within a traditional care setting, is associated with less morbidity, an enhanced recovery of gastro-intestinal motility, and a shorter hospital stay ${ }^{37}$. However, others have shown 
no differences between laparoscopic and open surgery within a fast track perioperative care programme ${ }^{38}$.

Surgical incisions are infiltrated with a local anaesthetic agent which results in less wound pain. Infiltration of the operative field prior to the incision, results in a better pain control when compared to infiltration during wound closure ${ }^{39,40}$.

During (prolonged) operative procedures there is a risk of hypothermia. During rewarming of the patient, catecholamines and cortisol are released which enhance the stress-response. Prevention of hypothermia with upper-body forced-air heating covers (Bair Hugger ) and infusion of warmed fluids, is important for the reduction of the stress-response, complications, and organ dysfunction ${ }^{4}$. It has been shown that active hypothermia prevention reduces the risk of wound infection, blood loss, cardiac complications and discomfort ${ }^{41,42}$.

Recent literature has demonstrated that restriction of perioperative iv. fluids $(1500-3000 \mathrm{ml})$ reduces postoperative morbidity and shortens postoperative ileus $^{32,43,44}$. Furthermore, patients treated according to fast track perioperative care principles have a reduced need for iv. fluids because of the omission of oral bowel preparation and an increased oral intake perioperatively. Patients with an epidural may experience vasodilatation leading to hypotension. Judicious use of vasopressors in the treatment of this hypotension can avoid excessive fluid administration ${ }^{45}$. In two meta-analyses it has been demonstrated that routine nasogastric decompression should be avoided after elective colorectal surgery ${ }^{46,47}$. A nasogastric tube is very unpleasant for the patient, hinders oral intake and prolongs (artificially) postoperative ileus. Early removal of the nasogastric tube is not accompanied by an increased number of complications. Moreover, the incidence of postoperative fever, atelectasis, and pneumonia might be reduced. Therefore, in daily practice the nasogastric tube is removed during extubation. If a patient develops nausea and vomiting postoperatively, treatment should be started with a combination of anti-emetics and not directly by nasogastric tube insertion.

\section{Postoperative fast track care elements}

Postoperative bed rest results in an increased insulin resistance, muscle loss with decreased strength, decreased pulmonary function and tissue oxygenation, and an increased risk of thrombo-embolic complications ${ }^{3,14,15}$.

The presence of an abdominal drain represents a significant burden during early mobilisation. It has never been demonstrated that the use of drains after colonic surgery beneficially influences the occurrence of anastomotic leakage and morbidity $^{48,49}$. Therefore, the use of abdominal drains should be minimized.Also, urinary drainage holds patients back during mobilisation. For this reason, it is recommended to use urinary bladder drainage only for the duration of epidural analge$\operatorname{sia}^{15}$ 
Since the day of surgery must be considered as the first day of recovery, patients are mobilised directly after surgery. The aim is to have patients out of bed for two hours on the day of surgery and at least six hours per day thereafter, until discharge. The early mobilisation is facilitated by adequate pain relief with thoracic epidural analgesia and encouragement to achieve the daily targets. The early mobilisation reduces the risk of thrombo-embolic and pulmonary complications, decreases the amount of muscle loss and increases muscle strength, and postoperative insulin resistance is also reduced ${ }^{3,14,15}$.

Early introduction of oral intake postoperatively is well tolerated by most patients. Early feeding might increase bowel motility resulting in a shorter postoperative ileus and a shorter hospital stay ${ }^{50}$. A meta-analysis on early enteral or oral feeding versus "nil by mouth" demonstrated that early feeding reduced both the risk of infectious complications and hospital stay. Furthermore, there was a trend towards less anastomotic leakages. However, early feeding was associated with some gastro-intestinal symptoms, especially vomiting ${ }^{51}$.

To further enhance oral intake, it is important to prevent postoperative gut dysfunction. Postoperative ileus is partly caused by an inhibitory reflex from the surgical field. A thoracic epidural, in contrast to a lumbar epidural, blocks this reflex and therefore might have a positive effect on the prevention of paralytic ileus. Another important issue regarding postoperative analgesia is opioid sparing and thereby avoiding opioid-related side effects such as sedation and a negative effect on gut motility. For this reason, patients additionally receive paracetamol and after discontinuation of the epidural a non steroidal anti-inflammatory drug (NSAID) is started $^{14,15 .}$

Furthermore, it is important to avoid fluid overload (i.v. fluids) and medicinal support is started such as oral magnesium oxide and pro-kinetic drugs ${ }^{14,15,30,32}$.

\section{The implementation of the programme into daily practice}

The relative contribution of each of the single elements in the fast track programme remains uncertain. For some elements there is solid evidence that its implementation as a single modality within a traditional care setting results in less morbidity and/or a faster recovery, i.e. the omission of bowel preparation, removal of the nasogastric tube at the time of extubation, and optimal pre- and postoperative nutritional care ${ }^{23-28}$. For other elements the evidence is less robust, and the implementation into the fast track programme is in those cases either based on "common sense" or on consensus interpretation of accumulating evidence ${ }^{15}$. 
The effect of a fast track perioperative care programme might be, for an important part, caused by working according to a clearly defined evidence-based protocol. Both patient and care takers are well informed which targets have to be reached at a certain point in the recovery of a patient.

In the fast track care programme it is important to discharge patients "under supervision". Once at home, patients are contacted by phone within 24-48 hours after discharge to ensure that there are no questions or complications. Patients should be discharged according to predefined discharge criteria. These discharge criteria include adequate pain control with oral analgesics, absence of nausea, ability to take solid foods, passage of flatus and/or stool, mobilisation and self support as compared to the preoperative level, and finally acceptance of discharge by the patient.

When the postoperative course of a patient is uncomplicated, discharge can normally be expected between the third and sixth postoperative day ${ }^{2,7,8,52,53}$. Facilities should be created to rapidly deal with complications that occur after discharge. Readmission in itself does not always imply an overnight stay. Often patients can re-attend the hospital as an out-patient, receive treatment (e.g. antiemetics/fluids) and be discharged the same day. Nevertheless, it is essential that there is a dear pathway for the prompt and safe readmission of patients who experience major complications (e.g. anastomotic leakage) ${ }^{15}$.

Most likely, fast track perioperative care programmes are not associated with an increased workload of the first line home care takers (e.g. district nurse or general practitioner). This is because patients are discharged in the same condition as formerly in a traditional care setting. Moreover, the patient is instructed to contact the hospital if any questions or complications may arise. First line home care takers should be involved earlier because the discharge process has already started at the preadmission counselling session. Problems regarding the patients' social environment or special needs are addressed in this session and if necessary first line care takers are contacted at this stage ${ }^{15}$.

There are no absolute contra-indications for fast track perioperative care itself. However, there may be certain contra-indications for individual protocol elements. For example, in patients with coagulation disorders the application of an epidural catheter is not possible. In those circumstances only the contra-indicated elements are omitted, the other elements are applied normally. It has been shown that fast track perioperative care is safe, feasible, and associated with positive results in an older population or for patients with significant co-morbidity ${ }^{9,54}$. However, for this patient population it might be difficult to achieve certain targets, such as the amount of postoperative mobilisation. In those cases targets are set at the highest level possible.

It is important that the outcome is documented and evaluated during the introduction of a fast track perioperative care programme. This not only ensures that mor- 
bidity and mortality are optimal but also that feedback is provided on the protocol compliance to the individual elements and to identify aspects of the programme that may need further development of infrastructure and staff education ${ }^{15}$.

\section{Systematic review; what can be accomplished with the implementation of a fast track perioperative care programme in colonic surgery?}

The Medline, EMBASE, and Cochrane Library databases were searched for all randomised or controlled clinical trials with a prospective intervention group comparing a multimodal fast track perioperative care programme with traditional care in patients undergoing elective segmental colonic resection. Two investigators (JW, SP) independently performed the literature search, data-extraction and quality assessment of the included studies.

The search identified 39 publications, of which 34 were excluded due to insufficient details, a completely retrospective, uncontrolled study design or because the data had been used in other selected publications. Five studies were included in the final analysis comprising two randomised ${ }^{7,8}$ and three controlled clinical trials ${ }^{2,52,53}$. The studies were published between 1998 and 2004. In Table 1 the patient characteristics and quality assessment is shown.

The application of the predefined fast track perioperative care elements varied widely between the studies. The programmes that were reported on in the five studies contained an average of 7.6 (range 4-10) fast track perioperative care elements. Accelerated mobilisation and early postoperative feeding were present in all studies, while other elements, such as omission of sedative pre-medication, the use of preoperative carbohydrate loaded liquids, omission of bowel preparation, and perioperative restriction of iv. fluids, were less effectively applied. Particularly the preoperative care elements were less implemented.

The primary hospital stay (PHS) and overall hospital stay (OHS), including the readmissions within 30 days are shown in Table 1 . PHS was significantly shorter after fast track perioperative care in four of the five studies ${ }^{2,7,52,53}$. OHS was reported in three studies, all of which reported a significantly shorter OHS in the fast track perioperative care group as compared to the traditional care group ${ }^{2,7,8}$. It has been suggested that a reduction of PHS might increase the number of readmissions. However, in the included studies there were no significant differences in the number of readmissions between the fast track perioperative care and traditional care groups. Readmission rates were $0-21 \%$ and $0-18 \%$ respectively. 
The morbidity and mortality rates are shown in table 1 . With the exception of one study that reported significant less morbidity in the fast track perioperative care group, there were no further differences ${ }^{2}$.

Table 1. Patient characteristics, quality assessment, and results of the included studies

\begin{tabular}{|c|c|c|c|c|c|}
\hline & $\begin{array}{l}\text { Anderson } \\
\text { et al. } \\
\text { BJS }\end{array}$ & $\begin{array}{l}\text { Delaney } \\
\text { et al. } \\
\text { DCR }\end{array}$ & $\begin{array}{l}\text { Raue } \\
\text { et al. } \\
\text { Surg.Endosc }\end{array}$ & $\begin{array}{l}\text { Bradshaw } \\
\text { et al. } \\
\text { J Am Coll surg }\end{array}$ & $\begin{array}{l}\text { Basse } \\
\text { et al. } \\
\text { DCR }\end{array}$ \\
\hline & 2003 & 2003 & 2004 & 1998 & 2004 \\
\hline Design $^{a}$ & RCT & RCT & CCT & $\mathrm{CCT}$ & CCT \\
\hline \multicolumn{6}{|l|}{$\mathbf{N}$} \\
\hline $\mathrm{FT} / \mathrm{TC}^{\mathrm{b}}$ & $14 / 11$ & $31 / 33$ & $23 / 29$ & $36 / 36$ & $130 / 130^{\mathrm{g}}$ \\
\hline \multicolumn{6}{|l|}{ Age (y) } \\
\hline $\mathrm{FT} / \mathrm{TC}$ & $64 / 68$ & $51 / 42 *$ & $63 / 65$ & $63 / 60$ & $72 / 74$ \\
\hline \multicolumn{6}{|l|}{$\% A_{S A}^{c} I / I I$} \\
\hline $\mathrm{FT} / \mathrm{TC}$ & 93/91 & $61 / 79$ & $52 / 72$ & No ASA IV & $60 / 77^{*}$ \\
\hline \multicolumn{6}{|l|}{ PHS $^{\text {d }}$ (days) } \\
\hline $\mathrm{FT} / \mathrm{TC}$ & $4(3) / 7(7)^{*}$ & $5.2 / 5.8$ & $(4) /(7)^{*}$ & $4.9 / 6^{*}$ & $3.3(2) / 10(8)^{*}$ \\
\hline \multicolumn{6}{|l|}{$\mathrm{OHS}^{\mathrm{e}}$ (days) } \\
\hline $\mathrm{FT} / \mathrm{TC}$ & $4(3) / 7(7)^{*}$ & $5.4 / 7.1^{*}$ & & & $5.5(2) / 13(10)^{*}$ \\
\hline \multicolumn{6}{|l|}{$\begin{array}{l}\text { Readmissions \% } \\
\text { (n) }\end{array}$} \\
\hline $\mathrm{FT} / \mathrm{TC}$ & $0(0) / 0(0)$ & $10(3) / 18(6)$ & $4(1) / 7(2)$ & $3(1) / 3(1)$ & $21(27) / 12(16)$ \\
\hline \multicolumn{6}{|l|}{ Morbidity (\%) } \\
\hline $\mathrm{FT} / \mathrm{TC}$ & $29(4) / 45(5)$ & $23(7) / 30(10)$ & $17(4) / 24(7)$ & $8(3) / 11(4)$ & $25(33) / 55(72)^{*}$ \\
\hline Quality score $^{f}$ & 4 & 3 & 2 & 2 & 3 \\
\hline
\end{tabular}

* $\mathrm{p}<0.05$

${ }^{a}$ RCT: Randomised Clinical Trial; CCT: Clinical Controlled Trial; ${ }^{\text {b }}$ FT: Fast Track perioperative care; TC: Traditional Care; ${ }^{\mathrm{c}}$ American Society of Anaesthesilogists; ${ }^{d}$ Primary Hospital Stay; ${ }^{\mathrm{e}}$ Overall Hospital Stay, including readmissions within 30 days; ${ }^{f}$ Quality assessment: score ranging from 0 (worst) -5 (best) based on the cumulative score on the items, randomisation, consecutivety, adequate follow-up ( $>30$ days), independent collection of data and similarity of the groups; ${ }^{\mathrm{g}}$ Traditional care group retrospectively collected in another hospital

\section{Conclusion}

Fast track perioperative care programmes are intensive multimodal and multidisciplinary programmes with the goal to reduce loss of functional capacity and to enhance postoperative recovery, resulting in a shorter hospital stay and an earlier return to normal life.

Concerning cost-effectiveness, costs are reduced for the health care insurers and society on the one hand. This is due to a reduction in hospital stay and an earlier 
resumption of work. On the other hand, the costs for the hospital are increased because the hospital invests in a multimodal and multidisciplinary programme which results in a shorter hospital stay and correspondingly a smaller reimbursement by the health care insurer. To compensate for this, an adjusted reimbursement should be introduced for procedures performed within a fast track perioperative care programme.

When hospital stay is reduced, it is important to assure that patients are discharged in the same condition as would have been the case in a traditional care situation; an earlier discharge is possible because the patient has recovered earlier. This, in part, can be achieved by applying strict discharge criteria. In addition to this, patients should be able to easily contact the hospital for questions. Also, readmission procedures should be simplified to assure that there is no delay in admission and to provide the necessary treatment.

Finally, the question remains how to implement such evidence based perioperative care programmes on a broader basis in the Netherlands. Future studies should investigate the added benefit of laparoscopic surgery within a fast track perioperative care programme ${ }^{12,55}$. 


\section{References}

1. Basse L, Jakobsen DH, Billesbølle P, Werner M, Kehlet H. A Clinical Pathway toAccelerate Recovery After Colonic Resection. Ann Surg 2000;232:51-57.

2. Basse L, Thorbol JE, Lossl K, Kehlet H. Colonic surgery with accelerated rehabilitation or conventional care. Dis Colon Rectum 2004,47:271-278,

3. Basse L, Raskov HH, Jakobsen $\mathrm{H}$, Sonne E, Billesbolle $\mathrm{P}$, Hendel HW, et al. Accelerated postoperative recovery programme after colonic resection improves physical performance, pulmonary function and body composition. Br J Surg 2002;89:446-453.

4. Kehlet H, Dahl JB. Anaesthesia, surgery, and challenges in postoperative recovery. Lancet. 2003;362:921-928.

5. Kehlet H, Wilmore DW. Multimodal strategies to improve surgical outcome. Am J Surg. 2002; 183:630-641

6. Hjort Jakobsen D, Sonne E, Basse L, Bisgaard T, Kehlet H . Convalescence after colonic resection with fast-track versus conventional care. Scand J Surg. 2004;93: 24-28

7. Anderson AD, McNaught CE, MacFie J, Tring I, Barker P, Mitchell CJ. Randomized clinical trial of multimodal optimization and standard perioperative surgical care. Br J Surg. 2003;90:1497-1504

8. Delaney CP, Zutshi M, Senagore AJ, Remzi FH, Hammel J, Fazio VW. Prospective, randomized, controlled trial between a pathway of controlled rehabilitation with early ambulation and diet and traditional postoperative care after laparotomy and intestinal resection. Dis Colon Rectum. 2003;46:851-859.

9. Delaney CP, Fazio VW, Senagore AJ, Robinson B, Halverson AL, Remzi FH. 'Fast track' postoperative management protocol for patients with high co-morbidity undergoing complex abdominal and pelvic colorectal surgery. Br J Surg. 2001 ;88: 1533-1538

10. Soop M, Carlson GL, Hopkinson J, Clarke S, Thorell A, Nygren J, et al. Randomized clinical trial of the effects of immediate enteral nutrition on metabolic responses to major colorectal surgery in an enhanced recovery protocol. Br J Surg. 2004;91:1138-1145.

11. Fearon KC, Luff R. The nutritional management of surgical patients: enhanced recovery after surgery. Proc Nutr Soc. 2003;62:807-811.

12. Nygren J, Hausel J, Kehlet $\mathrm{H}$, Revhaug A, Lassen $\mathrm{K}$, Dejong $\mathrm{CH}$, et al. A comparison in five European Centres of case mix, clinical management and outcomes following either conventional or fasttrack perioperative care in colorectal surgery. Clin Nutr. 2005;24:455-461.

13. Lassen K, Hannemann P, Ljungqvist 0, Fearon KC, Dejong CH, von Meyenfeldt MF, et al. Patterns in current perioperative practice: survey of colorectal surgeons in five northern European countries. BMJ. 2005;330: 1420-1421.

14. Wilmore DW, Kehlet H. Recent advances: management of patients in fast track surgery. BMJ 2001 ;322:473-476

15. Fearon KC, Ljungqvist 0 , von Meyenfeldt MF, Revhaug A, Dejong $\mathrm{CH}$, Lassen $\mathrm{K}$, et al. Enhanced recovery after surgery: a consensus review of clinical care for patients undergoing colonic resection. Clin Nutr. 2005;24:466-477

16. Tovar EA, Roethe RA, Weissig MD, Lloyd RE, Patel GR. One-day admission for lung lobectomy: an incidental result of a clinical pathway. Ann Thorac Surg 1998: 65;803-806

17. Trondsen E, Mjaland 0, Raeder J, Buanes T. Day-case laparoscopic fundoplication for gastrooesophageal reflux disease. Br J Surg 2000;87:1708-1711

18. Podore PC, Throop EB. Infrarenal aortic surgery with a 3-day hospital stay: a report on success with a clinical pathway. J Vasc Surg 1999;29:787-792.

19. Egbert LD, Bant GE, Welch CE, Bartlett MK. Reduction of postoperative pain by encouragement and instruction of patients. N Engl J Med 1964;207:824-827

20. Daltroy $\mathrm{LH}$, Morlino $\mathrm{Cl}$, Eaton $\mathrm{HM}$, Poss $\mathrm{R}$, Liang $\mathrm{MH}$. Preoperative education for total hip and knee replacement patients. Arthritis Care Res 1998;11:469-478 
21. Kiecolt-Glaser JK, Page GG, Marucha PT, MacCallum RC, Glaser R. Psychological influences on surgical recovery. Perspectives from psychoneuroimmunology. Am Psychol 1998;53:1209-1218

22. Disbrow EA, Bennett HL, Owings JT. Effect of preoperative suggestion on postoperative gastrointestinal motility. West J Med 1993;158:488-492

23. Guenaga KF, Matos D, Castro AA, Atallah AN, Wille-Jorgensen P. Mechanical bowel preparation for elective colorectal surgery. Cochrane Database Syst Rev. 2005 25;(1):CD001544

24. Buchher P, Mermillod B, Gervaz P, Morel P. Mechanical bowel preparation for elective colorectal surgery: a meta-analysis. Arch Surg. 2004;139:1359-1364

25. Slim K, Vicaut E, Panis Y, Chipponi J. Meta-analysis of randomized clinical trials of colorectal surgery with or without mechanical bowel preparation. Br J Surg. 2004; 91 :1125-1130.

26. Caumo W, Hidalgo MP, Schmidt AP, Iwamoto CW, Adamatti LC, Bergmann J, et al. Effect of preoperative anxiolysis on postoperative pain response in patients undergoing total abdominal hysterectomy. Anaesthesia. 2002;57:740-746.

27. Ljungqvist 0, Soreide E. Preoperative fasting. Br J Surg. 2003;90:400-406. 28. Soop M, Nygren J, Myrenfors $\mathrm{P}$, Thorell A, Ljungqvist 0 . Preoperative oral carbohydrate treatment attenuates immediate postoperative insulin resistance. Am J Physiol Endocrinol Metab. 2001;280:E576-583.

29. Nygren J, Thorell A, Jacobsson H, Larsson S, Schnell P0, Hylen L, et al. Preoperative gastric emptying. Effects of anxiety and oral carbohydrate administration. Ann Surg. 1995;222:728-734.

30. Jorgensen H, Wetterslev J, Moiniche S, Dahl JB. Epidural local anaesthetics versus opioid-based analgesic regimens on postoperative gastrointestinal paralysis, PONV and pain after abdominal surgery. Cochrane Database Syst Rev. 2000; (4): CD001893.

31. Rodgers A, Walker N, Schug S, McKee A, Kehlet H, van Zundert A, et al. Reduction of postoperative mortality and morbidity with epidural or spinal anaesthesia: results from overview of randomised trials. BMJ. 2000;321:1493.

32. Schwenk W, Muller JM. Was ist fast track chirurgie? Dtsch Med Wochenschr. 2005,130:536-540.

33. Apfel CC, Korttila K, Abdalla M, Kerger H, Turan A, Vedder I, et al. A factorial trial of six interventions for the prevention of postoperative nausea and vomiting. N Engl J Med. 2004;350:24412451.

34. Kehlet H. Surgical stress response: does endoscopic surgery confer an advantage? World J Surg. 1999;23:801-807.

35. Shea JA, Berlin JA, Bachwich DR, Staroscik RN, Malet PF, McGuckin M, et al. Indications for and outcomes of cholecystectomy: a comparison of the pre and postlaparoscopic eras. Ann Surg. 1998,227:343-350.

36. Brown SR, Goodfellow PJ, Adam IJ, Shorthouse AJ. A randomised controlled trial of transverse skin crease vs. vertical midline incision for right hemicolectomy. Tech Coloproctol. 2004;8: 15-18.

37. Abraham NS, Young JM, Solomon MJ. Meta-analysis of short-term outcomes after laparoscopic resection for colorectal cancer. Br J Surg. 2004;91:1111-1124.

38. Basse L, Jakobsen DH, Bardram L, Billesbolle $P$, Lund $C$, Mogensen $T$, et al. Functional recovery after open versus laparoscopic colonic resection: a randomized, blinded study. Ann Surg. 2005;241:416-423.

39. Dath D, Park AE. Randomized, controlled trial of bupivacaine injection to decrease pain after laparoscopic cholecystectomy. Can J Surg. 1999;42:284-288.

40. Hannibal K, Galatius H, Hansen A, Obel E, Ejlersen E. Preoperative wound infiltration with bupivacaine reduces early and late opioid requirement after hysterectomy. Anesth Analg, 1996;83:376381.

41. Sessler DI. Complications and treatment of mild hypothermia. Anesthesiology. 2001;95:531-543.

42. Sessler DI. Mild perioperative hypothermia. N Engl J Med. 1997;336:1730-1737.

43. Lobo DN, Bostock KA, Neal KR, Perkins AC, Rowlands BJ, Allison SP. Effect of salt and water balance on recovery of gastrointestinal function after elective colonic resection: a randomised controlled trial. Lancet. 2002;359:1812-1818. 
44. Brandstrup B, Tonnesen H, Beier-Holgersen R, Hjortso E, Ording H, Lindorff-Larsen K, et al. Effects of intravenous fluid restriction on postoperative complications: comparison of two perioperative fluid regimens: a randomized assessor-blinded multicenter trial. Ann Surg. 2003;238:641-648.

45. Holte K, Foss NB, Svensen C, Lund C, Madsen JL, Kehlet H. Epidural anesthesia, hypotension, and changes in intravascular volume. Anesthesiology. 2004;100:281-286.

46. Nelson R, Edwards S, Tse B. Prophylactic nasogastric decompression after abdominal surgery. Cochrane Database Syst Rev. 2005 Jan 25;(1):CD004929

47. Cheatham ML, Chapman WC, Key SP, Sawyers JL. A meta-analysis of selective versus routine nasogastric decompression after elective laparotomy. Ann Surg. 1995; 221:469-476

48. Jesus EC, Karliczek A, Matos D, Castro AA, Atallah AN. Prophylactic anastomotic drainage for colorectal surgery. Cochrane Database Syst Rev. 2004 18;(4):CD002100.

49. Petrowsky H, Demartines N, Rousson V, Clavien PA. Evidence-based value of prophylactic drainage in gastrointestinal surgery: a systematic review and meta-analyses. Ann Surg. 2004;240:10741084

50. Stewart BT, Woods RJ, Collopy BT, Fink RJ, Mackay JR, Keck JO. Early feeding after elective open colorectal resections: a prospective randomized trial. Aust N Z J Surg. 1998;68:125-128.

51. Lewis SJ, Egger M, Sylvester PA, Thomas S. Early enteral feeding versus "nill by mouth" after gastrointestinal surgery: systematic review and meta-analysis of controlled trials. BMJ. 2001;323:773-776.

52. Raue W, Haase O, Junghans T, Scharfenberg M, Muller JM, Schwenk W. 'Fast-track' multimodal rehabilitation program improves outcome after laparoscopic sigmoidectomy: a controlled prospective evaluation. Surg Endosc. 2004;18:1463-1468.

53. Bradshaw BG, Liu SS, Thirlby RC. Standardized perioperative care protocols and reduced length of stay after colon surgery. J Am Coll Surg. 1998;186:501-506.

54. DiFronzo LA, Yamin N, Patel K, O'Connell TX. Benefits of early feeding and early hospital discharge in elderly patients undergoing open colon resection. J Am Coll Surg. 2003;197:747-752

55. Urbach DR, Baxter NN. Reducing variation in surgical care. BMJ. 2005;330:1401-1402. 


\section{Chapter 3}

\section{A protocol is not enough to implement an enhanced recovery programme for colorectal resection}

J. Maessen, C. Dejong, J. Hausel, J.Nygren, K. Lassen, J. Andersen, A. Kessels, A, Revhaug, H. Kehlet, O. Ljungqvist, K. Fearon, M. von Meyenfeldt

British Journal of Surgery 2007:94: 224-231

"Alles gaat weer als vanouds".

Patiënt W. 12 dagen na operatie 


\section{Abstract}

\section{Aim}

Single-centre studies have suggested that enhanced recovery can be achieved with multimodal perioperative care protocols. This international observational study evaluated the implementation of an enhanced recovery programme in five European centres and examined the determinants affecting recovery and length of hospital stay.

\section{Methods}

Four hundred and twenty-five consecutive patients undergoing elective open colorectal resection above the peritoneal reflection between January 2001 and January 2004 were enrolled in a protocol that defined multiple perioperative care elements. One centre had been developing multimodal perioperative care for 10 years, whereas the other four had previously undertaken traditional care.

\section{Results}

The case mix was similar between centres. Protocol compliance before and during the surgical procedure was high, but it was low in the immediate postoperative phase. Patients fulfilled predetermined recovery criteria a median of 3 days after operation but were actually discharged a median of 5 days after surgery. Delay in discharge and the development of major complications prolonged length of stay.

Previous experience with fast-track surgery was associated with a shorter hospital stay.

\section{Conclusion}

Functional recovery in 3 days after colorectal resection could be achieved in daily practice. A protocol is not enough to enable discharge of patients on the day of functional recovery; more experience and better organization of care may be required. 


\section{Introduction}

With traditional perioperative care, hospital stay after colorectal surgery is commonly between 1 and 2 weeks ${ }^{1}$. Kehlet's group in Denmark identified factors that delay postoperative recovery (pain, gut dysfunction and immobilization), and combined a series of interventions to reduce perioperative stress and organ dysfunction $^{2}$. These measures enhance recovery and constitute a multimodal rehabilitation programme aimed at optimizing perioperative care in colonic surgery.

This evidence-based programme was subsequently integrated into a highly efficient organization, with preoperative evaluation of informal care, strictly defined discharge criteria and a prescheduled discharge plan $^{3}$, and could therefore be considered best clinical practice. The programme resulted in a remarkable reduction in length of hospital stay to a median of 2 days ${ }^{4,5}$. These results were achieved not only by reducing the need for care, but also by decreasing the influence of care provision ('supply factors') on hospital stay.

Kehlet's group and other single-centre groups have demonstrated that recovery can be enhanced, and hospital stay and costs reduced, by multimodal rehabilitation programmes $^{6-13}$. However, such protocols have not been widely adopted. The delay in integrating novel management strategies within routine practice may be ascribed to the time required to develop guidelines, the implementation process, the target group of professionals, the patients, the cultural and social setting, and the organizational and economic environment ${ }^{14,15}$. Clearly the issue of effective implementation and a consequent high rate of compliance are essential in terms of problem solving and achieving uniformity of patient management. Although fasttrack programmes have been evaluated in a variety of centres, little has been published on the degree of compliance with such protocols.

In 2000 the Enhanced Recovery After Surgery (ERAS) collaboration was established between five northern European centres: Kehlet's group in Denmark and four traditional practice centres (one each in the Netherlands, Norway, Sweden and the UK), with the aim of reaching a situation in which the same enhanced recovery perioperative protocol was followed in all the participating centres, resulting in comparable outcomes. In the initial phase of the ERAS collaboration, perioperative care processes and outcomes in the participating centres were assessed retrospectively in a patient cohort treated just before initiation of the ERAS programme ${ }^{16}$.

The present report documents the outcome of the process of changing routines to a multimodal rehabilitation programme and how this can be applied in daily practice in multiple centres. It further examines which particular elements contributed to length of hospital stay during implementation of such a programme. 


\section{Methods}

In 2000 the ERAS collaborationwas established, representing five northern European centres (University Hospital, Maastricht, The Netherlands; University Hospital Northern Norway, Troms $\varnothing$, Norway; Karolinska Institute at Ersta Hospital, Stockholm, Sweden; The Royal Infirmary, Edinburgh, UK; Hvidovre University Hospital, Copenhagen, Denmark).

At the Hvidovre hospital in Denmark 'fast-track' colorectal perioperative care had been developed over the previous 10 years, whereas the other four university centres had been adhering to a more traditional pattern of care. With the Danish experience as a starting point, the ERAS collaboration developed a new modified evidence-based core protocol and defined more than 20 perioperative standard care elements.

This core protocol has been documented in detail elsewhere ${ }^{17}$. It includes preoperative counselling, no bowel preparation, no preoperative oral fluid restriction, carbohydrate loading (Nutricia preOp ; Nutricia, Zoetermeer, The Netherlands) up to $2 \mathrm{~h}$ before surgery, short acting anaesthetics, standard thoracic epidural, limited use of opioids, perioperative fluid restriction, early mobilization, and early postoperative use of oral nutritional supplements (ONS) (NutriDrink ${ }^{\circledR}$ or Ensini ; Nutricia) and oral diet.

Local project teams followed an education programme provided by the Hvidovre hospital team and spent 6 months disseminating the ERAS protocol locally to surgeons, anaesthetists and nursing staff. Regular meetings were arranged to allow members of the ERAS collaboration to monitor progress and pinpoint impediments to.implementation of the core protocol. An examination of the implementation of such evidence-based clinical practice using a non-randomized non-blinded design was adopted.

\section{Data collection}

A central database was designed specifically for the project and the data were collected over the internet. Each patient's data field contained approximately 140 different variables. For security purposes the data were de-identified and the database was localized on a password and firewall protected secure internet server. Where national legislation precluded direct electronic submission (Norway), a spreadsheet containing the data was sent by regular mail to the Stockholm database site. All centres had ethical approval for the collection of data, except where the de-identification of data provided a dispensation of this obligation.

Research nurses at each centre recorded data prospectively for patients enrolled in the ERAS programme during the hospital stay and during follow-up for 30 days after surgery. 


\section{Study population and evaluation of case mix}

Patients undergoing elective open colorectal resection above the peritoneal reflection for benign or malignant disease were managed perioperatively according to the ERAS core protocol. Patients who needed emergency surgery and those requiring an end or diverting ileostomy or colostomy were excluded.

To allow comparison between patients at the different sites, all subjects were scored according to the American Society of Anesthesiologists (ASA) classification, and according to the risk-adjusted, predicted-outcome measure, the Portsmouth modification of the Physiological and Operative Severity Score for the enUmeration of Mortality and morbidity equation (P-POSSUM). Briefly, the P-POSSUM uses a 12factor physiological score (age, cardiac status, pulse rate, systolic blood pressure, respiratory status, Glasgow Coma Score, serum urea, potassium and sodium, haemoglobin concentration, white blood cell count and findings on electrocardiography), and a six-factor operative severity score (operative severity, number of procedures, total blood loss, peritoneal soiling, presence of malignancy, mode of surgery $)^{18,19}$. Missing values (less than 5 per cent of all variables) for POSSUM were assumed to be normal.

\section{Measurements}

Data on patient demographics, surgical procedures and postoperative outcome were collected prospectively in all centres. Follow-up for mortality, anastomotic leak, reoperations and readmissions was verified either during the primary admission, by telephone contact at 30 days or at the subsequent outpatient clinic visit. Of more than 20 protocol care elements, 17 index elements were selected as readily recordable and having a direct influence on recovery. They were therefore analysed for compliance and relationship with outcome.

Three recovery criteria were defined: good pain control on oral analgesics, no intravenous fluids along with tolerance of solid food, and mobilization to preoperative level. The first day after operation on which all three criteria were fulfilled was used to indicate functional recovery, that is fit for discharge. In addition, the day on which patients were considered both fit for discharge and willing to go home was recorded, as was the actual date of discharge.

Delayed discharge time (DDT) was calculated by subtracting the day of functional recovery from the actual day of discharge. This variable indicated both organizational aspects of the care and discharge process and societal adaptation to the ERAS programme. Full adaptation and acceptance was in place if the value was 0 ; this was not the case if the value was greater than 0 .

Length of hospital stay was defined as the number of nights spent in hospital after surgery, whereas total length of stay was defined as the number of nights spent in hospital, including nights after readmission within 30 days after surgery. 
To define the influence of complications on postoperative recovery and hospital stay, all adverse events in the postoperative period were recorded prospectively as described previously ${ }^{16}$. A patient's postoperative course was considered complicated if any complication by accepted standard definitions occurred ${ }^{11,20 \text {. }}$

\section{Statistical analysis}

The data set was analysed for rate of recovery, the day of full functional recovery and length of hospital stay. Elements possibly influencing length of stay were retrieved from the data set, including patient characteristics (age, sex, ASA classification, type of resection, complexity, presence of malignancy and POSSUM), presence of complications, previous experience with fast-track surgery (Denmark versus the other countries), organization of care and compliance with the ERAS guidelines. Univariate analysis of the relationship between all the elements described above and length of hospital stay was performed using Cox regression. In addition, Cox multivariate regression analysis was performed with adjustment for all variables influencing length of stay in the univariate analysis.

Data processing was done with SPSS ${ }^{\circledR} 10.1$ for Windows. $\mathrm{P}<0.050$ was considered statistically significant.

\section{Results}

Four hundred and twenty-five consecutive patients from five centres (The Netherlands, 53; Norway, 32; Sweden, 167; UK, 81; Denmark, 92) were entered prospectively into the ERAS protocol between January 2001 and January 2004. The characteristics of the patients are shown in Table 1.

In general this was an elderly population with a slight preponderance of women. More than three-quarters of the patients were ASA grade II or more, reflecting significant co-morbidity. There was a preponderance of left-sided resections, with 16 per cent of patients undergoing a complex multiple organ resection. Approximately two-thirds of the patients had colorectal cancer. The mean(SD.) P-POSSUM score was 32(7) and did not differ significantly between centres.

\section{Outcomes}

Follow-up for mortality, anastomotic leak, reoperations and readmissions was complete at all institutions. Reoperation was undertaken in 8.9 per cent of the patients, anastomotic leakage occurred in 4.2 per cent and the overall mortality rate was 1.2 per cent. Median length of initial stay was 5 days. As a result of the readmission of nearly 14 per cent of patients, the median total hospital stay was 6 days. 
Table 1. Characteristics of 425 patients who took part in the enhanced recovery after surgery protocol

\begin{tabular}{ll}
\hline & $\mathbf{N}=\mathbf{4 2 5}$ \\
\hline Age (sd) & $67(14)$ \\
Gender \% & \\
Male & 54 \\
Female & 56 \\
ASA ${ }^{\text {a } \%}$ & 22 \\
I & 57 \\
II & 21 \\
III/IV & \\
Colectomy \% & 42 \\
Right sided & 58 \\
Left sided & 17 \\
Complex resection \% & 67 \\
Malignancy \% & 32 (6.5) \\
P-Possum b (sd) & \\
\hline a ASA, American Society of Anesthesiologists; b P-POSSUM, Portsmouth modification of the Physiologi- \\
cal and Operative Severity Score for the enUmeration of Mortality and morbidity equation.
\end{tabular}

\section{Protocol compliance}

The degree of adherence to the various core protocol care elements is summarized in Table 2.

Most patients were cared for according to the core protocol before and during the operation, whereas adherence to the protocol fell considerably in the immediate postoperative phase. Compliance within different centres varied for individual elements of the protocol (range 13-100 per cent).

\section{Recovery versus length of stay}

In general, patients entered into the ERAS protocol were either willing to consider leaving hospital or actually did leave hospital a median of 2 days after fulfilling the preset recovery criteria (Figure 1). On day 2 after surgery 27 per cent of patients fulfilled all three recovery criteria, whereas only 13 per cent wanted to go home and 12 per cent were actually discharged. On day 3 over 50 per cent of patients fulfilled all recovery indicators, but only a quarter were prepared to go home and actually did so. On day 5 the proportion of patients discharged exceeded 50 per cent.

Thirty-one per cent of the patients were discharged on the day of functional recovery (DDT 0 days). In the centre with previous experience of fast-track surgery the percentage of patients with no delay in discharge was 66 per cent, compared with 26 per cent in the other centres $\left(\chi^{2}\right.$ test, $\left.P<0 \cdot 001\right)$. 
Table 2. Percentage of patients treated acoording to protocol care element

\begin{tabular}{ll}
\hline & ERAS \\
& $\mathbf{n = 4 2 5}$ \\
\hline Before surgery & 81 \\
Preoperative counseling & 82 \\
Bowel preparation & 76 \\
CHO drink & 53 \\
No premedication & \\
Operative factors & 79 \\
Active warming by Bair Hugger & \\
Transverse/curved incision & 46 \\
Epidural analgesia at all & 93 \\
Postoperative factors day 0 & \\
Oral analgesia & 85 \\
Out of bed at all & 51 \\
Nutritional supplements $>200 \mathrm{ml}$ & 37 \\
Oral fluids $>800$ ml & 37 \\
Day 1 after operation & \\
No iv fluids & 37 \\
Nutritional supplements $>400 ~$ & 61 \\
Normal food & 43 \\
Out of bed $>6$ hours & 67 \\
Day 2 after operation & 40 \\
Urinary catheter out & \\
Epidural removed & 54 \\
\hline Total & \\
\hline
\end{tabular}

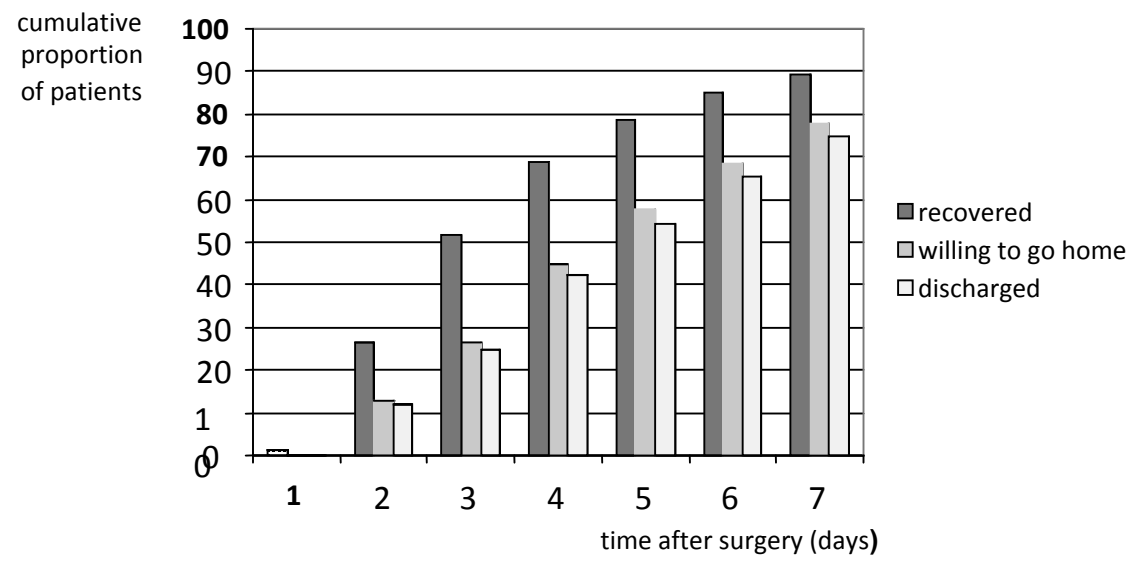

Figure 1 Proportion of patients who recovered, were willing to go home and were actually discharged 


\section{Factors influencing length of stay}

Patient characteristics that influenced length of hospital stay are shown in Figure 2. Age over 60 years, ASA grade above I, complex resections and higher P-POSSUM scores were factors that had a negative influence on length of stay. The development of major complications and inability to discharge patients when they had reached functional recovery (DDT more than 0 days) was strongly associated with prolonged length of stay, whereas previous experience with fast-track surgery (Denmark) was strongly associated with reduced hospital stay.

ERAS core protocol elements that were related to a shortened length of stay included being mobilized out of bed, intake of ONS and fluids on day 0 , taking solid food and ONS, discontinuation of intravenous fluids and mobilization on day 1 , and removal of urinary and epidural katheters on day 2 . Inclusion of patient characteristics, presence of complications, country of treatment and organization of care in multivariate analysis revealed that the same protocol care elements (except removal of epidural catheter) were significantly related to the length of hospital stay (Figure 3).

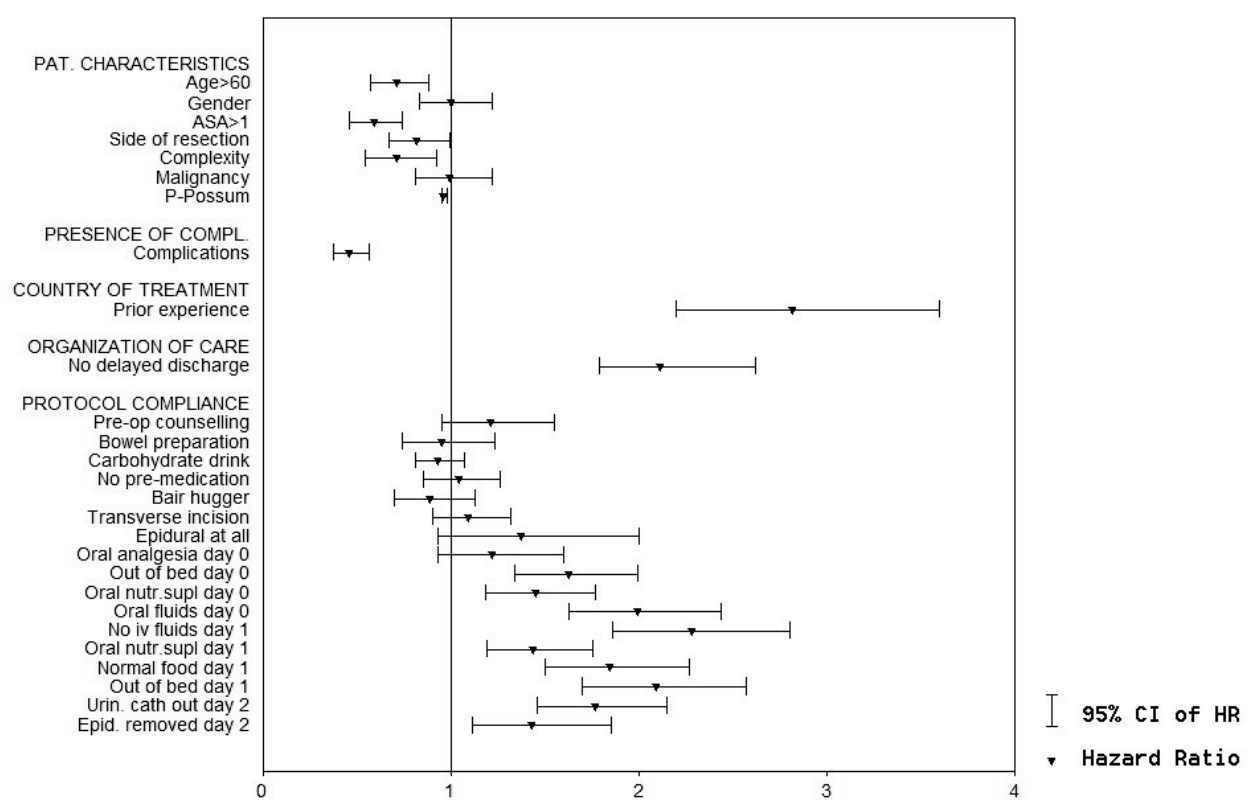

Figure 2. Influence of patient characteristics, country of treatment, presence of complications, organisation of care and protocol compliance on length of hospital stay determined by univariate analysis. Hazard ratios are shown with 95 per cent confidence intervals. A hazard ratio above 1 indicates a better chance of early discharge, whereas a value below 1 indicates a lower chance. 


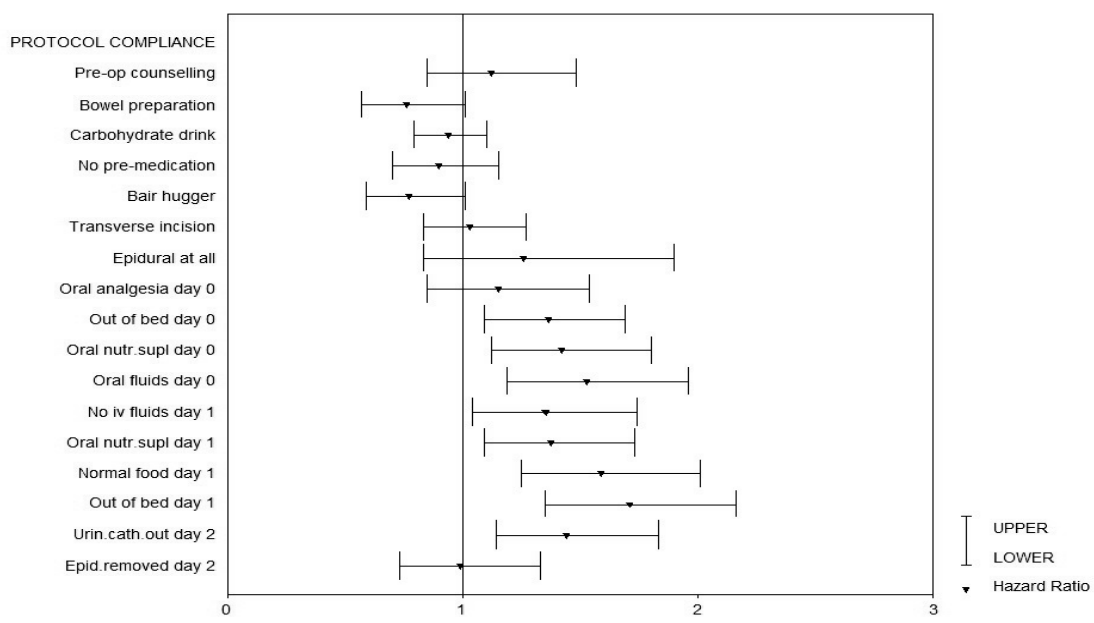

Figure 3. Influence of compliance with the separate care elements on length of hospital stay, adjusted for patient characteristics, presence of complications, country of treatment and organization of care. Hazard ratios are shown with 95 per cent confidence intervals. A hazard ratio above 1 indicates a better chance of early discharge, whereas a value below 1 indicates a lower chance.

\section{Discussion}

The data in the present international observational study show that it is possible to introduce an evidence-based enhanced recovery programme in colorectal surgery in surgical units that hitherto adhered to a more traditional perioperative practice. As this enhanced recovery programme is evidence based, it was considered unethical to withhold such care in the control arm of a randomized clinical trial. Furthermore, such a study set-up would give in to the apparent inability of surgical units to introduce published evidence-based perioperative care elements into daily clinical practice $^{21}$.

Major morbidity and mortality rates were similar to those reported before the introduction of the ERAS protocol ${ }^{16}$, indicating that the enhanced recovery programme is safe. Stress reduction using preoperative measures was successfully introduced, whereas postoperative protocol compliance was less complete. $\mathrm{Pa}$ tients made an early functional recovery (median day 3 ), but discharge was generally 2 days later (median day 5). Nevertheless, the length of stay observed in the present study was substantially shorter $(P<0.001)$ than that obtained (median 8 days) with traditional perioperative care in the same units before the implementation of this enhanced recovery programme ${ }^{16}$. Reducing length of hospital stay will probably lead to an increased readmission rate. The observed rate of 14 per cent 
was derived from a full 30-day follow-up and is within the range of published rates $^{5,11,12}$.

Recovery from surgery is adversely affected by pain, organ dysfunction, nausea and vomiting, ileus, hypoxaemia, fatigue and immobilization ${ }^{2}$. In contrast, the patient's need for care ('demand factors', determined by patient characteristics such as age, severity of disease and complications, co-morbidity and social circumstances ${ }^{22-24}$ ) and the provision of care ('supply factors', including clinical practice style ${ }^{25}$, availability of beds ${ }^{26}$ and hospital discharge policies ${ }^{27}$ ) are recognized as significant factors influencing ultimate length of hospital stay.

In the present study the development of postoperative complications had the strongest adverse influence on length of stay. In contrast, cultural factors (familiarity with and acceptance of enhanced recovery, with ensuing early discharge), organization and previous exposure to fast-track concepts (as experienced in Denmark) most strongly promoted reduced length of stay. These observations corroborate the view that it is particularly the integration of well known (evidence based) surgical care elements in the organization of care that improves outcome of care, that is earlier recovery and shorter hospital stay ${ }^{28}$. Elements associated with restoration of intake of food were also associated with early recovery and discharge. This observation concurs well with the common view that nutritional support in the perioperative phase is associated with decreased morbidity, particularly in severely nutritionally depleted patients ${ }^{29,30}$.

On average, patients fulfilled predefined functional recovery criteria on day 3 but were only discharged on day 5 after operation. This suggests that a further reduction of 2 days in length of stay could be achieved by decreasing the influence of supply factors. Integration into a highly efficient organization, with preoperative evaluation of informal care and a prescheduled discharge plan are important elements that might further shorten hospital stay ${ }^{3,11}$.

The ERAS programme includes about 20 evidence based care elements to reduce surgical stress and postoperative catabolism ${ }^{17,31}$. In the present study 17 index elements that could be recorded readily were audited prospectively to assess protocol compliance. Univariate analysis of these elements in the ERAS protocol suggested that compliance with postoperative rather than preoperative and perioperative factors significantly influenced length of hospital stay.

A similar analysis with functional recovery as the dependent variable yielded equivalent information. Compliance with preoperative factors was high and this might have obscured a possible relationship with length of stay, resulting in loss of statistical significance. The preoperative protocol elements were all designed to ameliorate the impact of surgical stress but might also contribute substantially to postoperative recovery and the observed shortened total length of stay (6 days) compared with that reported previously (more than 9 days) in a similar cohort of patients ${ }^{16}$. 
In the present study it was not possible to determine whether any of the protocol elements had an independent influence on outcome. Univariate analysis identified a relationship between postoperative factors and shortened hospital stay. However, these postoperative variables are both markers of protocol compliance and markers of recovery (outcome). Thus, a multivariate analysis of the determinants of outcome that included such variables is likely to be confounded.

The results of the present study suggest that improving protocol compliance in the postoperative phase is perhaps the most challenging area, but also one that might provide the greatest room for improvement in recovery rates. Self-completed recovery diaries may be one method by which to encourage patients to keep track of their own recovery process and to meet protocol targets. Possible organizational interventions to improve protocol adherence include planning of operations early in the day and early in the week to allow discharge before the weekend, and reorganization of part of the surgical ward to a rehabilitation ward, where mobilization of patients and other care elements (fluid intake, oral diet resumption, use of ONS) can be carefully structured.

Furthermore, although preoperative and intraoperative management can be changed readily, postoperative care routines appear to be more difficult to influence. This perhaps reflects the fact that postoperative patient management involves more disciplines, with greater participation of nursing and junior medical staff. To improve protocol adherence in this phase may necessitate major structural changes within the entire surgical unit, particularly with regard to the organization and education of registrars and nurses. In addition, junior nurses and doctors change frequently in a unit and so continuous re-education is important.

It is likely that increasing experience will lead to further positive alterations in everyday perioperative routine, and that this may well be extrapolated to other domains of gastrointestinal surgery. Furthermore, patient satisfaction may be expected to increase and create further support for such programmes across Europe. Apart from the economic implications of reduced length of hospital stay, improvements in patient outcome will no doubt provide a prominent stimulus for patients, nursing staff, surgeons and anaesthetists alike.

The present study provides evidence that enhanced recovery can be implemented safely in multiple centres using the present core protocol ${ }^{17}$. However, further research is required to determine how best to achieve complete protocol compliance (especially in the postoperative period), the optimal day of planned discharge, and the necessary structural and organizational changes for such a protocol to allow discharge on the day of functional recovery. 


\section{Acknowledgements}

The authors thank the patients who agreed to participate in the study and the surgeons, anaesthetists and nursing colleagues who helped implement the protocol: S.Nimmo, D. Brown, D. Bartolo and A. McGregor in the UK; H. Willigers, M. Bemelmans and G. Beets in the Netherlands; M. Soop in Sweden; T. Pedersen, P. A. Nilsen and T. Arntsen in Norway; and T. Mogensen, C. Lund and M. Hallin in Denmark. They also thank R. Luff, E. Franden, K. Fosland and D. Hjort-Jakobsen who played a key role in implementation of the protocol and collected the primary prospective data.

Nutricia was the main funding source of the ERAS collaboration and also sponsored the preparatory meetings with an unrestricted grant. C.H.C.D. was supported by a grant from the Dutch Organization for Scientific Research (NWO Clinical Fellowship 907-00-033). Part of the work at Ersta Hospital was supported by the Swedish Research Council (no. 09101), and the Stockholm County Council, Public Health and Medical Services Committee. O.L. is the holder of the patent for the product from which Nutricia PreOp ${ }^{\circledR}$ is made. Nutricia has the licence to use the patent. 


\section{References}

1. Schoetz DJ Jr, Bockler M, Rosenblatt MS, Malhotra S, Roberts PL, Murray JJ et al. Ideal length of stay after colectomy: whose ideal? Dis Colon Rectum 1997; 40: 806-810.

2. Kehlet $\mathrm{H}$. Multimodal approach to control postoperative pathophysiology and rehabilitation. $\mathrm{Br} \mathrm{J}$ Anaesth 1997; 78: 606-617.

3. Kehlet H,Wilmore DW. Multimodal strategies to improve surgical outcome. Am J Surg 2002; 183 : 630-641.

4. Kehlet $\mathrm{H}$, Mogensen T. Hospital stay of 2 days after open sigmoidectomy with a multimodal rehabilitation programme. Br J Surg 1999; 86: 227-230.

5. Basse L, Hjort Jakobsen D, Billesbolle $P$, Werner $M$, Kehlet $H$. A clinical pathway to accelerate recovery after colonic resection. Ann Surg 2000; 232: 51-57.

6. Bradshaw BG, Liu SS, Thirlby RC. Standardized perioperative care protocols and reduced length of stay after colon surgery. J Am Coll Surg 1998; 186: 501-506.

7. Delaney CP, Fazio VW, Senagore AJ, Robinson B, Halverson AL, Remzi FH. 'Fast track' postoperative management protocol for patients with high co-morbidity undergoing complex abdominal and pelvic colorectal surgery. Br J Surg 2001; 88: 1533-1538.

8. Henriksen MG, Jensen MB, Hansen HV, Jespersen TW, Hessov I. Enforced mobilization, early oral feeding, and balanced analgesia improve convalescence after colorectal surgery. Nutrition 2002; 18: 147-152.

9. Basse L, Raskov HH, Hjort Jakobsen D, Sonne E, Billesbolle P, Hendel HW et al. Accelerated postoperative recovery programme after colonic resection improves physical performance, pulmonary function and body composition. Br J Surg 2002; 89: 446-453.

10. Anderson AD, McNaught CE, MacFie J, Tring I, Barker P, Mitchell CJ. Randomized clinical trial of multimodal optimization and standard perioperative surgical care. Br J Surg 2003; 90: 1497-1504.

11. Basse L, Thorbol JE, Lossl K, Kehlet $\mathrm{H}$. Colonic surgery with accelerated rehabilitation or conventional care. Dis Colon Rectum 2004; 47: 271-278.

12. Senagore AJ, Duepree HJ, Delaney CP, Brady KM, Fazio VW. Results of a standardized technique and postoperative care plan for laparoscopic sigmoid colectomy: a 30-month experience. Dis CoIon Rectum 2003; 46: 503-509.

13. Stephen $A E$, Berger DL. Shortened length of stay and hospital cost reduction with implementation of an accelerated clinical care pathway after elective colon resection. Surgery 2003; 133: 277282.

14. Grol R, Grimshaw J. From best evidence to best practice: effective implementation of change in patients' care. Lancet 2003; 362: 1225-1230.

15. Schwenk W, Haase O, RaueW, Neudecker J, Muller JM. Establishing 'fast-track'- colonic surgery in the clinical routine. Zentralbl Chir 2004; 129: 502-509.

16. Nygren J, Hausel J, Kehlet $\mathrm{H}$, Revhaug A, Lassen $\mathrm{K}$, Dejong $\mathrm{C}$ et al. A comparison in 5 European centres of case mix, clinical management and outcomes following either conventional or fast track perioperative care in colorectal surgery. Clin Nutr 2005; 24: 455-461.

17. Fearon $\mathrm{KCH}$, Ljungqvist $\mathrm{O}$, Von Meyenfeldt $\mathrm{M}$, Revhaug $\mathrm{A}$, DeJong $\mathrm{CHC}$, Lassen $\mathrm{K}$ et al. Enhanced recovery after surgery: a consensus review of clinical care for patients undergoing colonic resection. Clin Nutr 2005; 24: 466-477.

18. Copeland GP, Jones D, Walters M. POSSUM: a scoring system for surgical audit. Br J Surg 1991; 78: $355-360$.

19. Sagar PM, Hartley MN, MacFie J, Taylor BA, Copeland GP. Comparison of individual surgeon's performance. Risk-adjusted analysis with POSSUM scoring system. Dis Colon Rectum 1996; 39: 654-658.

20. Lang M, Niskanen M, Miettinen $\mathrm{P}$, Alhava $\mathrm{E}$, Takala J. Outcome and resource utilization in gastroenterological surgery. Br J Surg 2001; 88: 1006-1014. 
21. Lassen $\mathrm{K}$, Hannemann $\mathrm{P}$, Ljungqvist $\mathrm{O}$, Fearon $\mathrm{KCH}$, Dejong $\mathrm{CHC}$, von Meyenfeldt MF et al. Patterns in current perioperative practice: survey of colorectal surgeons in five northern European countries. BMJ 2005; 330: 1420-1421.

22. Seymour DG, Pringle R. Elderly patients in a general surgical unit: do they block beds? BMJ 1982; 284: 1921-1923.

23. Burns LR, Wholey DR. The effects of patient, hospital, and physician characteristics on length of stay and mortality. Med Care 1991; 29: 251-271.

24. Epstein AM, Stern RS, Tognetti J, Begg CB, Hartley RM, Cumella E Jr et al. The association of patients' socioeconomic characteristics with the length of hospital stay and hospital charges within diagnosis-related groups. N Engl J Med 1988; 318: 1579-1585.

25. Wennberg J, Gittelsohn A. Variations in medical care among small areas. Sci Am 1982; 246: 120134.

26. van Doorslaer EK, van Vliet RC. 'A built bed is a filled bed?' An empirical re-examination. Soc Sci Med 1989; 28: 155-164.

27. Braveman P, KesselW, Egerter S, Richmond J. Early discharge and evidence- based practice. Good science and good judgment. JAMA 1997; 278: 334-336.

28. Urbach DR, Baxter NN. Reducing variation in surgical care requires innovative methods for getting evidence into surgical practice. BMJ 2005; 330: 1401-1402.

29. Howard L, Ashley C. Nutrition in the perioperative patient. Annu Rev Nutr 2003; 23: 263-282.

30. Lewis SJ, Egger M, Sylvester PA, Thomas S. Early enteral feeding versus 'nil by mouth' after gastrointestinal surgery: systematic review and meta-analysis of controlled trials. BMJ 2001; 323: 773776.

31. Kehlet H. Manipulation of the metabolic response in clinical practice. World J Surg 2000; 24: 690695. 



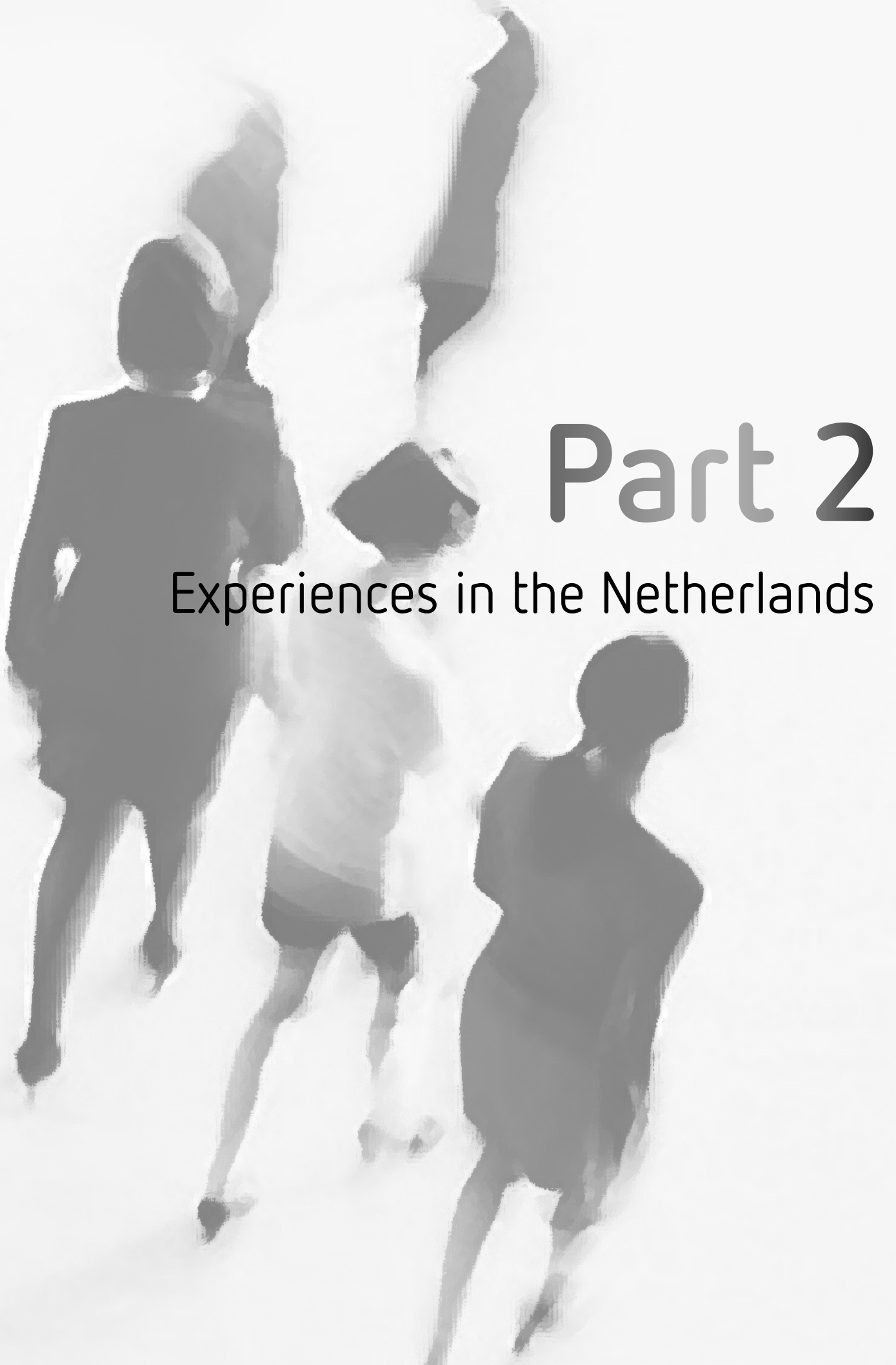





\section{Chapter 4}

\section{Length of Stay: An Inappropriate Readout of the Succes of Enhanced Recovery Programmes}

J.M.C. Maessen, C.H.C. Dejong, A.G.H. Kessels, M.F. von Meyenfeldt, On behalf of the Enhanced Recovery After Surgery (ERAS) group

World Journal of Surgery 2008; 32: 971-975

"Mijn man is niet thuis, hij is met de auto naar de keuring".

Mevrouw S. echtgenoot van patiënt S, 7 dagen na darmoperatie. 


\section{Abstract}

\section{Aim}

Enhanced recovery after surgery (ERAS) programms are designed to reduce hospital length of stay by shortening the postoperative recovery period. The intended effect of an accelerated recovery on the length of stay may be frustrated by a delayed discharge. This study was designed to asses the influence of an ERAS program on the proportion, appropriateness, and extent of delay in discharge.

\section{Methods}

Patients who enrolled in the ERAS program ( $n=121)$ between 2003 and 2006 were compared with 52 patients who were managed traditionally in 2001.

\section{Results}

Ninety percent of the pre-ERAS patients and $87 \%$ of the ERAS patients were not discharged on the day that discharge criteria were fulfilled. The additional stay of $59 \%$ of the pre-ERAS patients and $69 \%$ of the ERAS patients was inappropriate Wound care (15\% in the pre-ERAS group and 3\% in the ERAS group) and observation of any symptoms pointing to an anastomotic leakage ( $10 \%$ in both groups) were the most important reasons for a medical appropriate delay of discharge. The extent of delay in discharge decreased significantly from a median of 2 days in the pre-ERAS group to a median of 1 day in the ERAS group $(p=0.004)$.

\section{Conclusions}

Reductions in length of stay up to a median of 2 days after start of an enhanced recovery program may relate to changes in organization of care and not to a shorter recovery period. Recovery statistics should replace or at least be added to the length of stay as outcome of enhanced recovery programs. 


\section{Introduction}

Because hospital services are the most expensive component of health care systems, hospitals are under increasing pressure to enhance the efficiency of hospital care. Length of stay for inpatient care is quoted as an important index of efficiency ${ }^{1}$ and several changes in health care have been induced the past decades to limit the length of hospitalization.

An important development is the increased range of health care interventions offered outside the hospital or at the home. External family accommodations near the hospital and home care services, such as visiting nurses for wound and stoma care, are now available to expedite the recovery of patients who no longer require the acute hospital setting.

In a parallel development, discharge planning programs ${ }^{2,3,4}$ discharge planning conferences $^{5}$ and even discharge professionals ${ }^{6,7}$ are introduced to facilitate the transmission of patients to the home or to other care services, outside the hospital. These measures are designed to reduce medically unnecessary hospital stays, notably the lower intensity days at the end of the hospital stay, during which the patient could have been discharged on clinical grounds but was not.

Protocols, clinical guidelines, and critical care pathways have been introduced in the belief that they have the potential to maintain the appropriateness of care offered while regulating inefficient hospital use ${ }^{8,9,10,11}$.

In recent times, standardized perioperative care programs, with a more focused perioperative treatment plan designed to accelerate recovery, are in increasing interest. Kehlet and colleagues ${ }^{12,13}$ demonstrated a dramatic reduction in hospital stay after abdominal surgery, by combining a series of interventions in perioperative care to shorten recovery time ${ }^{14}$ with a number of actions to reduce unnecessary hospital stay. Compared with traditional care, there seems to be no difference in morbidity and mortality ${ }^{15}$.

In 2000 the ERAS (Enhanced Recovery After Surgery) group was established, as a collaboration of five university or specialised departments of surgery. The ERAS group developed an evidence based per-operative care protocol for patients undergoing colorectal resection ${ }^{16}$ and introduced this protocol into daily practice. To deal with the growing concern of care givers regarding adverse outcomes in patients who were discharged early, the ERAS group defined criteria to be fulfilled before discharge ${ }^{16}$.

A first evaluation of the program showed that almost $70 \%$ of the patients were not going home on the day that discharge criteria were fulfilled and that any delay in discharge was strongly associated with a prolonged hospital length of stay ${ }^{17}$.

In the current paper this gap between the moment a patient could go home theoretically, based on predefined discharge criteria, and the moment of actual dis- 
charge was evaluated. The objectives were to assess the influence of the enhanced recovery after surgery program on the proportion, appropriateness and extent of delay in discharge.

\section{Methods}

The ERAS program for patients undergoing elective colonic resections above the peritoneal reflection without formation of a stoma, was instituted in the beginning of 2002. With a focus on stress reduction and promotion of return to function, the goal of the ERAS program is a quicker recovery from major abdominal surgery with a reduced hospital stay as a consequence. Preoperative patient information, minimal invasive surgery, optimal pain relief, early nutrition, and enforced mobilisation are key elements of an enhanced recovery after surgery approach.

An analysis of perioperative care before initiation of the program showed that the principles of the ERAS program were not adopted in patients who underwent a colonic resection in 2001 and that the perioperative routines did not differ from the traditional routines as published by K. Lassen ${ }^{18,19}$

The traditionally managed patients in 2001 ( the pre-ERAS group) were compared with the patients who were managed according to the ERAS program between 2003 and 2006 (the ERAS group). The study included consecutive patients undergoing elective colorectal resection above the peritoneal reflection, without formation of a stoma.

Patients treated in $\mathbf{2 0 0 2}$ were excluded to guarantee the study group to be managed according to the fully implemented new program, to exclude transition effects and to consist of consecutively treated patients. Before start of the study ethical approval for collection of the data was obtained.

Data of the ERAS group were assessed prospectively. Data of the pre-ERAS group were obtained retrospectively by analysis of medical and nursing charts.

In the current study, primary outcome was delay in discharge. Discharge criteria were defined as tolerance of food, good pain control on oral analgesics, defecation and independency in activities of daily living (ADL) to preoperative care level.

The first day postoperatively that a patient fulfilled all four discharge criteria was considered to be the day that the patient was recovered and ready for discharge. Delay in discharge was defined as any difference between the moment the patient was ready for discharge and the actual discharge.

Recovery data were recorded for 30 days after surgery. Seven percent of the patients in the pre-ERAS group and 8 percent of the patients in the ERAS group were not ready for discharge within 30 days after surgery (died, still in hospital or discharged to a higher care level). These cases were omitted from analysis. 
The Dutch model of the Appropriateness Evaluation Protocol ( DAEP) was used to assess the appropriateness of hospital stay in case of a delay in discharge. Appropriate hospital stay was defined as: "Hospital stay, requiring continuous and active medical, nursing or paramedical treatment, which under existing legislation can not be provided through extramural care, day care or outpatient care" ${ }^{20}$.

The DAEP is a modification of the US Appropriateness Evaluation Protocol and was proven to be a valid, reliable and user friendly instrument for evaluating the appropriateness of hospital stay ${ }^{21}$. The DAEP consists of 19 criteria for appropriate hospital stay.

\section{Statistics}

Data are given as mean (SD) or median (range). Differences in demographic and clinical variables were analyzed by using Mann-Whitney test for ordinal data and chi-square test for categorical data.

$P$ values $<0.05$ were considered to indicate statistical significance. Data analyses were done with SPSS 12.1 for Windows XP.

\section{Results}

Patient characteristics are presented in Table 1 and demonstrate that the two study groups were comparable with respect to demographic variables and surgical procedures.

Table 1. Comparison of patient characteristics of traditionally managed patients in 2001 (the pre-ERAS group) and patients managed according to the enhanced recovery after surgery program between 20032006 (ERAS group)

\begin{tabular}{lll}
\hline & $\begin{array}{l}\text { Pre-ERAS } \\
(\mathrm{n}=52)\end{array}$ & $\begin{array}{l}\text { ERAS* } \\
(\mathrm{n}=121)\end{array}$ \\
\hline Age mean (SD) & $64(11.8)$ & $66(12.3)$ \\
Male/female ratio \% & $42 / 58$ & $55 / 45$ \\
ASA classification III/IV \% & 10 & 20 \\
Colectomy \% & & \\
Right-sided & 44 & 45 \\
Left-sided & 56 & 55 \\
Complex resection \% & 12 & 9 \\
Malignancy \% & 75 & 74 \\
P-Possum mean (SD) & $30(6.2)$ & $31(6.9)$ \\
\hline
\end{tabular}

* no significant differences 
Table 2 shows that there were no significant differences in the proportion and the appropriateness of the delay in discharge between the two study groups.

Table 2.Proportion, appropriateness, and extent of delay of discharge before and after start of the ERAS program.

\begin{tabular}{lrr}
\hline & $\begin{array}{l}\text { Pre-ERAS } \\
\text { (n = 52) }\end{array}$ & $\begin{array}{l}\text { ERAS } \\
\text { (n =121) }\end{array}$ \\
\hline Delay in discharge (\%) & $5(10 \%)$ & $16(13 \%)$ \\
No & $47(90 \%)$ & $105(87 \%)$ \\
Yes & $31(59 \%)$ & $83(69 \%)$ \\
Medically inappropriate & $16(31 \%)$ & $22(18 \%)$ \\
Medically appropriate & $2(0-17)$ & $1 *(0-9)$ \\
Median extent of delay in discharge (range) &
\end{tabular}

Ninety percent of the pre-ERAS patients and 87 percent of the ERAS patients were not going home on the day that discharge criteria were met. The prolonged hospital stay of $59 \%$ of the pre-ERAS patients and $69 \%$ of the ERAS patients was labeled as inappropriate, according to the DAEP.

For $31 \%$ of the pre-ERAS group and $18 \%$ of the ERAS group the prolonged stay was rated as medically necessary, with as main reason wound care $(15 \%$ of the patients of the pre-ERAS group and $3 \%$ of the ERAS group) and observation of any symptoms pointing to an anastomotic leakage (10\% in both the pre-ERAS and ERAS group).

The extent of the delay was significantly reduced in the ERAS group. The additional stay after full recovery, according to the predefined discharge criteria, was a median of 2 days (range $0-17$ ) in the pre-ERAS group versus a median of 1 day (range $0-9)$ in the ERAS group $(p=0.004)$. The main cause of the shorter delay in discharge of ERAS patients was the reduced incidence of wound infections during hospital stay.

\section{Discussion}

The main rationale for implementing enhanced recovery programs in surgical practice is that an improved and shorter (enhanced) recovery period would reduce a patient's need to stay in hospital and thus reduce the length of hospitalisation ${ }^{16}$-a simple concept, but particularly revolutionary ${ }^{22}$ as it refers exclusively to a reduction in length of stay by influencing the number of the high intensity first days after surgery.

As the present study demonstrates, the intended effect of a shorter recovery period on length of stay is frustrated in part by an additional stay in hospital after the patient has fully recovered according to predefined discharge criteria. The current 
study shows that there was no significant difference in the proportion of patients with a delay in discharge, before and after start of the ERAS program. Aproximately $90 \%$ of the patients were not discharged on the day that functional recovery was achieved.

A validated appropriateness instrument, the Dutch Appropriateness Evaluation protocol (DAEP), was used to judge whether the stay after recovery criteria were fulfilled was medically necessary. According to the DAEP, the prolonged stay of $60 \%$ of the pre-ERAS patients and $70 \%$ of the ERAS patients was deemed inappropriate. The discharge scoring system defined adequately the readiness to go home of these patients, who had no medical reasons to stay in hospital after discharge criteria were fulfilled.

In $30 \%$ of the pre-ERAS patients and $20 \%$ of the ERAS patients the prolonged stay after recovery was rated as medically necessary. According to the discharge criteria, these patients were ready to go home, but the DAEP judged that these patients had medical reasons for a prolonged stay, with as main medical reasons wound care and observation of any symptoms pointing to an anastomotic leakage.

The question is whether wound care and observation of symptoms really require a hospital setting in order to be managed adequately. According to the recent changes in the perception of the role of an acute hospital bed ${ }^{22,23,24}$, wound care and observation of symptoms are both debatable reasons for staying in an acute hospital bed.

The lower incidence of prolonged stay because of wound care in the ERAS group ( $3 \%$ versus $15 \%$ ) illustrates that wound care can also be considered as an inappropriate reason for a prolonged stay. The incidence of wound infections was not influenced by the ERAS program, but more wound infections occurred at home and were subsequently treated in the outpatient setting.

In both groups, $10 \%$ of the patients were not discharged because of fever, abdominal distention, diarrhea, or other symptoms that could point to an anastomotic leakage. These symptoms resolved within some days, and none of these patients actually developed an anastomotic leakage.

It is part of our traditional thinking that patients should remain in the hospital after surgery to be observed for any complication that may occur; the main advantage is the immediate response to complications and the rapid access to repeat surgery. However, with repetitive phone calls after discharge or home care visits and a rapid access to the outpatient surgery department, observation of patients may become an inappropriate reason for offering an acute hospital bed. Thus, if wound care and observation of symptoms that point to an anastomotic leakage both would be rated as inappropriate reasons for stay, only $5 \%$ of patients have a delay in discharge that could be categorized as truly medically appropriate.

Actually, the discrepancy between the DAEP and the discharge scoring system shows that besides the medical requirements for hospitalisation expressed in the 
discharge criteria, length of stay is influenced by local perceptions and organisation of the acute hospital bed.

The length of the additional stay, beyond the "fit for discharge" point, was a median of 2 days in the traditionally managed group and a median of 1 day in the enhanced recovery group. This statistically significant and clinically important reduction in delay after the start of the ERAS program was mainly caused by the reduction in the incidence of wound infections during hospital stay, which was an unintended effect of the ERAS program.

This observation confirms that reductions in length of stay up to a median of two days are not necessarily related to the effect of the program on the recovery period. Instead, they may relate to changes in local nursing and doctor's policy, bringing the point of actual discharge closer to the fit for discharge moment.

Therefore, recovery criteria are superior to length of stay for the evaluation of the success of an enhanced recovery program. The first day that the patient is able to eat, has good pain control while taking oral analgesics, has had defecation and is nursed back to ADL self-care must be the most important outcome parameter of enhanced recovery programs, becuase it defines most adequately the recovery of the patient and eliminates the influence of the organization of care. 


\section{References}

1. Health Do. NHS perfomance indicators. London: Department of health 2002.

2. Shepperd S, Parkes J, McClaran J, Philips C. Discharge planning from hospital to home Cochrane database Syst Rev 2006(3).

3. Patterson CJ, Mulley GP. The effectiveness of predischarge home assessment visits: a systematic review. Clin Rehabil 1999;13(2): 101-104.

4. Hyde CJ, Robert IE, Sinclair AJ. The effects of supporting discharge from hospital to home in older people. Age Ageing 2000;29(3): 271-279.

5. Efraimsson E, Sandman PO, Hyden LC, Holritz Rasmussen B. How to get one's voice heard: the problems of the discharge planning conference. J Adv Nurs 2006;53(6): 646-655.

6. Armitage SK, Kavanagh KM. The discharge liaison nurse at the interface of hospital and community nursing services. International Journal of Nursing Practice 1996;2: 215-221.

7. Dukkers van Emden DM, Ros WJ, Berns MP. Transition of care: an evaluation of the role of the discharge liaison nurse in The Netherlands. J Adv Nurs 1999;30(5): 1186-1194.

8. Wollersheim H, Burgers J, Grol R. Clinical guidelines to improve patient care. Neth J Med 2005;63(6): 188-192.

9. Weingarten S, Riedinger MS, Sandhu M, Bowers C, Ellrodt AG, Nunn C, Hobson P, Greengold N. Can practice guidelines safely reduce hospital length of stay? Results from a multicenter interventional study. Am J Med 1998;105(1): 33-40.

10. Pearson SD, Goulart Fisher D, Lee TH. Critical pathways as a strategy for improving care: problems and potential. Ann Intern Med 1995;123(12): 941-948.

11. Cook DJ, Greengold NL, Ellrodt AG, Weingarten SR. The relation between systematic reviews and practice guidelines. Ann Intern Med 1997;127(3): 210-216.

12. Kehlet $\mathrm{H}, \mathrm{Mogensen} \mathrm{T}$. Hospital stay of 2 days after open sigmoidectomy with a multimodal rehabilitation program. Br J Surg 1999;86(2): 227-230.

13. Basse L, Hjort Jakobsen D, Billesbolle P, Werner M, Kehlet H. A clinical pathway to accelerate recovery after colonic resection. Ann Surg 2000;232(1): 51-57.

14. Kehlet $\mathrm{H}$, Wilmore DW. Multimodal strategies to improve surgical outcome. Am J Surg 2002;183(6): 630-641.

15. Nygren J, Hausel J, Kehlet $\mathrm{H}$, Revhaug A, Lassen K, Dejong C, Andersen J, von Meyenfeldt M, Ljungqvist $\mathrm{O}$, Fearon KC. A comparison in five European Centres of case mix, clinical management and outcomes following either conventional or fast-track perioperative care in colorectal surgery. Clin Nutr 2005;24(3): 455-461.

16. Fearon KC, Ljungqvist $\mathrm{O}$, Von Meyenfeldt $\mathrm{M}$, Revhaug A, Dejong $\mathrm{CH}$, Lassen $\mathrm{K}$, Nygren J, Hausel J, Soop $\mathrm{M}$, Andersen J, Kehlet $\mathrm{H}$. Enhanced recovery after surgery: a consensus review of clinical care for patients undergoing colonic resection. Clin Nutr 2005;24(3): 466-477.

17. Maessen J, Dejong CHC, Hausel J, Nygren J, Lassen K, Andersen J, Kessels AGH, Revhaug A, Kehlet $\mathrm{H}$, Ljungqvist $\mathrm{O}$, Fearon $\mathrm{KCH}$, Meyenfeldt MF. A protocol is not enough to implement an enhanced recovery programm for colorectal resection. Br J Surg 2007;94:224-231.

18. Lassen K, Hannemann P, Ljungqvist O, Fearon K, Dejong CH, von Meyenfeldt MF, Hausel J, Nygren $\mathrm{J}$, Andersen J, Revhaug A. Patterns in current perioperative practice: survey of colorectal surgeons in five northern European countries. BMJ 2005;330(7505): 1420-1421.

19. Lassen $\mathrm{K}$, Dejong $\mathrm{CH}$, Ljungqvist $\mathrm{O}$, Fearon $\mathrm{K}$, Andersen J, Hannemann $\mathrm{P}$, von Meyenfeldt MF, Hausel J, Nygren J, Revhaug A. Nutritional support and oral intake after gastric resection in five northern European countries. Dig Surg 2005;22(5): 346-352.

20. Panis $\mathrm{L}$, Verheggen FW, Pop P, Prins MH. Appropriate length of extended day care. Int J Health Care Qual Assur 2004;17(2-3): 81-86. 
21. Smeets PM, Verheggen FW, Pop P, Panis LJ, Carpay JJ. Assessing the necessity of hospital stay by means of the appropriateness evaluation protocol: how strong is the evidence to proceed? Int J Qual Health Care 2000;12(6): 483-493.

22. Clarke A, Rosen R. Length of stay. How short should hospital care be? Eur J Public Health 2001;11(2): 166-170.

23. Clarke A. Length of in-hospital stay and its relationship to quality of care. Qual Saf Health Care 2002;11(3): 209-210.

24. Schoetz DJ, Jr., Bockler M, Rosenblatt MS, Malhotra S, Roberts PL, Murray JJ, Coller JA, Rusin LC. "Ideal" length of stay after colectomy: whose ideal? Dis Colon Rectum 1997;40(7): 806-810. 


\section{Chapter 5}

\section{Enhanced Recovery After Surgery Fact or Fiction?}

J.M.C. Maessen, C.H.C. Dejong, H.M.M. Willigers A.G.H. Kessels, M.F. von Meyenfeldt, on behalf of the Enhanced Recovery After Surgery (ERAS) group

Submitted

"Ik ben soms wat moe. Ik loop wat hard van stapel".

Patient A. 8 dagen na operatie. 


\section{Abstract}

\section{Aim}

Recovery statistics are superior to length of stay as outcome of enhanced recovery after surgery (ERAS) programmes as they define most adequately the recovery of the patient and eliminate the influence of organisation of care. The present study examines the effect of the implementation of an ERAS programme in an every day setting on the time to clinical recovery of patients undergoing elective colorectal resections.

\section{Methods}

A prospective case series implementation study was performed, comparing clinical recovery of 132 patients that enrolled the ERAS programme between 2003 and 2006 with recovery of a historical control group of 55 traditionally treated patients. Patients undergoing open elective colonic resection above the peritoneal reflection without formation of a stoma were eligible.

Clinical recovery was defined as the first day that a patient tolerated food, had had defecation, had good pain control on only oral analgesics and was ADL independent.

\section{Results}

The time to clinical recovery decreased from a median of 6 days in traditionally treated patients to 4 days in the ERAS group (adjusted Hazard Ratio 1.6, 95\% Cl 1.2$2.3, p=0.005)$. ERAS patients were eating three days earlier, were ADL independent two days earlier and the time to first defecation and to pain control on oral analgesia decreased by one day.

Complexity of surgery was the only surgical detail that significantly influenced time to clinical recovery.

\section{Conclusion}

Patients undergoing elective colorectal surgery within an ERAS programme recover faster than patients managed traditionally. A clinical recovery of three days is a realistic target in patients that undergo non-complex colorectal surgery. 


\section{Introduction}

In ambulatory surgery the concept of fast track surgery was introduced in the early 1990's. The fast track concept aims at a more rapid awakening from anaesthesia by the use of ultra short acting drugs. The early recovery period may be completed in the operating room and patients may be transferred directly to the day surgery unit, bypassing the post anaesthesia care unit ${ }^{1,2}$ Fast tracking is claimed to streamline ambulatory surgery with faster patient recovery time and earlier discharge.

Several pioneers have taken up the challenge and have explored whether the fast track concept can also be applied to more major surgical procedures. Multimodal peri-operative rehabilitation programmes have been developed ${ }^{3,4}$ and remarkable reductions in length of stay have been demonstrated by running these fast track programmes ${ }^{5-11}$

As there appeared to be a wide variation in the application of perioperative care elements in fast track programmes ${ }^{12}$, the Enhanced Recovery After Surgery (ERAS) group, a European collaboration of five departments of surgery, considered the evidence-base for individual components of recovery programmes. Based on this, they defined a multimodal recovery programme, that presents the consensus of how patients undergoing colonic resection should be cared for (the ERAS protocol $)^{13}$. The ultimate aim of an enhanced recovery after surgery programme is "to allow patients to recover more quickly from major surgery".

A first evaluation of the effect of the ERAS programme demonstrated that a reduction in length of stay to a median of 2 days was not reproducible in real life clinical practice. The median hospital stay, including readmissions within 30 days after surgery, was 6 days ${ }^{14}$.

Organisation of care was identified as a major factor influencing length of hospital stay. Reductions in length of stay after institution of an enhanced recovery programme may thus not only be brought about by a shorter postoperative recovery period. To evaluate the success of an enhanced recovery after surgery programme, recovery statistics should replace or at least be added to length of stay, because they define most adequately the recovery of the patient and eliminate the influence of organisation of care ${ }^{15}$.

The current studie evaluates prospectively whether the ultimate aim of an enhanced recovery programme, a shorter postoperative recovery period, can be achieved in an every day setting, comprising all patients scheduled for a colorectal resection and all practitioners involved in colonic surgery. 


\section{Methods}

\section{Design}

The current study was a prospective case series implementation study comparing clinical recovery with recovery of a historical control group. The intervention group comprised 132 patients undergoing elective colonic resection between January 2003 and January 2006 and managed according to the ERAS programme (ERAS group). The control group consisted of a consecutive series of 55 patients that underwent a colonic resection in 2001 . These patients were managed according to a traditional care path way at a time when the ERAS programme was not yet known in the unit (control group).

\section{Patients}

Eligible for this study were patients older than 18 years of age, undergoing elective open colonic resection above the peritoneal reflection for benign or malignant disease. Patients who needed emergency surgery and those requiring an ileostomy or colostomy were excluded. Patients that underwent a colonic resection because of gynaecologic pathology, admitted to the department of gynaecology, were also excluded.

Surgeons started to treat a selected group of patients according to the new proto$\mathrm{col}$ in the beginning of 2002. To guarantee the study group to be managed according to a fully implemented ERAS programme, to exclude transition effects and to ensure a series of consecutively treated patients, the study group consists of consecutive colorectal surgery patient that enrolled the ERAS programme between 2003 and 2006.

Patients in the control group received conventional perioperative care including bowel preparation, preoperative fasting from midnight, bowel rest (nil by mouth, a nasogastric decompression tube for 2 days and a slow re- introduction of oral fluids and diet) and bed rest (appendix 1).

\section{Intervention}

The ERAS protocol consisted of the following procedures ${ }^{13}$. Patients were seen before admission during an educational session, that provided information about the hospital stay, the recovery programme and the patients' role in recovery. Patients received no oral bowel preparation and were allowed to eat until midnight and to drink clear liquids until two hours before surgery. A carbohydrate enriched supplement was offered early in the morning of surgery. Pre-anaesthetic long acting medication was avoided and patients received a thoracic epidural catheter, activated before the onset of surgery. An upper-body-forced-air heating cover was 
used routinely to prevent hypothermia. The nasogastric decompression tube was removed before the patient woke up from anaesthesia. Patients commenced oral fluids at arrival on the surgical ward and intravenous fluids were discontinued as soon as adequate oral intake was established.

The first day after surgery patients were allowed to eat at will and patients were supported to take oral nutritional supplements until a normal level of food intake was achieved. Mobilisation started on the day of surgery and patients were encouraged to stay out of bed for 6 hours from the first day after surgery. To promote mobilisation the epidural catheter and the urinary catheter were removed on the second day after surgery.

\section{Implementation activities}

A project team was appointed consisting of two surgeons, an anaesthetist and a nurse coordinator. This project team followed an educational programme provided by the experienced team of the Hvidovre hospital in Denmark. A clinical recovery of two days was promoted by the Hvidovre team and accepted by the project team as main goal of the change of practice.The project team educated the locally involved professionals about the protocol by means of presentations and discussions. The nurse coordinator led the implementation by executing the patient information and organising the follow up of patients enrolled in the programme.

\section{Data collection}

The primary endpoint of the present study was the day of recovery to home readiness, defined as the first day after surgery that the patient fulfilled all four discharge criteria: tolerance of food, independency in activities of daily living (ADL independency), defecation and adequate pain control on oral analgesics only.

A retrospective review of medical and especially nursing charts was carried out to evaluate traditional perioperative care in the control group. This baseline measurement provided also insight in the process of traditional perioperative care (Appendix 1).

Patients that were managed according to the ERAS programme were prospectively evaluated. Medical and nursing files were studied and data were checked by frequent interviews of the staff and the patients the first days after surgery. To allow comparison between the present prospectively studied patients group and the retrospective dataset, data collection include age, gender, presence of malignancy, side of operation and complexity of surgery and all subjects were scored according the ASA classification, and the P-Possum score (the Portsmouth modification of the Physiological and Operative Severity Score for the enumeration of Mortality and morbidity equation ${ }^{16}$.

Before start of the study, ethical approval for collection of the data was obtained. 


\section{Statistical analysis}

Differences between control and ERAS patients were analyzed using the Mann-Whitney test for continuous data and chi-square test for categorical data. Continuous data are presented as mean (SD) and categorical data as percentages. The Kaplan-Meier method was used to evaluate differences in time to recovery between the control and ERAS group. Patient data were censored if the patient was not recovered (deceased or was discharged to a higher care level). Additional Kaplan Meier analyses were carried out to compare the time to tolerance of food, defecation, oral analgesics and ADL independency in the two study groups. Log rank statistics were used to test for differences in the Kaplan-Meier recovery curves. Cox proportional hazards regression analyses were performed to adjust for age, gender, ASA classification, P-Possum score, presence of malignancy, site of operation and complexity of surgery.

P-values below 0.05 were considered to indicate statistical significance. Data processing was done with SPSS 15.0 for Windows.

\section{Results}

The relevant patient characteristics and surgical details are presented in Table 1.

Table1 . Comparison of patient characteristics and surgical details of patients managed traditionally (the control group) and patients managed according to the enhanced recovery after surgery programme (the ERAS group)

\begin{tabular}{lll}
\hline & $\begin{array}{l}\text { Control } \\
\mathbf{n}=55\end{array}$ & $\begin{array}{l}\text { ERAS } \\
\mathbf{n}=\mathbf{1 3 2}\end{array}$ \\
\hline Age (sd) & $65(12)$ & $67(12)$ \\
$\begin{array}{l}\text { Gender \% } \\
\text { male }\end{array}$ & & 55 \\
female & 40 & 45 \\
ASA classificationa III/IV \% & 60 & $22^{*}$ \\
P-Possum scoreb (sd) & 9 & $32(7)$ \\
Malignancy \% & $76(7)$ & 74 \\
Colectomy \% & 76 & \\
right sited & & 43 \\
left sited & 44 & 57 \\
Complexity \% & 56 & 12 \\
\hline
\end{tabular}

The groups were comparable with respect to age, gender distribution, P-Possum score, presence of malignancy, site of resection and complexity of surgery but differed in ASA status with a significantly higher ratio of ASA III/IV patients in the ERAS group ( $22 \%$ versus $9 \%$ in the control group). 
The time to clinical recovery was significantly shorter in the ERAS group as is also shown by the Kaplan-Meier survival curves (log-rank test $p=0.009$ ) (Fig. 1).

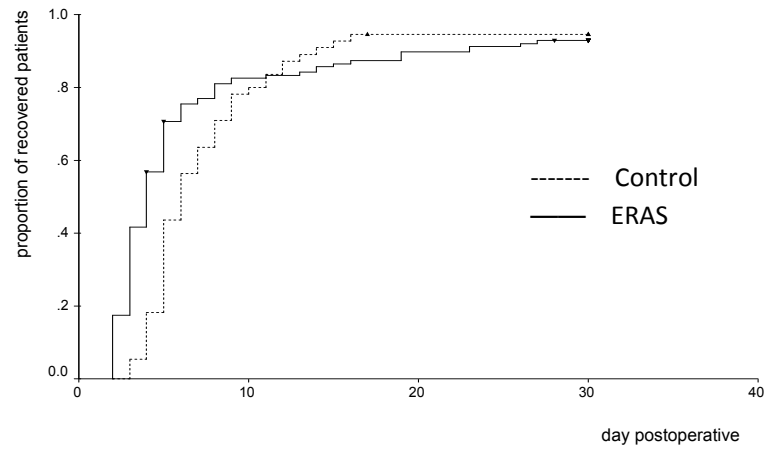

Log Rank test: $p=0.009$

Figure 1. Kaplan-Meier survival analysis of functional recovery in patients managed traditionally (Control) and patients managed according to the ERAS programme (ERAS).

The median day of recovery decreased from postoperative day 6 in the control group to postoperative day 4 in the ERAS group. When adjusted for patient characteristics and clinical variables, the time to recovery was still significantly reduced in patients who enrolled the ERAS programme (Hazard Ratio 1.6, 95\% Cl 1.2-2.3, $\mathrm{p}<0.005)$. Complexity of surgery was the only significant independent predictor of postoperative recovery (Table 2 ).

Table 2. Influence of the ERAS programme on time to recovery when adjusted for clinical and demographic variables.

\begin{tabular}{lcl}
\hline Variable & $\begin{array}{c}\text { Hazard ratio } \\
(\mathbf{9 5 \%} \mathrm{Cl})\end{array}$ & $\mathrm{p}$ Value \\
\hline Traditional versus ERAS management & $1.6(1.2-2.3)$ & 0.005 \\
Age (younger versus older than 65) & $0.8(0.5-1.1)$ & 0.10 \\
Gender (men/women) & $0.9(0.6-1.2)$ & 0.38 \\
ASA classification (I/II versus III/IV) & $0.6(0.4-1.0)$ & 0.06 \\
P-Possumscore (per point score) & $1.0(1.0-1.0)$ & 0.43 \\
Malignancy (no/yes) & $1.2(0.8-1.8)$ & 0.36 \\
Side operation ( right versus left) & $0.9(0.7-1.3)$ & 0.58 \\
Complexity (no/yes) & $0.5(0.3-0.8)$ & 0.01 \\
\hline
\end{tabular}

All four recovery criteria contributed to the enhanced recovery in the ERAS group (Figure 2). The median time to tolerance of food decreased from day 5 to day 2, to 
ADL independency from day 5 to day 3, to defecation from day 4 to day 3 and to good pain control on oral analgesics from day 3 to day 2 .
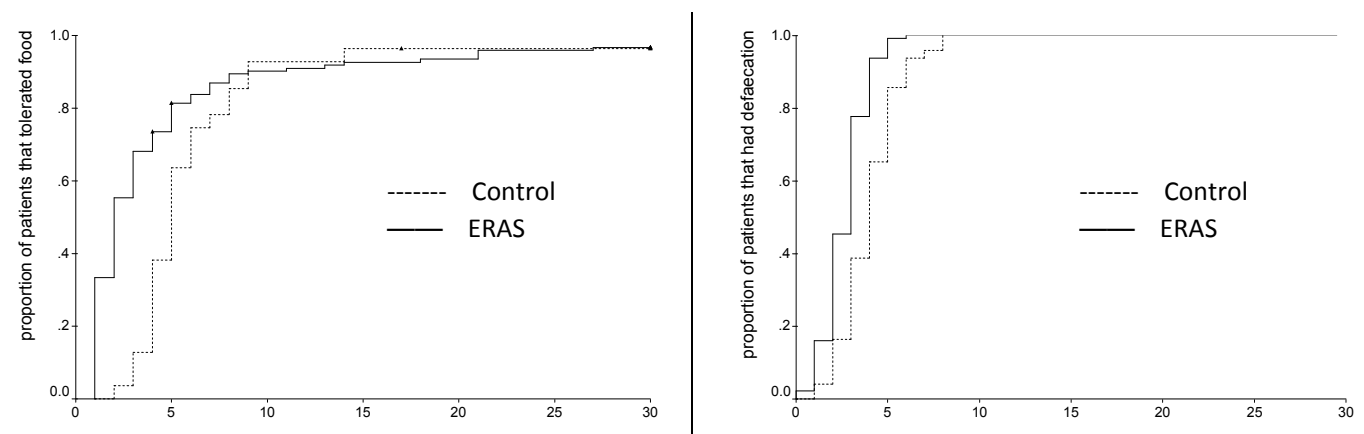

day postoperative Log Rank test: $p=0.000$
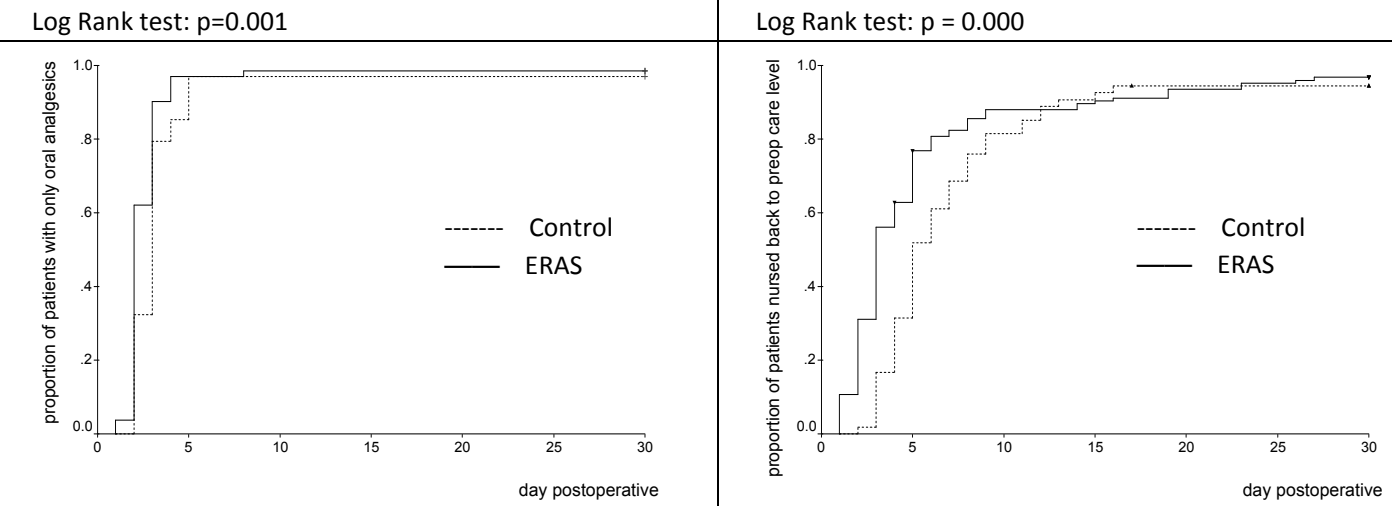

Log Rank test: $p=0.006$

Log Rank test: $p=0.007$

Figure 2. Kaplan-Meier survival analysis of the time to tolerate food, to defecation, to oral analgesics and to ADL independency of the Control and ERAS patients.

These reductions remained statistical significant after adjustment for demographics and clinical variables (Table 3).

Table 3. Unadjusted and adjusted estimate of Hazard Ratio's of the effect of the ERAS programme on time to tolerance of food, defecation, oral analgesics and ADL independency.

\begin{tabular}{llll}
\hline Event & $\begin{array}{l}\text { unadjusted } \\
\text { Hazard ratio } \\
(95 \% \mathrm{Cl})\end{array}$ & $\begin{array}{l}\text { adjusted } \\
\text { Hazard ratio } \\
(95 \% \mathrm{Cl})\end{array}$ & p-Value \\
\hline Overall recovery & $1.5(1.1-2.1)$ & $1.6(1.2-2.3)$ & 0.005 \\
Tolerance of normal food & $1.6(1.2-2.3)$ & $1.9(1.4-2.7)$ & 0.000 \\
Defecation & $2.1(1.5-3.0)$ & $2.2(1.5-3.3)$ & 0.000 \\
Oral analgesics & $1.4(1.0-2.1)$ & $1.5(1.0-2.3)$ & 0.037 \\
ADL independency & $1.5(1.0-2.1)$ & $1.7(1.2-2.4)$ & 0.003 \\
\hline
\end{tabular}

* $\mathrm{P}<0.05$ 


\section{Discussion}

The current study demonstrates that the time to clinical recovery after elective colonic resection can be shortened by treating patients according to an enhanced recovery after surgery (ERAS) programme. Before institution of the ERAS programme it was not until day six after surgery that patients who underwent a colorectal resection were recovered to home readiness. The change in every day clinical practice in accordance with the recommendations of the ERAS programme resulted in a significantly faster clinical recovery after surgery to a median of four days.

Patients were considered to be recovered to home readiness when they regained their gut function (tolerance of food and passage of stool), when pain levels could be controlled adequately with simple oral analgesics only and when they were mobile enough to resume normal activities of daily living. This study showed that patients that were treated according to the ERAS programme were eating 3 days earlier, were mobilised 2 days earlier and were having defecation and pain control on oral analgesics 1 day earlier than patients managed traditionally.

However, the anticipated recovery time of 2 days ${ }^{6}$ could by far not be achieved. On day 2 after surgery $45 \%$ of the patients were not eating normal food, $69 \%$ of the patients were not ADL independent, $55 \%$ of the patients had not had defecation and $38 \%$ still had the epidural catheter inserted. In our department of surgery, that was hitherto adhering to a traditional pattern of care, a recovery in 2 days appeared to be an unrealistic target.

Due to the nature of this implementation study, study patients were compared to a control group that was evaluated retrospectively. The strength of the current study was that it was possible to obtain reliable data of recovery by the retrospective evaluation of nursing charts. Whether a patient was eating and had defecation, whether the epidural catheter was removed and whether the patient was able to wash himself were classic items that were daily recorded in the nursing charts.

A limitation of the current study was the change in patients' characteristics due to secular trends over the long study period. Laparoscopic surgery has emerged in the beginning of 2005 and was performed in a selected group of patients. These patients also enrolled the ERAS programme but for reasons of comparison were left out of the current analysis. The proportion of non malignant patients decreased due to changed policy of treating diverticulitis.

It is difficult to interpret the results in the context of current evidence. Most studies report on length of stay and except for the study of Basse ${ }^{6}$, none of the studies achieve a median length of stay of two days. This suggest that recovery was achieved in two days in the Basse study, but probably not in any of the other studies. Only one randomized clinical trial evaluated the same modalities of recovery ${ }^{17}$. In this study the median day of tolerance of food, pain control on oral analgesics 
and defecation was equal to the results of our study, independent mobility was achieved one day earlier. Unfortunately the overall rate of recovery was not reported, but it is clear that a recovery rate of two days was not achieved in that study.

It is well known that results of controlled trials often can not be reproduced in every day practice ${ }^{18}$. Under experimental conditions patients may be highly selected, staff may give special attention to participants and any bias that arise from variation in exposure to the intervention may be eliminated. In every day practice usual practitioners treat real patients who may have significant co-morbidity and may be ambivalent about treatment.

The problem is that unrealistic implementation goals may have a detrimental effect on practitioners' motivation to adopt the current programme in every day practice. Positive experiences and visible effects on outcomes are important incentives for the embedding of a new practice into the organisation and daily routines ${ }^{19,20}$. Additionally, unrealistic targets of recovery will lead to a poor impression of the programme on patients. As part of the ERAS programme, targets of recovery are extensively discussed preoperatively with the patients. Not achieving these targets may negatively influence patients' satisfaction with the programme and subsequently with the surgical results ${ }^{21}$.

Another limitation was that structural attributes were not evaluated. Changes in clinical practice are only partly within doctors' control. Prevailing professional and organisational culture e.g., determine the effectiveness of the innovation to a large extent ${ }^{22}$. The extent to which traditional routines deviated from the evidence based recommendations described in the ERAS protocol suggests that the clinical environment was not attractive to induce change.

An important lesson learned from our attempt to introduce the ERAS protocol in everyday practice is that a baseline measurement of traditional care is a very important instrument in defining realistic targets of change. In addition to the outcomes of care and the extent to which traditional practice deviates from the recommended practice, the prevailing professional and organisational culture should be part of the evaluation. The cultural environment e.g. the presence of an infrastructure for quality and the involvement of clinical leaders determines the effect of an innovation to a large extent ${ }^{23}$.

Given the fact that before the start of the ERAS programme it was not until day 6 that patients were recovered, that only 2 elements of the protocol were partially implemented and that perioperative care was not standardised and protocols were not commonly applied, a gain of 4 days in recovery was probably too ambitious a goal. For centres adhering to a traditional pattern of care, with no prior exposure to fast track concepts, a recovery in 3 days is suggested as a attainable, realistic, but still ambitious goal to start with. This goal should certainly be achievable if patients that undergo complex surgery are excluded. As the motivation to change usually 
grows gradually under the influence of positive experiences in practice, a further improvement might be attained in a second cycle of improvement ${ }^{24}$.

\section{Conclusion}

The current study shows that the implementation of an enhanced recovery after surgery programme in an every day clinical practice results in a faster recovery. Recovery time of colorectal surgery patients decreased to a median of four days. A clinical recovery of three days in non complex elective colorectal surgery patients is a feasible goal for hospitals that accept the challenge of introducing an ERAS programme into their traditional surgical practice 


\section{References}

1. Watkins $A C$, White $P F$, et al, Fast-tracking after ambulatory surgery. Journal of PeriAnesthesia Nursing 2001 Dec;16(6):379-387.

2. Apfelbaum JL, Walawander CA, Grasela $\mathrm{TH}$, et al, Eliminating intensive postoperative care in same-day surgery patients using short-acting anesthetics. Anesthesiology 2002, Jul;97(1):66-74.

3. Wilmore DW, Kehlet $\mathrm{H}$, Management of patients in fast track surgery. BMJ 2001; 322(7284):473476.

4. Kehlet $\mathrm{H}$, Multimodal approach to control postoperative pathophysiology and rehabilitation. $\mathrm{Br} \mathrm{J}$ Anaesth 1997;78(5):606-617.

5. Kehlet $\mathrm{H}$, Mogensen $\mathrm{T}$, Hospital stay of 2 days after open sigmoidectomy with a multimodal rehabilitation programme Br J Surg 1999, 86(2):227-230.

6. Basse L, Hjort Jakobsen D, Billesbolle $\mathrm{P}$, et al, A clinical pathway to accelerate recovery after colonic resection, Ann Surg.2000;232(1):51-57.

7. Delaney CP, Fazio VW, Senagore AJ, et al, 'Fast track' postoperative management protocol for patients with high co-morbidity undergoing complex abdominal and pelvic colorectal surgery. $\mathrm{Br} \mathrm{J}$ Surg 2001;88(11):1533-1538.

8. Anderson $\mathrm{AD}, \mathrm{McNaught} \mathrm{CE}$, MacFie J, et al, Randomized clinical trial of multimodal optimization and standard perioperative surgical care Br J Surg 2003 Dec;90(12):1497-1504.

9. Gatt $M$, Anderson $A D$, Reddy $B S$, et al, Randomized clinical trial of multimodal optimization of surgical care in patients undergoing major colonic resection. Br J Surg 2005, Nov;92(11):13541362.

10. Raue W, Haase $\mathrm{O}$, Junghans $\mathrm{T}$, et al, 'Fast-track' multimodal rehabilitation program improves outcome after laparoscopic sigmoidectomy: a controlled prospective evaluation. Surgical Endoscopy 2004, Oct;18(10):1463-1468.

11. Muller S, Zalunardo MP, Hubner M, et al, A fast-track program reduces complications and length of hospital stay after open colonic surgery. Gastroenterology 2009, Mar;136(3):842-847.

12. Wind J, Polle SW, Fung Kon Jin PH, et al, Systematic review of enhanced recovery programmes in colonic surgery. Br J Surg 2006, Jul;93(7):800-809.

13. Fearon $\mathrm{KC}$, Ljungqvist $\mathrm{O}$, Von Meyenfeldt $\mathrm{M}$, et al, Enhanced recovery after surgery: a consensus review of clinical care for patients undergoing colonic resection. Clin Nutr 2005, Jun;24(3):466477.

14. Maessen J, Dejong $\mathrm{CH}$, Hausel J, et al. A protocol is not enough to implement an enhanced recovery programme for colorectal resection. Br J Surg 2007, Feb; 94(2): 224-231.

15. Maessen JM, Dejong $\mathrm{CH}$, Kessels AG, et al, Length of stay: an inappropriate readout of the success of enhanced recovery programs. W J Surg 2008, Jun;32(6):971-975.

16. Sagar PM, Hartley MN, MacFie J, et al, Comparison of individual surgeon's performance. Riskadjusted analysis with POSSUM scoring system, Dis Colon Rectum 1996;39(6):654-658.

17. Khoo CK, Vickery CJ, Forsyth $\mathrm{N}$, et al, A prospective randomized controlled trial of multimodal perioperative management protocol in patients undergoing elective colorectal resection for cancer. Annals of Surgery 2007, Jun;245(6):867-872.

18. Knottnerus JA, Dinant GJ, Medicine based evidence, a prerequisite for evidence based medicine. BMJ 1997, Nov 1;315(7116):1109-1110.

19. Cabana MD, Rand CS, Powe NR, et al, Why don't physicians follow clinical practice guidelines? A framework for improvement. JAMA 1999, Oct 20; 282(15): 1458-1465.

20. Rogers E. Lessons for guidelines from the diffusion of innovation Jt Comm J Qual Improv 1995;21:324-328.

21. Grol R, Wensing $M$, What drives change? Barriers to and incentives for achieving evidence-based practice. Medical Journal of Australia 2004, Mar 15;180:S57-60. 
22. Grimshaw JMMP, Shirran LMAM, Thomas RB, et al, Changing Provider Behavior: An Overview of Systematic Reviews of Interventions, Medical Care 2001, 39(8) Supplement(2):II-2-II-45.

23. Glickman SW, Baggett KA, Krubert CG, et al, Promoting quality: the health-care organization from a management perspective. International Journal for Quality in Health Care 2007, Dec;19(6):341348.

24. Grol R, Grimshaw J, From best evidence to best practice: effective implementation of change in patients' care. Lancet 2003, Oct 11;362(9391):1225-1230. 
Appendix 1. Analysis of perioperative care before the introduction of the ERAS programme. Data are percentages of patients that were managed according to the various elements of the ERAS programme

Perioperative care elements

Perioperative care

in 2001

$(n=55)$

Before surgery

Preoperative counselling $\quad 0$

No bowel preparation $\quad 5$

Oral carbohydrate treatment 0

Operative factors

Active warming by Bair Hugger ${ }^{\circledR} 56$

Epidural analgesia at all $\quad 71$

Postoperative factors, day $\mathbf{0}$

No nasogastric drainage 6

Out of bed at all 0

Oral fluids $>800 \mathrm{ml}$

Oral nutritional supplements $>200 \mathrm{ml}$

Day 1 after operation

Intravenous fluid infusion stopped 0

Out of bed $>6$ hours 0

Solid food 6

Oral nutritional supplements $>400 \mathrm{ml}$

Day 2 after operation

Epidural removed 33

Urinary catheter out together with epidural $\quad 11$ 


\section{Chapter 6}

\section{Reasons for poor adoption of evidence based recommendations for postoperative recovery in colonic surgery}

J.M.C. Maessen, T. van der Weijden, H.M.M. Willigers, C.H.C. Dejong, M.F. von Meyenfeldt on behalf of the Enhanced Recovery After Surgery (ERAS) group

"lk heb gewinkeld en geklusd.

Ik heb nog niet stil gezeten vandaag".

Patiënt V, 8 dagen na operatie 


\section{Abstract}

\section{Aim}

Active dissemination of an Enhanced Recovery After Surgery (ERAS) protocol is an important yet insufficient condition to achieve changes in traditional practice. This study ascertains protocol adherence, perceived barriers and incentives to change practice in order to promote the incorporation of the ERAS protocol into daily care routines.

\section{Methods}

A prospective process evaluation was performed to measure actual performance and reasons for deviation from the protocol. An expert panel translated reasons for deviation into barriers and facilitators.

\section{Results}

Pre- and peri-operative care elements were generally implemented in a successful manner, whereas the adoption of postoperative elements was poor. The reduce in discomfort of patients pre and postoperatively and the appointment of a coordinator were identified as the most important facilitators of the protocol. The most important barriers were patients' postoperative condition, lack of experience with the protocol, lack of evidence for some of the recommendations and a poor focus on recovery as an important outcome of care.

\section{Conclusion}

This process evaluation has identified factors that facilitated or impeded the adoption of the ERAS protocol in every day practice. These insights may be of value for other hospitals that face the challenge of implementation of an ERAS protocol. 


\section{Introduction}

The immediate challenge in improving the quality of surgical care is not to discover new knowledge, but to integrate what we already know into practice ${ }^{1,2}$. The development and dissemination of clinical practice guidelines is one of the most popular approaches to translate research findings in every day practice ${ }^{3}$. These guidelines detail explicit recommendations for specific clinical circumstances ${ }^{4,5}$. Following their introduction, improvements in the process and outcomes of care have been demonstrated $^{6}$, although the extent of the improvement can vary considerably and is usually small to moderate ${ }^{7}$.

In 2001 the Enhanced Recovery after Surgery (ERAS) group, a collaborative of five Departments of Surgery from five northern European countries, reviewed the state of knowledge regarding clinical care for patients undergoing elective colonic resection. Aiming for an enhanced recovery after major surgical procedures, the ERAS group formulated more than twenty key elements of best practice perioperative care $^{8}$.

The programme was disseminated in the five participating centres and a first evaluation of the effect of the programme showed that active dissemination of the ERAS programme into traditional surgical practice was not enough to fully realise the anticipated recovery and hospitalisation rates ${ }^{9,10,11}$.

This is in line with the consistent finding that guidelines do not implement themselves but need a systematic well-planned approach that takes into account the complexity of health care practice. Most experts in healthcare interventions emphasise the importance of acquiring a good understanding of the factors that facilitate or impede changes in everyday practice. Interventions tailored to overcome identified barriers may improve the process and outcome of care ${ }^{12-15}$.

The aim of the current study was to identify barriers and facilitators for implementation of the ERAS protocol. It was felt that this might inspire others to develop interventions promoting the implementation of the ERAS protocol in routine perioperative care. A prospective process evaluation was undertaken to evaluate adherence to the ERAS protocol and to assess the most important reasons for deviating from the protocol.

\section{Methods}

\section{Design and population}

Between 2003 and 2006 peri-operative care was prospectively registered for all patients that underwent an elective colorectal resection above the peritoneal reflection enrolled in the ERAS programme. For reason of comparison we also evalu- 
ated perioperative care before the introduction of the protocol by a retrospective chart audit over the period January 2001- January 2002, during which 55 patients were exposed to the same type of surgery.

\section{Intervention as planned: the ERAS protocol}

In 2001 the ERAS collaboration developed an evidence based perioperative care programme for patients undergoing colonic resections above the peritoneal reflection $^{8}$. Structured patient information, cessation of bowel preparation, new fasting rules, removal of nasogastric tubes at the end of surgery, epidural anaesthesia, early nutrition and early mobilisation were the key elements of the ERAS protocol (Appendix 1).

\section{Dissemination and implementation activities}

At the beginning of the project in 2001, a project team was appointed in Maastricht, consisting of two surgeons, an anaesthetist and a nurse coordinator. The project team followed a training programme provided by the experienced team of the Hvidovre hospital in Denmark and spent 6 months on dissemination and implementation activities. The project team educated the locally involved professionals about the protocol by means of presentations and discussions.

After dissemination of the programme the surgeons started to treat a selected group of patients according to the new protocol in the beginning of 2002. At the end of 2002 the first results were evaluated and feedback on performance was given to involved surgeons, anaesthetists and nurses. From January 2003 consecutive colorectal surgery patients were managed fully according to the ERAS protocol. From 2002 onwards key elements of the programme were summarised on a one page information sheet that was added to the medical and nursing charts of every colorectal surgery patient to remind professionals of the recommendations of the ERAS programme. Additionally, small lecture style presentations of all protocol care elements were repeated every year.

A written patient information sheet was developed and was used to support the face-to-face patient instruction before surgery. The nurse coordinator guided the implementation by carrying out the patient information and organising the follow up of patients enrolled in the programme. Patients were daily visited the first days after surgery and deviations from the protocol were immediately fed back to the responsible professionals.

\section{Data collection}

A retrospective chart review of perioperative care before the introduction of the ERAS protocol was carried out. Based on the extensive descriptive reports of patients' well being in nursing charts it was possible to analyse to what extent con- 
ventional care deviated from the ERAS recommendations. This baseline measurement provided insight in elements of care that were already (partially) implemented.

Practitioners and surgical nurses prospectively recorded relevant data of process of care during implementation of the ERAS programme in the medical files. Additionally, the nurse coordinator interviewed patients and caregivers daily the first days after surgery using a structured case report form. Reasons for deviation from the protocol were standardised and categorised, with room for open answers.

\section{Data analysis}

Reasons for non compliance were divided in necessary deviations (beyond the control of individuals involved in care in hospital such as medical contra-indications and comorbidities), possibly unnecessary deviations (e.g. patients feeling miserable postoperatively) and unnecessary deviations (to be solved with better organisation of care). Thus, the elements with most room for improvement (a high percentage of unnecessary deviations or possibly unnecessary deviations) could be identified.

An expert panel (the nurse coordinator, lead surgeons and anaesthetist, and an implementation expert) reviewed the changes in perioperative care and identified factors explaining success or failure of changes in surgical practice, in doing so evaluating and judging the reasons for non adherence.

To increase the trustworthiness of the interpretation of the data by the expert panel a surgeon, an anaesthetist and a nurse who had a key role in the implementation activities on the surgical ward, were given the opportunity to respond to and correct the panels' description of barriers and facilitators.

\section{Results}

\section{Characteristics of patients.}

The mean age of the ERAS patients was $67,55 \%$ was male, $22 \%$ had ASA status III/IV, 74\% had colorectal cancer, 57\% underwent a left sided colectomy and $12 \%$ underwent a complex resection. The pre-ERAS patients and the ERAS patients were comparable with respect to age, gender distribution, presence of malignancy, site and complexity of resection, but differed in ASA status with a significantly higher ratio of ASA III/IV patients in the ERAS group ( $22 \%$ versus $9 \%$ in the pre-ERAS group). 


\section{Improvement after implementation}

The retrospective analysis of conventional care demonstrated that perioperative care before the introduction of the ERAS programme was mainly based on non evidence based traditions in surgical care (table 1).

Oral bowel preparation, a nasogastric decompression tube, nil by mouth, unrestricted use of intravenous fluids and bed rest were standard elements of care. Only two elements of the ERAS programme were already partially implemented. Epidural analgesia was used in almost three quarters of the patients and half of the patients were warmed during surgery with an upper-body forced-air heating.

Table 1. Analysis of perioperative care before (2001) and after introduction of the ERAS programme (2003-2006). Data are percentages of patients managed according to the various care elements of the ERAS programme. In column 3 estimated adherence to the protocol without unnecessary and possibly unnecessary deviations.

\begin{tabular}{|c|c|c|c|}
\hline Perioperative care elements & $\begin{array}{l}2001 \\
n=55\end{array}$ & $\begin{array}{l}20032006 \\
n=132\end{array}$ & $\begin{array}{l}\text { Highest possible } \\
\text { protocol } \\
\text { adherence }\end{array}$ \\
\hline \multicolumn{4}{|l|}{ Before surgery } \\
\hline Preoperative counselling & 0 & 93 & 99 \\
\hline No bowel preparation & 5 & 94 & 95 \\
\hline Oral carbohydrate treatment & 0 & 87 & 90 \\
\hline \multicolumn{4}{|l|}{ Operative factors } \\
\hline Active warming by Bair Hugger ${ }^{\circ}$ & 56 & 98 & 100 \\
\hline Epidural analgesia at all & 71 & 92 & 95 \\
\hline \multicolumn{4}{|l|}{ Postoperative factors, day 0} \\
\hline No nasogastric drainage & 6 & 92 & 100 \\
\hline Out of bed at all & 0 & 51 & $70-85$ \\
\hline Oral fluids $>800 \mathrm{ml}$ & 0 & 36 & $70-85$ \\
\hline Oral nutritional supplements $>200 \mathrm{ml}$ & 0 & 29 & $65-80$ \\
\hline \multicolumn{4}{|l|}{ Day 1 after operation } \\
\hline Intravenous fluid infusion stopped & 0 & 44 & $60-90$ \\
\hline Out of bed $>6$ hours & 0 & 28 & $40-90$ \\
\hline Solid food & 6 & 48 & $60-90$ \\
\hline Oral nutritional supplements $>400 \mathrm{ml}$ & 0 & 50 & $60-80$ \\
\hline \multicolumn{4}{|l|}{ Day 2 after operation } \\
\hline Epidural removed & 33 & 77 & $80-90$ \\
\hline Urinary catheter out & 11 & 84 & $85-90$ \\
\hline
\end{tabular}

The prospective evaluation of every day practice after the introduction of the programme showed that pre- and peri-operative care elements were generally implemented in a successful manner. This was also true for the postoperative elements "nasogastric drainage", "removal of the epidural cathether", and "removal of the urinary catheter". The other postoperative care elements considering early nutri- 
tion and mobilisation were poorly adopted. Nutrition and mobilisation as to the prescheduled care plan were realised in less than half of the patients.

\section{Reasons for protocol deviation}

The most frequently mentioned reasons for protocol violation were patients returning late from the recovery room as a consequence of which time and staff were too restricted to fully adhere to the protocol, patients' malaise on the day of surgery and day after surgery, and the reliance of surgeons, anaesthetists and nurses on traditional dogmatic routines (table 2).

Table 2. Most important reasons for protocol deviation per protocol care element

\begin{tabular}{|c|c|c|}
\hline Care elements & $\begin{array}{l}\text { \% Non } \\
\text { Compliance }\end{array}$ & Reasons protocol deviation \\
\hline Preoperative counselling & 3 & $\begin{array}{l}\text { Counselling impossible: demented, mentally disabled and non- } \\
\text { native patients }\end{array}$ \\
\hline No bowel preparation & 5 & $\begin{array}{l}\text { Participation in a trial requiring preoperative bowel prepara- } \\
\text { tion }\end{array}$ \\
\hline Carbohydrate drinks & 10 & Contra-indication: Diabetes Mellitus \\
\hline Bair Hugger & 2 & No reason \\
\hline Epidural analgesia at all & 3 & $\begin{array}{l}\text { Fall back to more traditional analgesia in patients with severe } \\
\text { co-morbidity }\end{array}$ \\
\hline No nasogastric drainage & 7 & $\begin{array}{l}\text { Reliance on tradition, selection of patients "who really need a } \\
\text { tube" }\end{array}$ \\
\hline Mobilisation at all & 23.5 & Late return from recovery room \\
\hline \multirow[t]{3}{*}{ day 0} & 9 & Stay over on recovery room \\
\hline & 6 & Patients'malaise \\
\hline & 5 & Pain \\
\hline \multirow{6}{*}{$\begin{array}{l}\text { Oral nutritional supple- } \\
\text { ments day } 0\end{array}$} & 23 & Late return from recovery room \\
\hline & 13 & Nausea and vomiting \\
\hline & 13 & Staff error, supplements not offered \\
\hline & 8 & Stay over on recovery room \\
\hline & 7 & Patient refusal: aversion or no appetite \\
\hline & 7 & Reliance on tradition: nil by mouth \\
\hline \multirow{4}{*}{$\begin{array}{l}\text { Oral fluid intake }>800 \mathrm{ml} \\
\text { day } 0\end{array}$} & 29 & Late return from recovery room \\
\hline & 12 & Nausea and vomiting \\
\hline & 12 & $\begin{array}{l}\text { Reliance on tradition: nil by mouth,limited support, limited } \\
\text { supply }\end{array}$ \\
\hline & 8 & Stay over on recovery room \\
\hline
\end{tabular}




\begin{tabular}{|c|c|c|}
\hline \multirow[t]{2}{*}{ Care elements } & $\%$ Non & Reasons protocol deviation \\
\hline & \multicolumn{2}{|l|}{ Compliance } \\
\hline Intravenous fluid infusion & 19.5 & Nausea and vomiting \\
\hline \multirow[t]{4}{*}{ stopped day 1} & 7.5 & Insufficient intake of oral fluids \\
\hline & 7.5 & Decreased urinary secretion \\
\hline & 7 & Reliance on tradition: wait and see approach \\
\hline & 5.5 & Nil by mouth, nasogastric tube \\
\hline \multirow[t]{6}{*}{ Out of bed $>6$ hours day 1} & 21.5 & Patients' malaise \\
\hline & 13 & $\begin{array}{l}\text { Reliance on tradition: limited support to achieve } 6 \text { hours } \\
\text { mobilisation }\end{array}$ \\
\hline & 10 & Pain \\
\hline & 7 & Hypotension, dizziness \\
\hline & 7 & Tired \\
\hline & 5 & Co-morbidity \\
\hline \multirow[t]{3}{*}{ Solid food day 1} & 26.5 & Nausea and vomiting \\
\hline & 13 & Reliance on tradition: still on liquids \\
\hline & 7 & Nasogastric tube still inserted \\
\hline \multirow{5}{*}{$\begin{array}{l}\text { Oral nutritional supple- } \\
\text { ments }>400 \mathrm{ml} \text { day } 1\end{array}$} & 19 & Nausea and vomiting \\
\hline & 11 & Patients refusal: aversion or no appetite \\
\hline & 7 & Nasogastric tube inserted or replaced \\
\hline & 5.5 & Staff error, supplements not offered \\
\hline & 5 & Reliance on tradition in extensive surgery: clear liquids \\
\hline \multirow[t]{2}{*}{ Epidural removed day 2} & 7 & Local protocol deviation for left sided resection \\
\hline & 5 & $\begin{array}{l}\text { Reliance on tradition: watch and see approach in patients } \\
\text { that feel miserable }\end{array}$ \\
\hline Urinary catheter out day 2 & 4.5 & Patient immobile, unable to go to the toilet \\
\hline
\end{tabular}

Medical contra-indications as the most acceptable reason for deviation of the protocol were responsible for less than $10 \%$ of non compliance. The highest possible adherence rates varied between $90-100 \%$ for the pre and per-operative care elements and $40-90 \%$ for the postoperative care elements. Most room for improvement (table 1 , third column) was identified in elements concerning early mobilisation and nutrition, the elements that were most poorly adopted.

The expert panel identified the following three key facilitators of implementation: the reduced discomfort of patients because of cancellation/early discontinuation of inconvenient peri-operative practices such as bowel preparation, nasogastric tubes, fasting, iv lines, epidurals and urinary catheters, the appointment of a nurse coordinator and a high level of evidence supporting key elements of the programme.

The lack of patients' well being postoperatively was a major barrier to the implementation of the enhanced recovery programme. According to caregivers some patients were too sick and miserable or in too much pain to achieve the targets of early nutrition and mobilisation. Lack of experience in new routines made it difficult to tailor the interventions to the individual patient and to judge when the patient required a different course of action. Lack of robust evidence behind the recommendations regarding nutrition and mobilisation hindered the integration in 
daily practice. Finally, enhanced recovery was not regarded as an important outcome of care by surgeons, anaesthetist, nurses, as well as by the patients.

Table 3. Facilitators and barriers to the implementation of the ERAS programme

\begin{tabular}{|c|c|c|}
\hline Care elements & $\begin{array}{l}\text { Facilitators to its imple- } \\
\text { mentation }\end{array}$ & Barriers to its implementation \\
\hline $\begin{array}{l}\text { Preoperative } \\
\text { counselling }\end{array}$ & $\begin{array}{l}\text { Appointment of a specific } \\
\text { coordinator who is responsi- } \\
\text { ble for organisation of preop- } \\
\text { erative information } \\
\text { No doubt of importance of } \\
\text { preoperative extensive pa- } \\
\text { tient information }\end{array}$ & $\begin{array}{l}\text { Coordinator not incorporated in established structures } \\
\text { and team communication }\end{array}$ \\
\hline $\begin{array}{l}\text { No bowel } \\
\text { preparation }\end{array}$ & $\begin{array}{l}\text { Level A evidence } \\
\text { Bowel preparation is very } \\
\text { inconvenient for patients }\end{array}$ & $\begin{array}{l}\text { Trial protocols that are not compatible with ERAS } \\
\text { protocol }\end{array}$ \\
\hline $\begin{array}{l}\text { Oral carbohy- } \\
\text { drate treatment }\end{array}$ & $\begin{array}{l}\text { Carbohydrate drinks reduce } \\
\text { patients' preoperative discom- } \\
\text { fort }\end{array}$ & $\begin{array}{l}\text { Traditional fasting rules were easier to adhere to. } \\
\text { Algorithm to identify risk patients is required. }\end{array}$ \\
\hline $\begin{array}{l}\text { Upper body } \\
\text { forced air } \\
\text { heating }\end{array}$ & Level A evidence & \\
\hline $\begin{array}{l}\text { Epidural anal- } \\
\text { gesia at all }\end{array}$ & $\begin{array}{l}\text { Department of anaesthesia } \\
\text { that is familiar with epidural } \\
\text { analgesia }\end{array}$ & $\begin{array}{l}\text { Experienced anaesthetist required for patients with } \\
\text { co-morbidity } \\
\text { Recovery is not an important outcome of anaesthesia } \\
\text { in traditional care }\end{array}$ \\
\hline $\begin{array}{l}\text { No nasogastric } \\
\text { drainage }\end{array}$ & $\begin{array}{l}\text { Level A evidence } \\
\text { A nasogastric tube is very } \\
\text { inconvenient for the patient }\end{array}$ & $\begin{array}{l}\text { Lack of experience in selecting patients who really } \\
\text { need a tube }\end{array}$ \\
\hline $\begin{array}{l}\text { Mobilisation at } \\
\text { all day } 0\end{array}$ & $\begin{array}{l}\text { The increased risk of bed rest } \\
\text { on thrombo-embolism is well } \\
\text { known. }\end{array}$ & $\begin{array}{l}\text { Lack of experience in early mobilisation with the risk of } \\
\text { bad first experiences } \\
\text { Increased workload, especially in the evening shift } \\
\text { Patients postoperative malaise } \\
\text { Early recovery is not an important outcome for nurses } \\
\text { Lack of evidence of mobilisation on day } 0\end{array}$ \\
\hline $\begin{array}{l}\text { Fluid intake > } \\
800 \mathrm{ml} \text { and } \\
\text { nutritional } \\
\text { supplements > } \\
200 \mathrm{ml} \\
\text { day } 0\end{array}$ & $\begin{array}{l}\text { The traditional postoperative } \\
\text { nil by mouth regime is very } \\
\text { inconvenient for patients }\end{array}$ & $\begin{array}{l}\text { Patients' postoperative malaise, bad experiences with } \\
\text { patients vomiting after first drink } \\
\text { Lack of experience in selecting patients who really } \\
\text { need a nil by mouth regime postoperatively } \\
\text { Target of } 800 \mathrm{ml} \text { oral fluids and } 200 \mathrm{ml} \text { supplements } \\
\text { not feasible in patients who return late from recovery } \\
\text { room } \\
\text { Lack of evidence of recommended } \mathrm{ml} \text { of intake (Why is } \\
750 \mathrm{ml} \text { not enough?) }\end{array}$ \\
\hline
\end{tabular}




\begin{tabular}{|c|c|c|}
\hline Care elements & $\begin{array}{l}\text { Facilitators to its imple- } \\
\text { mentation }\end{array}$ & Barriers to its implementation \\
\hline $\begin{array}{l}\text { Termination } \\
\text { intravenous } \\
\text { fluid infusion } \\
\text { day } 1\end{array}$ & $\begin{array}{l}\text { No iv line is promotes mobili- } \\
\text { sation }\end{array}$ & $\begin{array}{l}\text { Patients' postoperative malaise } \\
\text { Lack of experience in selection of patients that do } \\
\text { need iv fluids }\end{array}$ \\
\hline $\begin{array}{l}\text { Solid food } \\
\text { day } 1\end{array}$ & $\begin{array}{l}\text { Robust evidence that early } \\
\text { nutrition is safe }\end{array}$ & $\begin{array}{l}\text { Patients' postoperative malaise } \\
\text { Lack of experience in selecting patients that should } \\
\text { continue fasting }\end{array}$ \\
\hline $\begin{array}{l}\text { Mobilisation }>6 \\
\text { hours } \\
\text { day } 1\end{array}$ & $\begin{array}{l}\text { Early mobilisation leads to } \\
\text { early independency and thus } \\
\text { to decreased nursing work } \\
\text { load }\end{array}$ & $\begin{array}{l}\text { Patients' postoperative malaise } \\
\text { Lack of experience in selecting patients that should } \\
\text { not be forced to mobilise } \\
\text { Lack of evidence for recommended hours } \\
\text { Patients not cooperative, rapid recovery is not an } \\
\text { important outcome for patients }\end{array}$ \\
\hline $\begin{array}{l}\text { Epidural remo- } \\
\text { ved on day } 2\end{array}$ & $\begin{array}{l}\text { Removal of epidural catheter } \\
\text { promotes mobilisation }\end{array}$ & $\begin{array}{l}\text { Patients' postoperative pain } \\
\text { Standard removal of epidural conflicts with best prac- } \\
\text { tice of removal of epidural on the basis of patients } \\
\text { pain scores }\end{array}$ \\
\hline $\begin{array}{l}\text { Urinary cathe- } \\
\text { ter out } \\
\text { day } 2\end{array}$ & $\begin{array}{l}\text { Removal of urinary catheter } \\
\text { promotes mobilisation } \\
\text { Increased risk of urinary infec- } \\
\text { tion is well known }\end{array}$ & Patients' postoperative malaise \\
\hline
\end{tabular}

\section{Discussion}

\section{Summary of the main results}

This process evaluation demonstrated the complex reality of introducing a multimodal evidence based protocol in everyday practice. In the preoperative phase, the intended changes in process of care were successfully implemented. There were hardly any reasons for protocol violation, no doubts about the value of the recommendations and few contra-indications and restrictions in patients. Protocol adherence was facilitated by the appointment of a coordinator who fully controlled the application of the protocol. This was much more difficult in the postoperative phase where limits in time and staff, restrictions in patients that felt sick after surgery, and motivational factors in care givers and patients hindered the adherence to the protocol.

The lack of motivation to enhance recovery and to shorten hospital stay was the most unforeseen and probably most important barrier. Unforeseen, as in the perspectives of health workers "one leaves a hospital as soon as possible". Most important because this barrier operated at the level of patients as well as nurses, anaesthetist and surgeons. Patients and colleagues that did not co-operate and 
responded negatively, seemed to have a demotivating effect on the other participants.

Patients considered early recovery and short hospital stay as not so important. Patients wanted to be cured "no matter how long that takes". As to a recent study of patients expectations of colorectal surgery, complete cure was rated as most important, followed by the avoidance of a stoma, a reliable control of defecation, normal digestion and little pain ${ }^{16}$.

At the nurses level, forcing rehabilitation conflicted with personal values as the desire to help patients and provide care, comfort and nurture ${ }^{17}$. There were concerns about the medical appropriateness of early discharge, a potential reduced welfare of patients and increased need for domiciliary support. Nurses on the ward perceived no benefits of a short hospital stay as "the bed will be filled as soon as the patient has left". The extra workload, a consequence of the increased patient flow $^{18}$, negatively influenced the motivation to change practice.

At the anaesthetist' and surgeons' level, the rate and quality of recovery were poorly accepted as new clinically relevant outcomes. Perioperative care remained driven by the assessment of anaesthetic- and surgery related complications and measures of postoperative morbidity ("as long as we do not have deaths and leakages").

\section{Strength and limitations of the current study}

The strength of this study was that the reported barriers and facilitators were actually reviewed during the process of care. Experiences, shortly after an intervention, were collected prospectively over a period of three years. Performance data were abstracted from medical records, but to improve the likelihood of reliable and complete data, the staff of the ward and the patients were frequently interviewed the first days after surgery. Direct observation of the behaviours and situation, and the use of a standardized and categorized report form prevented invalid conclusions about non adherence by care givers themselves.

Usually, an analysis of potential factors that may hinder or impede the implementation, precedes the implementation activities, as tailor made implementation strategies that are linked to perceived barriers may be more successful. The ERAS programme was implemented in a very intuitive and traditional way. Implementation activities were mainly concentrated on transfer of information to all involved professionals. There were no strategies to overcome barriers before the start of the project.

One of the limitations of the study was that the study was performed in a single medical centre. Some barriers and facilitators may act at the local level and findings may not be generalisable. 
Another limitation was that the prevailing professional and organisational culture were not evaluated. Changes in clinical practice are only partly within doctors' control. Structural characteristics of an organisation e.g. the presence of an infrastructure for quality and the involvement of clinical leaders, determine the effectiveness of an innovation to a large extent ${ }^{7}$. The extent to which traditional routines deviated from the evidence based recommendations described in the ERAS protocol suggests that the clinical environment was not attractive to induce change.

It was not possible to clearly define a realistic scale of change that can be achieved in a real live setting. In the ERAS protocol more than thirty recommendations regarding perioperative care are given. A selection was made of aspects that were considered to be strongly related to postoperative recovery. After analysing the performance data, postoperative nausea and vomiting (PONV) and pain appeared to be limiting factors in achieving an early recovery. The screening of patients at risk of PONV, the administration of a multimodal anti-emetic scheme and the administration of postoperative analgesia were protocol elements that were not analysed. Therefore, it was not possible to assess to what extent postoperative nausea and vomiting (PONV) and pain could have been prevented

\section{Comparison with existing literature.}

Only one study actually measured the degree of protocol adherence and addressed the difficulties arising from the introduction of such a program in everyday practice ${ }^{19}$. The care elements that were evaluated in this study differed from the care elements evaluated in the current study and overall compliance rates could not be compared. Only 6 elements of care could be compared. The degree of protocol compliance regarding preoperative counseling, omission of bowel preparation, and prevention of hypothermia did not differ substantially. Epidural catheters were used in 70 percent of patients versus 95 percent in the present study, but this variation may be due to difference of definition (epidural functioning or epidural at all). Adherence to carbohydrate drinks prior to surgery and oral nutritional supplements on day of surgery was less than reported in the present study ( 67 versus 87 percent, 13 versus 29 percent respectively). The conclusions correspond with the findings of the present study: the overall compliance was judged to be low, protocol adherence in the postoperative phase was lower than in the preoperative phase and full implementation of an ERAS protocol was troublesome.

\section{Suggested strategies to promote the adoption of the ERAS protocol in every day practice.}

To gain internal support for the ERAS programme it should be launched as a international well-developed multidisciplinary guideline, published by a respected over- 
arching institution, showing that the provision of such care is consistent with current professional knowledge ${ }^{20}$.

Studying current practice and demonstrating discrepancies between actual and optimal care as described in the guideline, and setting up a local version of the guideline by reaching local consensus among the target group may strengthen the internal support ${ }^{21}$. The nurses might be more easily persuaded if they are well aware of the positive effect of the programme on fatigue, need for sleep and regain of functional capacities ${ }^{22}$; on earlier achievement of the discharge criteria and therefore facilitating early discharge ${ }^{23}$; on the patients' satisfaction with the entire perioperative course without complaints about the timing of discharge ${ }^{24}$. Patients' support to the protocol should be gained by translating early recovery and short hospital stay in patient centred outcomes such as an earlier capacity to participate in social events, to travel, to return to work etc ${ }^{25}$.

Ensuring clinical leadership, the buy in of local opinion leaders ${ }^{26,27}$, the purposeful selection of the first patients that seem most fit to show successful outcomes and the feedback of these positive outcomes to the target group, may further promote the incorporation of the ERAS protocol in daily practice.

\section{Conclusion}

Although the ERAS protocol was implemented in a traditional and intuitive way and although many barriers and facilitators were identified, preoperative care was successfully changed and changes in postoperative care were realized in more than half of the patients. Understanding factors that hinder or enhance the implementation may be helpful for other institutions that deal with the need for a more systematic approach to implement the ERAS protocol. 


\section{References}

1. Urbach DR, Baxter NN, Reducing variation in surgical care.[comment]. BMJ 2005;330(7505): 14011402.

2. Fingerhut A, Borie F, Dziri C, How to teach evidence-based surgery. World Journal of Surgery 2005;29(5): 592-595.

3. McColl A, Smith H, White P, Field J, General practitioner's perceptions of the route to evidence based medicine: a questionnaire survey.[see comment]. BMJ 1998;316(7128): 361-365.

4. Field M, Lohr K. Clinical practice guidelines: directions for a new agency. Washington DC: National Academy Press 1990.

5. Field M, Lohr K. Guidelines for clinical practice. From development to use. Institute of Medicine, Washington DC: National Academy Press 1992.

6. Grimshaw J, Russell I, Achieving health gain through clinical guidelines. Developing scientifically valid guidelines. Quality in Health Care 1993;2(4): 243-248.

7. Grimshaw JMMP, Shirran LMAM, Thomas RB, Mowatt GMAMBA, Fraser CMA, Bero LP,et al. Changing Provider Behavior: An Overview of Systematic Reviews of Interventions. Medical Care 2001;39(8) Supplement(2): II-2-II-45.

8. Fearon KC, Ljungqvist $\mathrm{O}$, Von Meyenfeldt $\mathrm{M}$, Revhaug $\mathrm{A}$, Dejong $\mathrm{CH}$, Lassen $\mathrm{K}$, et al. Enhanced recovery after surgery: a consensus review of clinical care for patients undergoing colonic resection. Clin Nutr 2005;24(3): 466-477.

9. Maessen J, Dejong CH, Hausel J, Nygren J, Lassen K, Andersen J,et al. A protocol is not enough to implement an enhanced recovery programme for colorectal resection. Br J Surg 2007;94(2): 224231.

10. Kehlet $\mathrm{H}$, Mogensen $\mathrm{T}$. Hospital stay of 2 days after open sigmoidectomy with a multimodal rehabilitation programme. Br J Surg 1999;86(2): 227-230.

11. Basse L, Hjort Jakobsen D, Billesbolle P, Werner M, Kehlet H. A clinical pathway to accelerate recovery after colonic resection. Ann Surg 2000;232(1): 51-57.

12. Grol R,. Personal paper. Beliefs and evidence in changing clinical practice. BMJ 1997;315(7105): 418-421.

13. Grol R, Grimshaw J. From best evidence to best practice: effective implementation of change in patients' care. Lancet 2003;362(9391): 1225-1230.

14. Grol R, Wensing $M$, What drives change? Barriers to and incentives for achieving evidence-based practice. Med J Austr 2004;180(6 Suppl): S57-60.

15. Shaw B, Cheater F, Baker R, Gillies C, Hearnshaw H, Flottorp S, et al Tailored interventions to overcome identified barriers to change: effects on professional practice and health care outcomes. Cochr Dat of Syst Rev 2005(3): CD005470.

16. Holzer B, Gyasi A, Schiessel R, Rosen HR, Patients' expectations of colorectal surgery for cancer. Colorectal Disease 2006;8(3): 186-191.

17. Nettina SM. The lippincott manual of nursing practice. $2005 ; 8^{\text {th }}$ edition: Philadelphia:Lippincott.

18. Jakobsen DH. Perioperative nursing care programmes for fast track colonic resection. In: 1st Hvidovre symposium on perioperative care- colorectal surgery; 2001 21-22 juni 2001; Kopenhagen; 2001.

19. Polle SW, Wind J, Fuhring JW, Hofland J, Gouma DJ, Bemelman WA, Implementation of a fasttrack perioperative care program: what are the difficulties? Digestive Surgery 2007;24(6): 441449.

20. Rowell PA,. Appropriateness of care: the case for changing the focus of "quality" measurement. Quality Management in Health Care 2004;13(3): 178-182.

21. Rogers E. Lessons for guidelines from the diffusion of innovation. Jt Comm J Qual Improv 1995;21: 324-328. 
22. Jakobsen $\mathrm{DH}$, Sonne E, Andreasen J, Kehlet $\mathrm{H}$, Convalescence after colonic surgery with fast-track vs conventional care. Col Dis 2006;8(8): 683-687.

23. Maessen JMC, Dejong CHC, Kessels AG, Meyenfeldt von MF. Enhanced recovery after surgery, fact or fiction? submitted.

24. Andersen J, Hjort-Jakobsen D, Christiansen PS, Kehlet H, Readmission rates after a planned hospital stay of 2 versus 3 days in fast-track colonic surgery. British Journal of Surgery 2007;94(7): 890893.

25. Clark PA. Increase patient satisfaction by improving your discharge process Hospitalist Management Advisor 2006.

26. Felch WC, Bridging the gap between research and practice. The role of continuing medical education.[see comment][erratum appears in JAMA 1997 May 14;277(18):1438]. JAMA 1997;277(2): 155-156.

27. Soumerai SB, McLaughlin TJ, Gurwitz JH, Guadagnoli E, Hauptman PJ, Borbas C, et al Effect of local medical opinion leaders on quality of care for acute myocardial infarction: a randomized controlled trial.[see comment]. JAMA 1998;279(17): 1358-1363. 
Appendix 1. Enhanced Recovery After Surgery programme for patients undergoing colonic resection

Before surgery

Preadmission counselling

No bowel preparation

No preoperative fluid restriction

Oral carbohydrate loading

\section{Day of surgery}

No pre-anaesthetic medication

Single dose antibiotic prophylaxis

Standard thoracic epidural

Minimal incision

No nasogastric decompression tube

No drains

Upper body forced air-heating cover

Perioperative fluid restriction

Paracetamol as baseline analgesic

Oral fluids $>800 \mathrm{ml}$

Out of bed at all

Oral nutritional supplements $>200 \mathrm{ml}$,

Postoperative day 1

Discontinuation of iv fluids

Normal food

Oral nutritional supplements $>400 \mathrm{ml}$

Out of bed $>6$ hours

Postoperative day 2

Discontinuation of epidural analgesia

Urinary bladder drainage for the duration of thoracic epidural analgesia. 


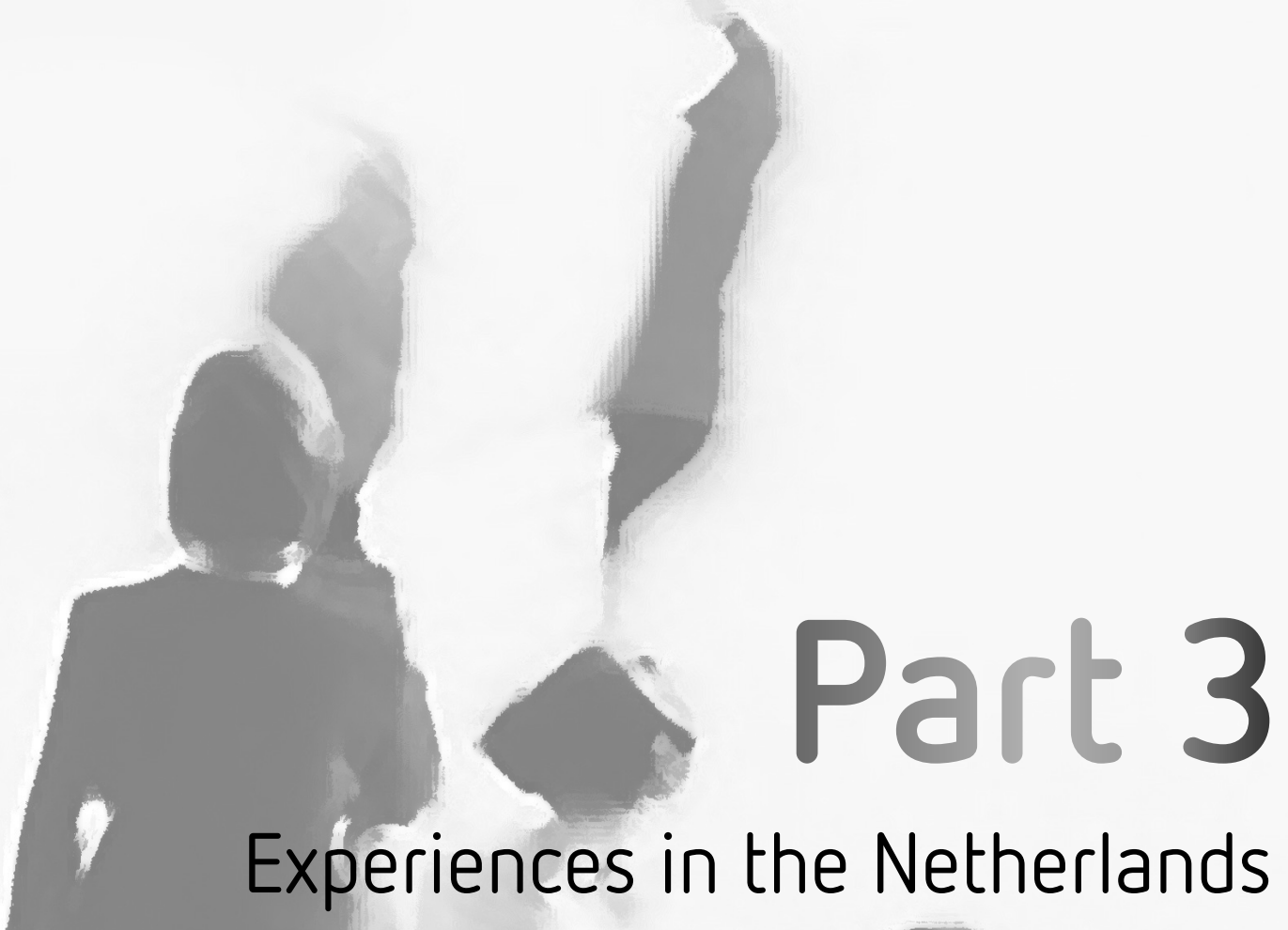





\section{Chapter 7}

\section{Perioperative care in elective colonic surgery in}

the Netherlands in the new millennium: are we doing what we should do?

C. Hoff, K. Jottard, J. Maessen, H. Tijink, J.S. Wien, S.J. van der Hagen, A.P.J. Houdijk, C. Rosman, C.H.C. Dejong , on behalf of the Perioperative Care Breakthrough Project Group and the ERAS group

Submitted

"Ik ben naar de verjaardag van mijn nichtje geweest en tot half een 's nachts gebleven".

Patiënt $M, 5$ dagen na de operatie 


\section{Abstract}

\section{Aim}

Evidence-based multimodal perioperative care protocols currently elicit much interest, because they seem to be instrumental in improving outcome of surgery both in terms of recovery and length of stay. However, recent reports in literature suggest that traditional care is still widespread and the available evidence and guidelines based on such evidence are not being adhered to. The aim of the present study was to obtain information on the current situation in the Netherlands with respect to perioperative care in elective colonic surgery.

\section{Methods}

A retrospective chart review was performed in 2006 in 26 Dutch hospitals (one quarter of all Dutch hospitals). Information was gathered on various aspects concerning perioperative care in elective colonic surgery performed in 2004, including the use of mechanical bowel preparation, nasogastric decompression tubes, thoracic epidural anaesthesia and resumption of oral intake.

\section{Results}

1165 patients were included in this study. Despite robust evidence in literature that mechanical bowel preparation does not have beneficial effects and may even be harmful, it was used in $71 \%$ of patients included in this study. Likewise, there is no evidence to support the routine use of a nasogastric decompression tube, but it was left in place almost invariably. It took a median of five days for patients to resume a normal diet.

\section{Conclusion}

As recent as 2004 the actual standard of care for patients undergoing elective colonic surgery in the Netherlands was lagging far behind the available evidence. 


\section{Introduction}

Colorectal cancer is one of the most common malignancies in the Netherlands, with some 9000 new cases each year. A colorectal resection is carried out in most cases. Including benign disease, approximately 13000 colorectal resections are carried out yearly in the Netherlands. Therefore any improvement in the standard of care in elective colorectal surgery will have a major impact.

It has been clearly shown in elective colorectal surgery that patients benefit from a reduction of postoperative catabolism and neuro-endocrine stress response ${ }^{1}$. The reduction of catabolism and stress is achieved by using so-called multimodal perioperative care protocols also called fast track or enhanced recovery programmes. These protocols consist of a number of elements that form an evidence based best practice $^{2}$. Prevention of unnecessary starvation, early postoperative nutrition and thoracic epidural anaesthesia/analgesia are some of the key measures that contribute to an enhanced recovery after surgery.

Recent reports suggest that perioperative care in colorectal surgery does not follow the available evidence ${ }^{3-5}$.The present study was conducted to obtain comprehensive data on current perioperative routines in elective colonic surgery in the Netherlands, with a view to improving the standard of care by subsequent nationwide implementation of an Enhanced Recovery After Surgery (ERAS) protocol.

\section{Methods}

In late 2005 and early 2006, twenty six hospitals joined a structured implementation programme for Enhanced Recovery After Surgery (ERAS) in elective colorectal surgery in the Netherlands. As part of that programme, a retrospective analysis was done of the pre-existent standard of perioperative care in each of these hospitals. This was the starting point for a so-called Breakthrough Project for perioperative care in elective colonic surgery, that was organised by the Dutch Institute for Healthcare Improvement (CBO). The ERAS protocol published by Fearon et $\mathrm{al}^{2}$ was used for implementation.

Each participating hospital was asked to review the charts of approximately 50 consecutive patients or a one-year consecutive series of patients undergoing elective colonic resections above the peritoneal reflection from January 2004. This time period was chosen to avoid any influence of prior knowledge of enhanced recovery programmes. The items that were scored included demographic characteristics, length of stay, preoperative mechanical bowel preparation, the use of epidural analgesia and the day after surgery at which a nasogastric tube (if present) was removed, free fluid and free solid intake resumed and the drip taken down. 
Data were entered into an Excel database. Results are generally given as median for all patients and range of per hospital median values.

\section{Results}

The 26 hospitals participating in this study consisted of 2 university hospitals, 13 teaching hospitals and 11 non teaching hospitals. This represents approximately $25 \%$ of all Dutch hospitals. In all, 1165 patients were included in the study period (between 35 en 72 per hospital).

Mechanical bowel preparation was used in $71 \%$ of cases. Only 3 hospitals had abandoned the routine use of mechanical bowel preparation at the time of this study.

All but one of the centres routinely used postoperative nasogastric decompression tubes. When a nasogastric tube was used ( $88 \%$ of cases), it was removed after a median of 2 (1-3) days. Fluid intake at will was resumed on day 2 (0-5). In 7 hospitals free fluid intake was resumed one or even two days (median) after removal of the nasogastric tube ( 4 or 5 days after surgery).

A normal diet was resumed as late as 5 days post-surgery (2-9). Intravenous fluid administration was discontinued on day 6 (4-7).

Thoracic epidural anesthesia / analgesia was used in 52\% of patients. Eleven hospitals reported its use in more than two thirds of patients and five hospitals in less than one third.

Median length of hospital stay from the day of operation was 9 days (5-12).

\section{Discussion}

Evidence is accumulating in literature that significant improvement in outcome of surgical procedures can be achieved by implementing multimodal perioperative care protocols $^{6-11}$. These fast track or enhanced recovery programmes are composed of a number of elements, each of which is supported by scientific evidence ${ }^{2}$. Three previous surveys of perioperative care in colorectal surgery have been reported, all indicating that the available evidence is frequently not followed. Lassen et $\mathrm{al}^{3}$ conducted a postal survey concerning a hypothetical case of elective colonic surgery, which was sent to a large number of centres for digestive surgery in 5 European countries. They obtained a response from $76 \%$ of centres, including 36 teaching hospitals in the Netherlands. Kehlet et al $^{4}$ reviewed consecutive cases of colonic surgery in 295 centers in five European countries and the US during a 2 to 4 week period. In all, 1082 patients were included in the latter study. Hasenberg et $\mathrm{al}^{5}$, in a manner much like the study by Lassen et al, sent a questionnaire to all 
surgical units within Germany and Austria. The response rate in this study was only $30 \%$.

The present study is the first to review every day clinical practice in perioperative care over a contemporary one-year period in a representative sample of hospitals in the Netherlands (26 of 101), with consecutive series of patients and adequate sample size per hospital.

A selection bias cannot be excluded, since all hospitals in this study entered an implementation programme for enhanced recovery after surgery, so it was not a random sample of hospitals. The year 2004 was chosen because this was well before any of the participating hospitals had been approached for implementing an enhanced recovery after surgery programme and was thus felt to best represent contemporary care in the Netherlands.

There is robust ${ }^{12}$ and still growing ${ }^{13,14}$ evidence that mechanical bowel preparation is not indicated in colonic surgery and probably not in rectal surgery either. Not only does it not prevent complications, but it may lead to dehydration, electrolyte disturbances, prolonged preoperative starvation and stress. However, in the present series over half of all patients undergoing elective colonic surgery above the peritoneal reflection were still prepared for surgery in this way. Likewise, there is no evidence to support the routine use of postoperative nasogastric decompression. On the contrary, as was stated in a meta-analysis that was published over a decade ago by Cheatham et $\mathrm{al}^{15}$ the routine use of nasogastric tubes after elective laparotomy should be avoided, since for every NG tube really required in a patient, 20 NG tubes will be inserted unnecessarily. This statement has henceforth been corroborated by several meta-analyses, the most recent of which contained over 5000 patients from $33 \mathrm{RCT}^{\prime} \mathrm{s}^{16}$. However, nasogastric decompression was still standard of care in all but one of the hospitals in the present study.

In his questionnaire conducted in 2003, Lassen et al $^{3}$ found that almost half of patients in the Netherlands were allowed free eating on day one. We found that a nasogastric tube was generally in place on day one and was most frequently removed on day 2 or 3 . Intake of fluids at will was frequently allowed before removal, but postponed for a day or more after removal of the nasogastric tube in 7 hospitals. No sooner than the fifth postoperative day, half of the patients in this study were finally allowed a normal diet. This discrepancy between these two studies clearly illustrates that there may be a wide gap between the desired standard of care (which reflects an awareness of the available evidence in senior staff members, who would have completed the Lassen questionnaire) and the day-to-day clinical practice ${ }^{17,18}$.

A restriction in the administration of fluids in the perioperative period may accelerate recovery of gut function and may reduce postoperative complications and length of stay ${ }^{19,20}$. Due to the retrospective nature of this study, it was deemed impractical if not impossible to quantify the amount of intravenous fluid adminis- 
tered in either the perioperative or the postoperative period. However, since the drip was taken down several days after the resumption of free fluid intake and mostly even after resumption of solid food, it is not very likely that fluid restriction was part of perioperative practice in these hospitals in the Netherlands as per 2004. This is also in line with the general picture obtained from the present study that there is a difference between what is known and what is done.

In the survey by Lassen et $\mathrm{al}^{3}$ the routine use of thoracic epidural analgesia was reported in 30 of 36 Dutch centers (83\%). In the present study, only 11 of 26 hospitals were found to use this technique in more than two thirds of patients. With only $52 \%$ of 1165 patients actually getting thoracic epidural analgesia, it cannot truly be claimed as standard of care in the Netherlands as per 2004.

The present report is to our knowledge the largest single country assessment of contemporary perioperative care. It confirms the lack of adherence to the best available evidence in perioperative care in colorectal surgery in the Netherlands. Effective implementation strategies are urgently needed to make professionals adhere to guidelines, thereby bridging the gap between what we know and what we do.

\section{Acknowledgements}

The authors thank the Perioperative Care Breakthrough Project Group for collection of data: C.L.H. van Berlo, VieCurie Medisch Centrum, Venlo; A.J.A. Bremers, Universitair Medisch Centrum St Radboud, Nijmegen; M.A.M. Brouwers, Haga Ziekenhuis, Den Haag; D. Cobben, Medisch Centrum Leeuwarden; P.P.L.O. Coene, Medisch Centrum Rijnmond Zuid, Rotterdam; K.C.A. van Engelenburg, Slingeland Ziekenhuis, Doetinchem; S.J. van der Hagen, Refaja Ziekenhuis, Stadskanaal; K. Havenga, Universitair Medisch Centrum Groningen; E.J. Hesselink, Gelre Ziekenhuizen, Apeldoorn; I.H.J.T. de Hingh, Catharina Ziekenhuis, Eindhoven; A.P.J. Houdijk, Medisch Centrum Alkmaar; J.M. Klaase, Medisch Spectrum Twente, Enschede; E.A.G.L. Lagae, Ziekenhuis Zeeuws Vlaanderen; F. Logeman, Beatrix Ziekenhuis, Winterswijk; E.J. Mulder, Antonius Ziekenhuis Sneek; K.H. Ong, Ziekenhuis Rivierenland, Tiel; R.J. Oostenbroek, Albert Schweizer Ziekenhuis, Dordrecht; J.W.A. Oosterhuis, Isala Klinieken, Zwolle; R.T. Ottow, Groene Hart Ziekenhuis, Gouda; A.J. den Outer, Rijnland Ziekenhuis, Leiderdorp; B. van Ramshorst, St Antonius Ziekenhuis Nieuwegein; P.H.M. Reemst, Maxima Medisch Centrum, Eindhoven; C. Rosman, Canisius Wilhelmina Ziekenhuis, Nijmegen; G.A. Vos, Waterland Ziekenhuis, Purmerend; F. Wit, Ziekenhuis de Tjongerschans, Heereveen; R.J. Zijlstra, Ziekenhuis Nij Smellinghe, Drachten. 


\section{References}

1. Kehlet $\mathrm{H}$. Multimodal approach to control postoperative pathophysiology and rehabilitation. $\mathrm{Br} \mathrm{J}$ Anaesth 1997;78(5): 606-617.

2. Fearon KC, Ljungqvist $\mathrm{O}$, Von Meyenfeldt $\mathrm{M}$, Revhaug $\mathrm{A}$, Dejong $\mathrm{CH}$, Lassen $\mathrm{K}$, Nygren J, Hausel J, Soop M, Andersen J, Kehlet $\mathrm{H}$. Enhanced recovery after surgery: a consensus review of clinical care for patients undergoing colonic resection. Clin Nutr 2005;24(3): 466-477.

3. Lassen K, Hannemann P, Ljungqvist O, Fearon K, Dejong CH, von Meyenfeldt MF, Hausel J, Nygren $\mathrm{J}$, Andersen J, Revhaug A. Patterns in current perioperative practice: survey of colorectal surgeons in five northern European countries. BMJ 2005;330(7505): 1420-1421.

4. Kehlet $\mathrm{H}$, Buchler MW, Beart RW, Jr., Billingham RP, Williamson R. Care after colonic operation-is it evidence-based? Results from a multinational survey in Europe and the United States. J Am Coll Surg 2006;202(1): 45-54.

5. Hasenberg T, Rittler P, Post S, Jauch KW, Senkal M, Spies C, Schwenk W, Shang E. A survey of perioperative therapy for elective colon resection in Germany, 2006. Chirurg 2007;78(9): 818-826.

6. Bradshaw BG, Liu SS, Thirlby RC. Standardized perioperative care protocols and reduced length of stay after colon surgery. J Am Coll Surg 1998;186(5): 501-506.

7. Henriksen MG, Jensen MB, Hansen HV, Jespersen TW, Hessov I. Enforced mobilization, early oral feeding, and balanced analgesia improve convalescence after colorectal surgery. Nutrition 2002;18(2): 147-152.

8. Kehlet $\mathrm{H}$, Wilmore DW. Multimodal strategies to improve surgical outcome. Am J Surg 2002;183(6): 630-641

9. Anderson $\mathrm{AD}$, McNaught $\mathrm{CE}$, MacFie J, Tring I, Barker $\mathrm{P}$, Mitchell CJ. Randomized clinical trial of multimodal optimization and standard perioperative surgical care. Br J Surg 2003;90(12): 1497-1504.

10. Basse L, Thorbol JE, Lossl K, Kehlet H. Colonic surgery with accelerated rehabilitation or conventional care. Dis Colon Rectum 2004;47(3): 271-277; discussion 277-278.

11. Nygren J, Hausel J, Kehlet H, Revhaug A, Lassen K, Dejong C, Andersen J, von Meyenfeldt M, Ljungqvist $\mathrm{O}$, Fearon KC. A comparison in five European Centres of case mix, clinical management and outcomes following either conventional or fasttrack perioperative care in colorectal surgery. Clin Nutr 2005;24(3): 455-461.

12. Guenaga KF, Matos D, Castro AA, Atallah AN, Wille-Jorgensen P. Mechanical bowel preparation for elective colorectal surgery. Cochrane Database Syst Rev 2005(1): CD001544.

13. Ram E, Sherman Y, Weil R, Vishne T, Kravarusic D, Dreznik Z. Is mechanical bowel preparation mandatory for elective colon surgery? A prospective randomized study. Arch Surg 2005;140(3): 285-288.

14. Jung B, Pahlman L, Nystrom PO, Nilsson E. Multicentre randomized clinical trial of mechanical bowel preparation in elective colonic resection. Br J Surg 2007; 94(6): 689-695.

15. Cheatham ML, Chapman WC, Key SP, Sawyers JL. A meta-analysis of selective versus routine nasogastric decompression after elective laparotomy. Ann Surg 1995;221(5): 469-476; discussion 476-468.

16. Nelson R, Edwards S, Tse B. Prophylactic nasogastric decompression after abdominal surgery. Cochrane Database Syst Rev 2007(3): CD004929

17. Maessen J, Dejong CH, Hausel J, Nygren J, Lassen K, Andersen J, Kessels AG, Revhaug A, Kehlet H, Ljungqvist $\mathrm{O}$, Fearon $\mathrm{KC}$, von Meyenfeldt MF. A protocol is not enough to implement an enhanced recovery programme for colorectal resection. Br J Surg 2007;94(2): 224-231.

18. Lobo DN, Bostock KA, Neal KR, Perkins AC, Rowlands BJ, Allison SP. Effect of salt and water balance on recovery of gastrointestinal function after elective colonic resection: a randomised controlled trial. Lancet 2002;359(9320): 812- 1818.

19. Nisanevich V, Felsenstein I, Almogy G, Weissman C, Einav S, Matot I. Effect of intraoperative fluid management on outcome after intraabdominal surgery. Anesthesiology 2005;103(1): 25-32.

20. Urbach DR, Baxter NN. Reducing variation in surgical care. BMJ 2005 ;330(7505): 1401-1402. 



\section{Chapter 8}

\section{Life and death of the nasogastric tube in elective colonic surgery in the Netherlands}

K. Jottard, C. Hoff, J.M.C. Maessen, B. van Ramshorst,C.L.H. van Berlo, F.Logeman, C.H.C. Dejong, on behalf of the Dutch Perioperative Breakthrough Project and the ERAS group

Clinical Nutrition 2009; 28:26-28

"Als dit een darmoperatie is!. Ik heb me voorgenomen, nu ga ik ook naar de tandarts"

Patiënt K., 3 dagen na operatie 


\section{Abstract}

\section{Aim}

There is abundant evidence that the routine use of nasogastric decompression following elective abdominal surgery is ineffective in achieving any goals it is intended for. Nevertheless its use is still standard of care. The aim of the present study was to investigate whether it is possible to ban nasogastric decompression after elective colonic surgery.

\section{Methods}

At first baseline measurements concerning elements of perioperative care, including nasogastric tubes, were recorded retrospectively over the year 2004. In 2006-2007 the implementation of a fast-track colonic surgery project was guided by the Dutch Institute for Quality of Healthcare CBO, using Berwick's Breakthrough approach.

\section{Results}

A total of 2007 patients were enrolled. The baseline measurement showed that the use of nasogastric drainage is still common practice in the Netherlands. 953 patients (88.3\%) had a nasogastric tube postoperatively. That tube was removed after a median of 2.5 days (range 1-3 days). After the implementation of the breakthrough project "Perioperative Care" the percentage of patients having a nasogastric tube postoperatively dropped to $9.6 \%(p<0.0001)$.

\section{Conclusion}

Our results show using the Breakthrough Methodology it is possible to eradicate the inappropriate routine use of nasogastric tubes. 


\section{Introduction}

The use of nasogastric tubes after colonic surgery is still common worldwide with the intention to hasten the return of bowel function, prevent pulmonary complications, diminish the risk of anastomotic leakage, increase patient comfort and shorten hospital stay.

However, already in 1995, Cheatham and colleagues published the results of a meta-analysis of all published clinical trials so far comparing selective versus routine nasogastric decompression after elective laparotomy ${ }^{1}$. There conclusion was clear: routine nasogastric decompression is not supported by meta analysis of the literature.

In July 2004, the Cochrane Database of Systematic Reviews published the results of their systematic review on the prophylactic decompression after abdominal surgery ${ }^{2}$. That review was revised and up-dated in $2007^{3}$. Patients not having routine tube use had an earlier return of bowel function, a decrease in pulmonary complications and no difference in risk of anastomotic leakage. So, according to the Cochrane Database, routine nasogastric decompression should be abandoned in favour of selective use of the nasogastric tube.

In 2005, the ERAS group published the results of a comparison in five European centres of case mix, clinical management and outcomes following either conventional or fast-track perioperative care in colorectal surgery ${ }^{4}$. The article shows that in a representative university hospital in the Netherlands (University Hospital Maastricht) in $96 \%$ of the cases postoperative nasogastric drainage was used, in comparison to $0 \%$ in Sweden, UK, Norway and Denmark. This proved to be a good indicator of the overall situation in the Netherlands, as was later shown by Lassen ${ }^{5}$. This article, based on a questionnaire sent to the head surgeons of all digestive surgical centres in the five countries (NL, DK, NO, SE, UK) of the departments belonging to the ERAS group in 2003, shows that in the Netherlands in $78 \%$ of the cases a nasogastric tube was used postoperatively after elective colonic surgery. In $36 \%$ of the cases the tube was removed on the first postoperative day. In $25 \%$ of the cases the tube was only removed when first bowel movement was present. This widespread use of postoperative decompression was only found in this survey in the Netherlands. This routine deviates substantially from guidelines based on abundant, high quality medical evidence.

In 2006 the CBO (Dutch institute for quality in healthcare), organised a breakthrough project in 26 hospitals in the Netherlands, in the context of the implementation of a fast-track colonic surgery project. This article shows the results concerning the use and changes in use of nasogastric tubes after elective colonic surgery before and after the implementation of a fast-track project in a quarter of all Dutch hospitals. 


\section{Methods}

In 2005 and 2006 the CBO organised a 'breakthrough project' concerning the synchronous implementation of a fast-track colonic surgery program in 26 hospitals in the Netherlands. First, all 26 hospitals assembled retrospectively data for a baseline measurement during a one-year period or on a consecutive series of 50 patients in 2004. That period was chosen in such a way that fast track surgery wasn't heard of yet in most hospitals, to avoid bias.

Data were recorded concerning eight elements of perioperative care. Those elements were: length of stay, use of phosphate bowel preparation, use of thoracic epidural anaesthesia, use of nasogastric tube, time to start drinking, use of a stepup oral intake regimen, time to normal food intake and duration of intravenous fluid intake.

In this article only the changes in use concerning the nasogastric tube will be discussed. Following retrospective data collection, in 2006-2007 the elements of the fast-track protocol, according to the consensus by Fearon et $\mathrm{al}^{6}$ were implemented by all these hospitals. This implementation used Berwick's Breakthrough Methodology ${ }^{7}$ and was closely monitored and guided for by the CBO.

The breakthrough method has been developed by Donald Berwick and is known for its effectiveness in implementing changes in healthcare. A key element of the method is the so-called 'plan-do-study act cycles'.

For the present study, in January 2006 a starting meeting was organised where information was given about all the elements of the protocol and the various methods to implement it and, very importantly, the participating hospitals got acquainted with each other and had the possibility to exchange knowledge and practice experience. Each hospital had a contact person within the $\mathrm{CBO}$, who was available at all times. Every three months a meeting with all participating hospitals was organised, at which the progress and pitfalls of every hospital were discussed. Each hospital kept the liberty of implementing the ERAS fast-track protocol in a manner they had chosen for: implementing one or several elements of the protocol at a given time or implementing all elements at once.

During that period an online database was accessible for data recording for all hospitals and other members of the $\mathrm{CBO}$-breakthrough project. The following elective operations were included: right colectomy, left colectomy, total colectomy, APR, and low anterior resection either open or laparoscopic procedures.

Data are presented as median and range, unless stated otherwise. Statistics were performed using the Chi square test. 


\section{Results}

Per May 2007, exactly 2007 patients had been entered into the database. Of these, 1165 patients had been enrolled in the retrospective part of the study (historic controls), whilst 842 patients had been studied during the ERAS fast-track implementation phase (ERAS group). Data on the use of nasogastric tubes were missing in $7,4 \%$ of patients in the historic control and in $1.8 \%$ of patients in the ERAS group (5.0\% missing data in the whole group of 2007 patients), leaving 1079 patients for analysis in the historic control group and 827 patients in the ERAS group.

The baseline measurement showed that the majority of hospitals were using a nasogastric tube postoperatively as a routine prior to the implementation of the ERAS programme, and hence $88.3 \%$ of patients had a nasogastric tube in the baseline measurement (historic control group). Only one hospital had the policy to remove the nasogastric tube immediately after the operation. In the other hospitals the tube was removed after a median of 2.5 days (range 1-3 days).

Following the structured implementation of the ERAS programme in the 26 hospitals using the Breakthrough Methodology, the percentage of patients having a nasogastric tube postoperatively dropped to $9.6 \%(p<0.0001)$ (Figure1). As could be expected, these results had a major influence on the results concerning time to start drinking, time to normal food intake, duration of intravenous fluid intake and length of stay.

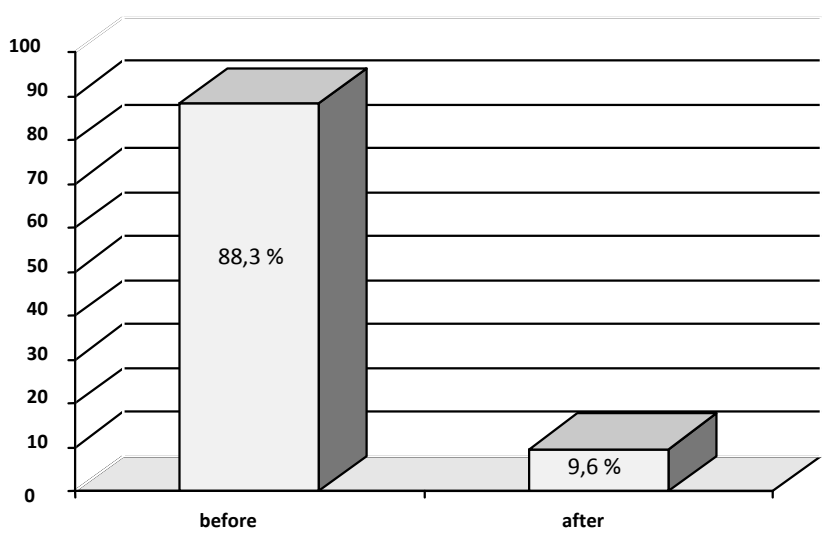

Figure 1. Use of nasogastric drainage before and after the implementation of a fast-track program. 


\section{Discussion}

The present study was undertaken to try and ban the routine use of nasogastric decompression tubes after elective colonic surgery in the Netherlands. The data confirm that as per 2004 the use of NG decompression after elective colonic surgery was still part of standard care in the Netherlands, despite abundant evidence that this is not beneficial and probably even harmful to the patient. Equally, we show that it is possible to change everyday clinical practice using the Breakthrough Methodology. The routine use of NG decompression dropped from $88 \%$ to below $10 \%$ within a year's time.

Although our data are collected partially retrospectively, they are representative for the overall situation in the Netherlands ${ }^{5}$ mostly due to the large number of patients and hospitals ( $25 \%$ of all Dutch hospitals) included. A prospective data analysis at this point of time would probably be biased because of the rapidly growing fast-track climate.

It is clear that the standard of perioperative care in Dutch hospitals following elective colonic surgery is not according to abundant medical evidence. It should be realised that this is not limited to Dutch hospitals, as also other European ${ }^{4,5}$ and North- American ${ }^{8}$ hospitals still apply this 'standard' care protocol. Furthermore, despite abundant evidence that NG tubes are unnecessary following elective laparotomy, there are still RCT being conducted about this subject ${ }^{9-11}$.

It is well known that changing common practice in hospitals is hard and at all levels resistance is usually abundant. For example, a guideline sent to the concerning parties has the ability to change practice in only $8 \%$ of the cases, whilst repeatedly sending a guideline increases this figure to only $13 \%$.

The breakthrough project we described here can be a good aid for changing and implementing new protocols. We recommend other hospitals who want to implement fast-track to start with young, ASA I patients so everyone can get familiar with the new protocol and good results will be obtained more easily. You can choose to implement all fast track items at once or some items first; this choice has to be taken in cooperation with the staff involved. It is very important to have data available so collect data before and during the implementation of the new protocol. Finally, we recommend having various points in time at which an evaluation can take place with all parties involved and possible problems can be dealt with.

This project should not be limited to the Netherlands, and these results should be a stimulus for other countries to undertake similar projects. 


\section{Conclusion}

These results show that the common practice in Dutch Hospitals concerning the use of nasogastric drainage after elective colonic surgery as per 2004 was not according to evidence-based medicine. In fact, the use of a NG tube was still standard of care. In addition our results show that the implementation of evidence-based elements of a multimodal perioperative care protocol is possible over a short period of time with the aid of the Breakthrough method.

Over a one-year period the use of nasogastric drainage after elective colonic surgery has almost been abandoned in 26 hospitals in the Netherlands.

\section{Acknowledgements}

The authors thank the Perioperative Care Breakthrough Project Group for collection of data: C.L.H. van Berlo, VieCurie Medisch Centrum, Venlo; A.J.A. Bremers, Universitair Medisch Centrum St Radboud, Nijmegen; M.A.M. Brouwers, Haga Ziekenhuis, Den Haag; D. Cobben, Medisch Centrum Leeuwarden; P.P.L.O. Coene, Medisch Centrum Rijnmond Zuid, Rotterdam; K.C.A. van Engelenburg, Slingeland Ziekenhuis, Doetinchem; S.J. van der Hagen, Refaja Ziekenhuis, Stadskanaal; K. Havenga, Universitair Medisch Centrum Groningen; E.J. Hesselink, Gelre Ziekenhuizen, Apeldoorn; I.H.J.T. de Hingh, Catharina Ziekenhuis, Eindhoven; A.P.J. Houdijk, Medisch Centrum Alkmaar; J.M. Klaase, Medisch Spectrum Twente, Enschede; E.A.G.L. Lagae, Ziekenhuis Zeeuws Vlaanderen; F. Logeman, Beatrix Ziekenhuis, Winterswijk; E.J. Mulder, Antonius Ziekenhuis Sneek; K.H. Ong, Ziekenhuis Rivierenland, Tiel; R.J. Oostenbroek, Albert Schweizer Ziekenhuis, Dordrecht; J.W.A. Oosterhuis, Isala Klinieken, Zwolle; R.T. Ottow, Groene Hart Ziekenhuis, Gouda; A.J. den Outer, Rijnland Ziekenhuis, Leiderdorp; B. van Ramshorst, St Antonius Ziekenhuis Nieuwegein; P.H.M. Reemst, Maxima Medisch Centrum, Eindhoven; C. Rosman, Canisius Wilhelmina Ziekenhuis, Nijmegen; G.A. Vos, Waterland Ziekenhuis, Purmerend; F. Wit, Ziekenhuis de Tjongerschans, Heereveen; R.J. Zijlstra, Ziekenhuis Nij Smellinghe, Drachten. 


\section{References}

1. Cheatham ML, Chapman WC, Key SP, Sawyers JL. A meta-analysis of selective versus routine nasogastric decompression after elective laparotomy. Ann Surg 1995;221(5):469-76 [discussion 476-478.

2. Nelson R, Tse B, Edwards S. Systematic review of prophylactic nasogastric decompression after abdominal operations. Br J Surg 2005;92(6):673-680.

3. Nelson R, Edwards S, Tse B. Prophylactic nasogastric decompression after abdominal surgery. Cochrane Database Syst Rev 2007;(3):CD004929.

4. Nygren J, Hausel J, Kehlet H, Revhaug A, Lassen K, Dejong C, et al. A comparison in five European centres of case mix, clinical management and outcomes following either conventional or fasttrack perioperative care in colorectal surgery. Clin Nutr 2005;24(3):455-461.

5. Lassen K, Hannemann P, Ljungqvist O, Fearon K, Dejong CH, von Meyenfeldt MF, et al. Patterns in current perioperative practice: survey of colorectal surgeons in five northern European countries. BMJ 2005;330(7505):1420-1421.

6. Fearon $\mathrm{KC}$, Ljungqvist $\mathrm{O}$, Von Meyenfeldt $\mathrm{M}$, Revhaug $\mathrm{A}$, Dejong $\mathrm{CH}$, Lassen $\mathrm{K}$, et al. Enhanced recovery after surgery: a consensus review of clinical care for patients undergoing colonic resection. Clin Nutr 2005;24(3):466-477.

7. Berwick DM. Disseminating innovations in health care. JAMA 2003;289(15):1969-1975.

8. Kehlet $\mathrm{H}$, Buchler MW, Beart Jr RW, Billingham RP, Williamson R. Care after colonic operation is it evidence-based? Results from a multinational survey in Europe and the United States. J Am Coll Surg 2006;202(1):45-54.

9. Zhou T, Wu XT, Zhou YJ, Huang X, Fan W, Li YC. Early removing gastrointestinal decompression and early oral feeding improve patients' rehabilitation after colorectostomy. World J Gastroenterol 2006;12(15):2459-2463.

10. Carrere N, Seulin P, Julio CH, Bloom E, Gouzi JL, Pradere B. Is nasogastric or nasojejunal decompression necessary after gastrectomy? A prospective randomized trial. World J Surg 2007 ;31(1): 122-127.

11. Pessaux P, Regimbeau JM, Dondero F, Plasse M, Mantz J, Belghiti J. Randomized clinical trial evaluating the need for routine nasogastric decompression after elective hepatic resection. $\mathrm{Br} J$ Surg 2007;94(3):297-303. 


\section{Chapter 9}

\section{To eat or not to eat: facilitating early oral intake after elective colonic surgery in the Netherlands}

J.M.C. Maessen, C. Hoff, K. Jottard, A.G.H. Kessels, A.J. Bremers, K. Havenga,

R.J.Oostenbroek, M.F. von Meyenfeldt, C.H.C. Dejong, on behalf of the Dutch Breakthrough Project Perioperative Care as well as the ERAS group

Clinical Nutrition 2009; 28:29-33

"Ik ben weer begonnen met werken, er was geen reden meer om thuis te blijven".

Patient N, 14 dagen na operatie. 


\section{Abstract}

\section{Aim}

It was shown that patients in the Netherlands remain exposed to unnecessarily prolonged starvation after abdominal surgery. The present study examined whether a structured collaborative effort would help to implement the early start of oral nutrition after colorectal surgery.

\section{Methods}

In 2006, twenty six Dutch hospitals signed up to a "breakthrough project" concerning the implementation of the enhanced recovery after surgery (ERAS) programme with early oral feeding as one of the key-elements. Each hospital determined the usual start of food intake by analyzing 50 patients that underwent a colorectal resection in $2004(n=1126)$. Subsequently, over the course of one year 861 colorectal surgery patients were treated according to the ERAS programme. The first day that patients were eating before and after the breakthrough project was compared using Kaplan-Meier analyses and Cox regression models

\section{Results}

Patients treated according to the ERAS programme were eating 3 days earlier than the patients traditionally treated $(p<0.000)$. Two days after surgery $65 \%$ of the ERAS patients were eating normal food versus $7 \%$ of the pre-ERAS patients.

\section{Conclusion}

The present nationwide collaborative effort was successful in implementing a change towards an early start of oral nutrition after abdominal surgery. 


\section{Introduction}

Traditional nutritional management of patients undergoing major abdominal surgery has involved a period of "nil by mouth" with nasogastric decompression followed by a clear liquid diet that gradually progresses to regular food on the $4^{\text {th }}$ to $5^{\text {th }}$ day postoperatively ${ }^{1,2}$. The practice of "fasting until flatus and stools have passed" dates back for more than 100 years ${ }^{3}$.

The rationale for this classical restriction of food after abdominal surgery was the anxiety that exposing the gastrointestinal tract to nutrition, would increase the risk of anastomotic dehiscence, aspiration pneumonia, bowel distension, bowel obstruction and nausea and vomiting.

Recently, it has been demonstrated that there is no scientific evidence of increased risk of complications in patients who received early oral nutrition ${ }^{4,5}$. Early nutrition after elective open colorectal surgery is tolerated by over $70 \%$ of the patients ${ }^{6,7}$.

Of even greater importance for questioning the historical restriction of oral intake after abdominal surgery, besides the safety and feasibility of early nutrition, is the shift in outcome measures in modern surgical care. Hospital length of stay, cost effectiveness and patient centred outcomes like postoperative level of function, quality of live and patient satisfaction, have been added to the traditional physiological outcomes mortality and morbidity ${ }^{8,9}$.

It has been shown that early nutrition can help to improve energy and protein intake and decrease the negative impact of the metabolic response to surgery ${ }^{10,11}$. An earlier return to function may be achieved by reduced loss of lean body mass and muscle function ${ }^{12,13}$. Thus, the avoidance of pre-operative fasting and the reestablishment of oral feeding as early as possible has become one of the key aspects of modern multimodal recovery programmes ${ }^{14}$.

However, in spite of a large body of evidence for the safety, feasibility and benefits of early postoperative nutrition, surgical patients in the Netherlands remain exposed to unnecessary postoperative starvation ${ }^{15}$.

In 2005 the Dutch Institute for Healthcare Improvement (CBO), initiated a breakthrough project "perioperative care in colonic surgery", because this was felt to be an area ripe for improvement. The evidence based perioperative care programme of the ERAS group ${ }^{16}$ was incorporated as basis for the change.

The current study evaluates whether the collaborative nationwide structured effort to implement the multimodal enhanced recovery after surgery programme in over $25 \%$ of all Dutch hospitals resulted in an accelerated start of oral nutrition after colonic surgery. 


\section{Methods}

\section{The Dutch Institute for Healthcare Improvement}

In 2005 the Dutch Institute for Healthcare Improvements (СВO) was asked to guide the simultaneous implementation of a multimodal perioperative care programme in four cooperating hospitals in the North of the Netherlands. Differences in everyday practice hindered the necessary collaboration.

The $\mathrm{CBO}$ identified the improvement of perioperative care practice as an interesting topic for a nationwide breakthrough project. All Dutch hospitals were invited to participate and within a short timeframe 26 Dutch hospitals (one quarter of all Dutch hospitals) signed up for the Breakthrough Series "Perioperative Care" . A first series with twelve institutions started in January 2006 and a second series with fourteen hospitals in May 2006.

\section{The Breakthrough Series}

The Breakthrough Series is a quality improvement methodology, developed by the Institute for Healthcare Improvement, a non profit organisation dedicated to the improvement of healthcare systems in the United States and Canada. Key features of the methodology are plan-do-study-act cycles, cycles of continuously implementing, measuring and refining small, rapid changes to create a large change that becomes standard practice. Changes are guided by the best available evidence. The design of each project covers a 12 month period. The Breakthrough Series "Perioperative Care" was motivated by the ready made multimodal care programme of the Enhanced Recovery After Surgery group ${ }^{16}$.

\section{The ERAS programme}

This evidence based care programme contains all the necessary elements of routine care for patients undergoing colorectal surgery. With the focus on stress reduction and promotion of return to function the ERAS programme aims at a faster recovery from major surgery ${ }^{16}$.

Early nutrition is one of the key elements of the ERAS programme and to achieve an early start of nutrition, the programme recommends extensive preoperative patient information, avoidance of nasogastric decompression tubes, mid-thoracic epidural anaesthesia/analgesia with low doses of opioids, avoidance of fluid overload and a multimodal management of postoperative nausea and vomiting (5-HT3antogonist and/or Dehydrobenzperidol and/or Dexamethason).

Patients should start drinking within 4 hours after surgery and are allowed to eat normal food on the first postoperative day. 


\section{Quality improvement intervention}

First, all hospitals gathered knowledge about their usual practice prior to the start of the project and retrospectively assembled data for a baseline measurement. A consecutive series of approximately 50 colorectal surgery patients operated before 2005 in each of the participating hospitals (the pre-ERAS group, $n=1126$ ) was analysed. That period was chosen on the presumption that the ERAS programme wasn't heard of yet in most hospitals.

Patient characteristics, length of hospital stay and a limited number of crucial aspects of care (the use of bowel preparation, nasogastric decompression tubes and thoracic epidural analgesia and the time to resumption of solid food and to independency of IV infusion) were abstracted from medical and nursing charts and were entered in a web-based central database.

IIn preparation for the project, the participating hospitals created a multidisciplinary team, including at least an anaesthetist, a surgeon and a nurse or nurse manager. These teams were to direct local improvement activities and to attend the project meetings.

A starting meeting was organised in January 2006 respectively May 2006, where information was given about all the elements of the ERAS programme and instructions were given about the various techniques of quality improvement. At the starting meeting, teams got acquainted with each other and had the possibility to exchange ideas, knowledge and practice experience.

Every three months learning sessions were organised, at which teams reported on activities, methods and results.

Each hospital started with treating patients according to the ERAS programme as soon as the local dissemination activities (educational sessions to involved professionals, development of care plans, re-design of care processes) were finished. At the end of the project, one year after the kick-off meeting, 861 patients had been treated according to the ERAS programme (the ERAS group).

An online database was accessible for the prospective collection of patient characteristics, process indicators (protocol adherence, reasons for non-adherence) and outcome measures (length of stay and time to resumption of normal food, to independency in activities of daily living ( $A D L$ )and to pain control on oral analgesics). Included in the present analysis were all colorectal resections above the peritoneal reflection.

\section{Statistics}

Data analyses were done with SPSS 15.0 for Windows XP. Potential differences in variables were tested by a Mann-Whitney test for ordinal data and a Chi-square test for categorical data. The time to resumption of normal food in the two study groups was compared with a univariate time-to-event analysis (Kaplan-Meier 
curve) and the log-rank statistic was used to test the differences in time to resumption of food. Additionally, a multivariable Cox regression analysis was performed with treatment according to the ERAS programme, study centre, age and gender as covariates.

Some explanatory variables (ASA classification, side and type of resection) were not recorded in the pre-ERAS group. To evaluate whether differences in the distribution of these variables might have influenced the effect of the ERAS programme on the start of nutrition, subgroups with the different levels of these prognostic variables within the ERAS group were compared with the pre-ERAS group using KaplanMeier analyses.

P-values below 0.05 were considered to indicate statistical significance.

\section{Results}

Patient characteristics are shown in Table 1 . There were no statistically significant differences between the two study groups regarding age and gender distribution.

Table 1. Comparison of characteristics of patients before and after start of the ERAS programme.

\begin{tabular}{|c|c|c|}
\hline & $\begin{array}{l}\text { Pre-ERAS } \\
n=1126\end{array}$ & $\begin{array}{l}\text { ERAS } \\
n=861\end{array}$ \\
\hline Age (mean) & 65 & $65^{*}$ \\
\hline \multicolumn{3}{|l|}{ Gender \% } \\
\hline male & 51 & $50 *$ \\
\hline female & 49 & 50 \\
\hline \multicolumn{3}{|l|}{$\mathrm{ASA}^{\mathrm{a}} \%$} \\
\hline $1 / 11$ & NAb & 87 \\
\hline III/IV & NA & 13 \\
\hline \multicolumn{3}{|l|}{ Side operation \% } \\
\hline right & NA & 45 \\
\hline left & NA & 55 \\
\hline Laparoscopic resection \% & NA & 37 \\
\hline
\end{tabular}

The Kaplan Meier curves demonstrate that the median time to resumption of normal food decreased significantly $(p<0.000)$ from 5 days in the historical control (pre-ERAS) group to 2 days in the ERAS group (Figure.1). A Cox regression analysis with the ERAS programme, study centre, age and gender as covariates confirmed that patients treated according to the ERAS programme had an accelerated start of normal food (hazard ratio $2.5,95 \% \mathrm{Cl} 2.25-2.77$, $\mathrm{p}<0.000$ ). Study centre and gender had no significant influence on the start of nutrition, where as older age was 
associated with a delay in start of nutrition (Hazard Ratio $0.99 / \mathrm{yr}, 95 \% \mathrm{Cl} 0.92$ 0.999, $p=0.006)$.

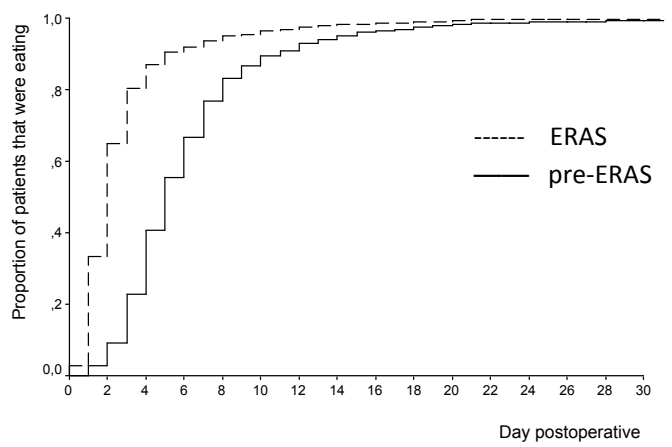

Log Rank test: $p<0.000$

Figure 1. Kaplan Meier curves comparing the time to resumption of normal food before and after the implementation of the ERAS programme.

Additional Kaplan-Meier analysis to evaluate the influence of other explanatory variables such as ASA classification, side of operation and type of resection (figure 2) showed that the median day that oral nutrition was started remained significantly earlier in the ERAS group, independent of the level of these prognostic variables within the ERAS group.

On the second day after surgery, $7 \%$ of the pre-ERAS patients were eating versus $65 \%$ of the ERAS patients. The main reasons for delayed start of oral nutrition in the ERAS group were nausea and vomiting (21\%) and reliance to tradition (13\%) (nasogastric tube not removed at the end of surgery, use of traditional nutritional step up schedules).

There were more men able to eat normal food on day 2 than women (68\% versus $62 \%, p=0.046)$. Postoperative nausea and vomiting as a reason for a delay in the start of oral intake of normal food was more frequently documented in women than in men ( $25 \%$ versus $16 \%, p=0.003)$. 


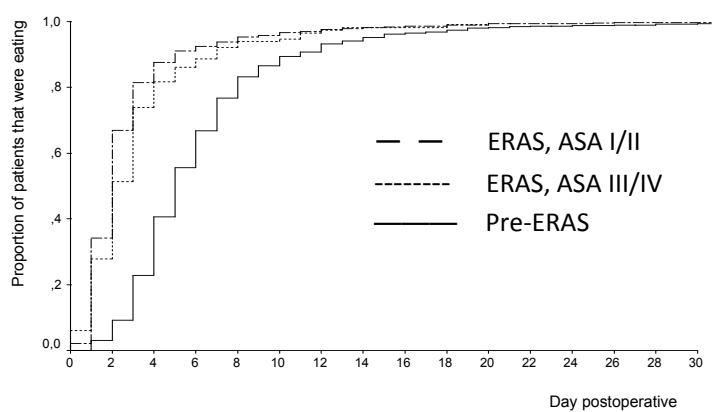

Log Rank test: $p<0.000$, ERAS versus pre-ERAS.

No significant differences between ASA I/II and ASA III/IV in ERAS patients

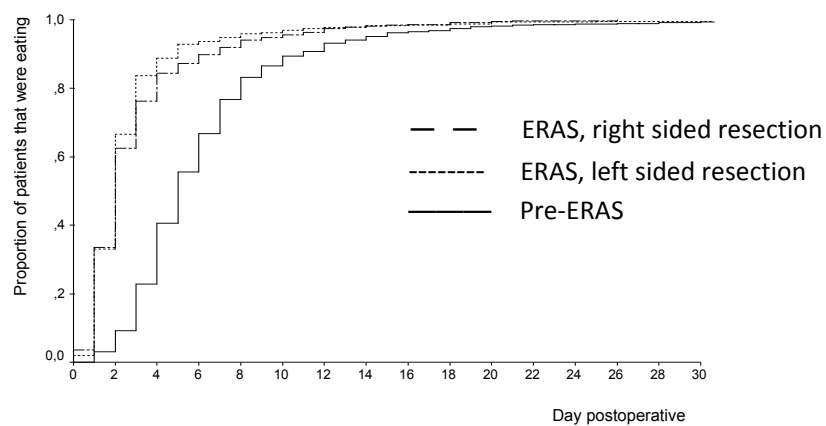

Log Rank test: $p<0.000$, ERAS versus pre-ERAS.

No significant differences between right sided and left sided resections in ERAS patients

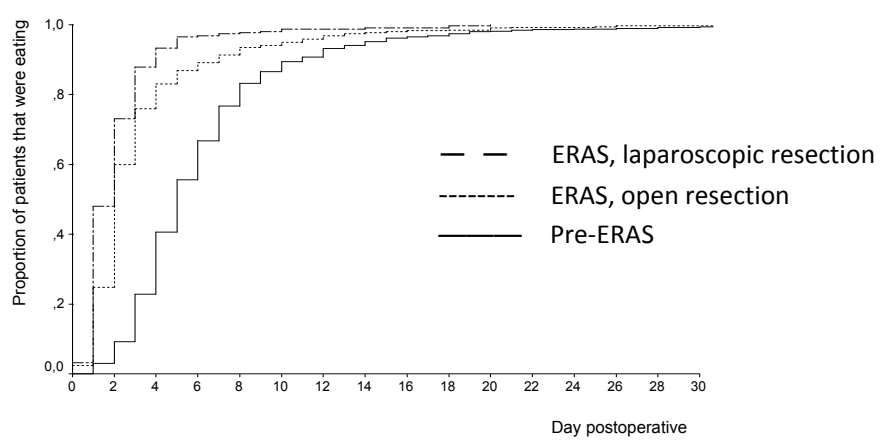

Log Rank test: $p<0.000$, ERAS versus pre-ERAS.

No significant differences between laparoscopic and open resection in ERAS patients

Figure 2. Kaplan Meier curves comparing the time to tolerance of food of pre-ERAS patients versus ERAS patients with different prognostic variables. 


\section{Discussion}

The current study shows firstly that new insights regarding early oral intake after abdominal surgery were not widely implemented in daily practice in the Netherlands as per 2004. One quarter of the Dutch hospitals were involved in the present project and the data show that in daily practice of patients undergoing colorectal surgery in 2004 less than $10 \%$ of the 1126 patients were eating within 2 days after surgery. The majority of patients were subjected to a period of starvation that lasted 5-6 days. This practice deviates substantially from what would be considered evidence based medicine.

Considering the overdose of information to which health care professionals are exposed (almost 10.000 well-organised trials are included in Medline every year ${ }^{17}$ ), it is hardly surprising that a lot of valuable new insights are not adopted in daily practice of patient care. Guidelines are an important intermediate step in the process of implementation of scientific knowledge.

The most recent scientific evidence regarding early nutrition is summarized in a Cochrane review ${ }^{5}$, which shows unequivocally that early feeding is feasible and safe. This is translated into useful recommendations that link up with everyday practice in the Guidelines on Enteral Nutrition of the European Society of Parenteral and Enteral Nutrition ${ }^{14}$ and the consensus review of clinical care for patients undergoing colonic resection of the Enhanced Recovery After Surgery group $^{16}$. Patients should be encouraged to commence oral intake within 4 hours after surgery.

Unfortunately, the availability of good quality information on evidence based practices and a successful dissemination of these practices very often do not suffice to change every day practice ${ }^{18,19}$. A systematic review of guideline implementation strategies noted a median improvement of $8 \%$ following the distribution of guidelines to professionals ${ }^{20}$. Guidelines do not implement themselves and need a comprehensive plan, targeting the different problems and barriers to change ${ }^{21,22}$. In 2005 the Dutch Institute for Healthcare Improvement (CBO) decided to support Dutch hospitals with the implementation of a multimodal perioperative care programme, designed by the ERAS group ${ }^{16}$ via the Breakthrough Series, one of the major ways to accelerate the uptake of research findings in everyday practice ${ }^{23}$. The current study shows that the breakthrough project "Perioperative Care in colorectal surgery" was successful in accelerating the start of oral nutrition after abdominal surgery. The first day that patients were eating after surgery decreased significantly from a median of 5 days to a median of 2 days. On the second day postoperatively, $65 \%$ of the ERAS patients were having normal food versus $7 \%$ of the pre-ERAS patients that received conventional care. Taking into account the $13 \%$ of patients that were not eating because of adherence to traditional nutritional 
step-up schedules, early nutrition would have been feasible in almost $80 \%$ of 861 patients that underwent colorectal surgery between January 2006 and May 2007 in 26 hospitals in the Netherlands.

This study had some inherent limitations. First, the "before and after" study design may have been vulnerable to unmeasured confounding factors. For example, the most dramatic improvement of care was seen in a hospital were the complete surgical team changed between 2004 and 2006, whereas another hospital showed a slight regression towards more traditional care when the key leader of the project left the hospital.

Another limitation of the present study was that most hospitals started the implementation of the ERAS programme in a selected group of patients. The expert panel of the project recommended, based on own experience, to start with ASA I/II patients that were undergoing a right sided resection, to try out the change without great risk and to convince the involved professionals of the success of the programme.

Due to the nature of this implementation study, the data collection was restricted because time and resources were limited. The baseline measurement provided no information about ASA classification and type of surgery. It was therefore not possible to estimate the effect of the ERAS programme on the resumption of food using the Cox regression model with these variables as covariates. To disentangle the effect of the intervention from the effects of the patient selection, the different levels of ASA classification and type of surgery within the ERAS group were compared with the pre-ERAS group using Kaplan Meier curves. It was shown that the start of oral nutrition remained significant earlier in the ERAS group, regardless of the ASA classification and type of surgery.

One out of five patients experiences postoperative nausea and vomiting (PONV). In the past, PONV has been considered as a common adverse event after surgery and anaesthesia of minor medical importance. This may have been due to the fact that , so to say, PONV "almost never kills, and it never becomes chronic" ${ }^{24}$. In modern surgical care with a focus on patient-centred outcomes, the control of nausea and vomiting has grown in importance. PONV is unpleasant and associated with patient discomfort and dissatisfaction. Patients prefer to suffer from pain rather than postoperative nausea and vomiting ${ }^{25}$ and are willing to pay a substantial sum of money for a completely effective anti-emetic ${ }^{26}$.

The current study provides additional evidence that PONV is a crucial limiting factor in realizing an early start of oral nutrition after surgery. The ERAS programme recommends to diminish PONV with a selective and structured use of anti-emetics ${ }^{16}$. And although all participating hospitals defined a local protocol for the management of PONV, still more than $20 \%$ of the patients were too sick to start eating again within 2 days after surgery.

It is obvious that attention is particularly required for women that are undergoing colorectal surgery. Female gender is a major risk factor for PONV and as confirmed 
by the current study, there was a significant higher proportion of women suffering from PONV than men. Various studies have demonstrated that oral nutrition is tolerated earlier by men because of anatomical differences. Women have a greater length of colon ${ }^{27}$ and slower gastric emptying ${ }^{28}$ compared with men.

All women that will undergo a laparotomy/laparoscopy have a moderate risk of PONV and thus should receive at least prophylactic monotherapy for PONV. A multimodal treatment is indicated in all females who have a higher risk of PONV such as non smokers and those having a history of PONV or motion sickness ${ }^{29}$.

\section{Conclusion}

The breakthrough project Perioperative Care was successful in integrating evidence with regard to early oral nutrition into every day practice in colorectal surgery. Within the course of one year early oral nutrition was implemented in 26 hospitals in the Netherlands. The feasibility of early oral nutrition in almost $80 \%$ of the patients stresses the necessity of abolishing postoperative starvation. Patients can eat and drink immediately postoperatively. Structured PONV management is an important pre-requisite for a successful early start of nutrition after abdominal surgery.

\section{Acknowledgements}

The authors thank the Perioperative Care Breakthrough Project Group for collection of data: C.L.H. van Berlo, VieCurie Medisch Centrum, Venlo; A.J.A. Bremers, Universitair Medisch Centrum St Radboud, Nijmegen; M.A.M. Brouwers, Haga Ziekenhuis, Den Haag; D. Cobben, Medisch Centrum Leeuwarden; P.P.L.O. Coene, Medisch Centrum Rijnmond Zuid, Rotterdam; K.C.A. van Engelenburg, Slingeland Ziekenhuis, Doetinchem; S.J. van der Hagen, Refaja Ziekenhuis, Stadskanaal; K. Havenga, Universitair Medisch Centrum Groningen; E.J. Hesselink, Gelre Ziekenhuizen, Apeldoorn; I.H.J.T. de Hingh, Catharina Ziekenhuis, Eindhoven; A.P.J. Houdijk, Medisch Centrum Alkmaar; J.M. Klaase, Medisch Spectrum Twente, Enschede; E.A.G.L. Lagae, Ziekenhuis Zeeuws Vlaanderen; F. Logeman, Beatrix Ziekenhuis, Winterswijk; E.J. Mulder, Antonius Ziekenhuis Sneek; K.H. Ong, Ziekenhuis Rivierenland, Tiel; R.J. Oostenbroek, Albert Schweizer Ziekenhuis, Dordrecht; J.W.A. Oosterhuis, Isala Klinieken, Zwolle; R.T. Ottow, Groene Hart Ziekenhuis, Gouda; A.J. den Outer, Rijnland Ziekenhuis, Leiderdorp; B. van Ramshorst, St Antonius Ziekenhuis Nieuwegein; P.H.M. Reemst, Maxima Medisch Centrum, Eindhoven; C. Rosman, Canisius Wilhelmina Ziekenhuis, Nijmegen; G.A. Vos, Waterland Ziekenhuis, Purmerend; F. Wit, Ziekenhuis de Tjongerschans, Heereveen; R.J. Zijlstra, Ziekenhuis Nij Smellinghe, Drachten. 


\section{References}

1. Meltvedt R, Jr., Knecht B, Gibbons $G$, et al. Is nasogastric suction necessary after elective colon resection? Am J Surg 1985; 149:620-622.

2. Reissman $\mathrm{P}$, Teoh TA, Cohen SM, et al. Is early oral feeding safe after elective colorectal surgery? A prospective randomized trial. Ann Surg 1995; 222:73-77.

3. Johnson Casto C, Krammer J, Drake J. Postoperative feeding: a clinical review. Obstet Gynecol Surv 2000; 55:571-573.

4. Lewis SJ, Egger M, Sylvester PA, Thomas S. Early enteral feeding versus "nil by mouth" after gastrointestinal surgery: systematic review and meta-analysis of controlled trials. BMJ 2001; 323:773-776.

5. Andersen HK, Lewis SJ, Thomas S. Early enteral nutrition within $24 \mathrm{~h}$ of colorectal surgery versus later commencement of feeding for postoperative complications. Cochrane Database Syst Rev 2006:Cd004080.

6. Di Fronzo LA, Cymerman J, O'Connell TX. Factors affecting early postoperative feeding following elective open colon resection. Arch Surg 1999; 134:941-945.

7. Ng WQ, Neill J. Evidence for early oral feeding of patients after elective open colorectal surgery: a literature review. J Clin Nurs 2006; 15:696-709.

8. Deutsch N, Wu CL. Patient outcomes following ambulatory anesthesia. Anesthesiol Clin North America 2003; 21:403-415.

9. Keenan SP, Carlet J, Curtis R, et al. Health services research rounds: patient-centered outcomes. J Crit Care 2002; 17:221-234.

10. Henriksen MG, Hansen HV, Hessov I. Early oral nutrition after elective colorectal surgery: influence of balanced analgesia and enforced mobilization. Nutrition 2002; 18:263-267.

11. Fearon KC, Luff R. The nutritional management of surgical patients: enhanced recovery after surgery. Proc Nutr Soc 2003; 62:807-811.

12. Henriksen MG, Jensen MB, Hansen HV, et al. Enforced mobilization, early oral feeding, and balanced analgesia improve convalescence after colorectal surgery. Nutrition 2002; 18:147-152.

13. Basse L, Raskov HH, Hjort Jakobsen D, et al. Accelerated postoperative recovery programme after colonic resection improves physical performance, pulmonary function and body composition. $\mathrm{Br} \mathrm{J}$ Surg 2002; 89:446-453.

14. Weimann A, Braga M, Harsanyi L, et al. ESPEN Guidelines on Enteral Nutrition: Surgery including organ transplantation. Clin Nutr 2006; 25:224-244.

15. Lassen $\mathrm{K}$, Hannemann $\mathrm{P}$, Ljungqvist $\mathrm{O}$, et al. Patterns in current perioperative practice: survey of colorectal surgeons in five northern European countries. BMJ 2005; 330:1420-1421.

16. Fearon $\mathrm{KC}$, Ljungqvist $\mathrm{O}$, Von Meyenfeldt $\mathrm{M}$, et al. Enhanced recovery after surgery: a consensus review of clinical care for patients undergoing colonic resection. Clin Nutr 2005; 24:466-477.

17. Chassin MR. Is health care ready for Six Sigma quality? Milbank Q 1998; 76: 565-591, 510.

18. Wennberg JE. Understanding geographic variations in health care delivery. N Engl J Med 1999; 340:52-53.

19. Cameron C, Naylor CD. No impact from active dissemination of the Ottawa Ankle Rules: further evidence of the need for local implementation of practice guidelines. CMAJ 1999; 160:1165-1168.

20. Eccles M, Grimshaw J, Walker A, et al. Changing the behavior of healthcare professionals: the use of theory in promoting the uptake of research findings. J Clin Epidemiol 2005; 58:107-112.

21. Grol R, Grimshaw J. From best evidence to best practice: effective implementation of change in patients' care. Lancet 2003; 362:1225-1230.

22. Davis DA, Taylor Vaisey A. Translating guidelines into practice. A systematic review of theoretic concepts, practical experience and research evidence in the adoption of clinical practice guidelines. CMAJ 1997; 157:408-416. 
23. Kilo CM. A framework for collaborative improvement: lessons from the IHI Improvement's Breakthrough Series. Qual Manag Health Care 1998; 6:1-13.

24. Quinn AC, Brown JH, Wallace PG, Asbury AJ. Studies in postoperative sequelae. Nausea and vomiting-still a problem. Anaesthesia 1994; 49:62-65.

25. van Wijk MG, Smalhout B. A postoperative analysis of the patient's view of anaesthesia in a Netherlands' teaching hospital. Anaesthesia 1990; 45:679-82.

26. Gan T, Sloan F, Dear GL, et al. How much are patients willing to pay to avoid postoperative nausea and vomiting? Anesth Analg 2001; 92:393-400.

27. Saunders BP, Fukumoto $M$, Halligan $S$, et al. Why is colonoscopy more difficult in women? Gastrointest Endosc 1996; 43:124-126.

28. Knight LC, Parkman HP, Brown KL, et al. Delayed gastric emptying and decreased antral contractility in normal premenopausal women compared with men. Am J Gastroenterol 1997; 92:968-75.

29. Gan TJ, Meyer T, Apfel CC, et al. Consensus guidelines for managing postoperative nausea and vomiting. Anesth Analg 2003; 97:62-71, 



\section{Chapter 10}

General discussion 


\section{Summary of main results}

Treatment of colorectal surgery patients according to an enhanced recovery after surgery programme leads to faster recovery and shorter hospital stay compared to patients that are traditionally treated. The introduction of the ERAS programme in every day practice resulted in a decrease of recovery time of two days and a decrease of length of stay of three days.

Additionally, the implementation of the enhanced recovery after surgery programme resulted in significant improvements of perioperative care. Preoperative patient information was structured, bowel preparation was cancelled, nasogastric decompression tubes were abandoned, epidural anaesthesia and analgesia became standard of care, bed rest was diminished and fasting regimes and step up schedules of nutrition were abolished.

\section{Interpretation of these findings}

The concepts of efficacy, effectiveness and efficiency are worthwhile for interpretation of these findings. The British pioneer clinical epidemiologist Archie Cochrane defined three concepts related to testing and implementing new health care interventions ${ }^{1}$. Efficacy is the extent to which an intervention produces a beneficial result under ideal conditions ("Can it work?"). Effectiveness assesses whether an intervention is effective in "real world" conditions. ("Does it work in practice?"). Efficiency measures the effect of an intervention in relation to the resources, including implementation efforts, it consumes (“Is it worth it?") ${ }^{2}$.

\section{Efficacy}

Randomised controlled trials are the gold standard for establishing the efficacy of new interventions, for determining "the maximum potential benefit of a new intervention in ideal circumstances and in a controlled environment" ${ }^{3}$. The ideal circumstances include highly selected participants who are likely to cooperate fully with the medical advice, who have no health problems other than the condition being investigated and who are not treated with concomitant medications. Participants receive special attention from expert practitioners who supplement or replace those employed in the usual clinical setting and follow the protocol carefully. Late in the nineties, Henrik Kehlet, hypothesised that the process of colon surgery could be improved leading to a reduction in hospital stay. He demonstrated the efficacy of a multimodal rehabilitation programme that combines preoperative education of patients, attenuation of surgical stress response, optimized pain relief, 
enforced mobilisation and nutritional support. He reported a median hospital stay of two days of 60 colectomy patients that he treated according to his perioperative care programme at his institute. Within 48 hours patients had bowel movements, tolerated solid food, were spending on average ten hours out of bed and were recovered to home readiness ${ }^{4,5}$.

With traditional perioperative care, hospital stay after colorectal surgery ranges between 10-12 days ${ }^{6}$ and Kehlet demonstrated that with a multimodal rehabilitation programme the length of stay after colorectal surgery can be reduced dramatically. However, this dramatic reduction in length of stay was derived from a local research setting under ideal circumstances. and in a controlled environment. The reproducibility of this reduction in length of stay in a real world setting with less controlled circumstances and environment was questioned, however.

\section{Effectiveness}

Effectiveness studies test the effect of an intervention under real world conditions in non-ideal circumstances comprising usual practitioners treating real patients who are frequently ambivalent about treatment, come from a variety of ethnic and socio-economic backgrounds and have significant co-morbidity ${ }^{7}$

In 2001 the Enhanced Recovery After Surgery (ERAS) group, a collaboration of five departments of surgery, including the department of Kehlet, was established. The ERAS group reviewed the evidence base for individual components of multimodal rehabilitation programmes and developed a core protocol that represented the consensus of how colorectal surgery patients based on best available scientific evidence should be cared for $^{8}$. The ultimate aim was to accelerate restoration of postoperative function, thereby improving clinical recovery and reducing length of stay.

The present thesis describes the effectiveness of the introduction of the ERAS programme in every day clinical practice. In 2001 the ERAS programme was implemented in the five departments of the ERAS group and in 2006 in 26 hospitals in the Netherlands via the breakthrough project "Perioperative Care".

It was demonstrated that the implementation of the enhanced recovery after surgery programme in every day practice was successful. The intended objectives of an improved clinical recovery and a reduced length of stay were achieved in all hospitals. Colonic surgery patients that were treated according to the multimodal care programme of the Enhanced Recovery After Surgery group were recovered a median of two days earlier and were discharged home a median of three days earlier than traditionally treated patients for whom hospital stay was a median of eight to nine days. 


\section{Difference between efficacy and effectiveness}

However, a clinical recovery of a median of two days and a length of stay of a median of two days, as demonstrated by Kehlet, were not achieved in every day practice. Patients that enrolled the ERAS programme recovered in a median of three to four days and were discharged home on a median of five to six days.

The current discussion compares the research circumstances in Kehlet's studies to the every day circumstances under which the ERAS protocol was implemented in order to elucidate factors that influenced effectiveness. Understanding why the ERAS protocol did not produce the intended effects may provide valuable insights in the possibilities to further improve effectiveness. An improved effectiveness i.e. an enhanced recovery and a reduced length of stay, is not only of great importance for demonstrating the efficiency of the programme but is also essential for motivating the wide spread dissemination of the ERAS programme.

\section{Differences between research setting and every day circumstances}

Under experimental conditions patients may be highly selected, staff may be particularly punctilious, the protocol may be strictly followed and the organisation of care may be extraordinary efficient. Good research will explicitly eliminate bias that arise from a heterogeneous patient population and from any variation in exposure to the intervention ${ }^{9}$.

The reproducibility of the beneficial effects of a programme in real world conditions may thus be dependent on the extent to what patients, practitioners, level of implementation, and organisation of care deviate from the research setting.

To explain why the intended results were not demonstrated in every day practice, four characteristics of the current ERAS study were compared with the conditions in Kehlet's study: patient selection, actual exposure to the intervention (fidelity), organisation of care and expertise of practitioners. The comparison on these four characteristics, which is described in more detail in the next section of this chapter, showed indeed differences between the setting of Kehlet and the every day setting under which the ERAS protocol was implemented. No differences were seen in patient selection, but differences were demonstrated in the degree of implementation of the protocol, in the organisation of perioperative care and discharge and in the expertise of practitioners. It seems reasonable that the higher protocol compliance, the better organisation of care and the more experienced practitioners have contributed to the superior outcomes in Kehlet's efficacy studies 


\section{Patient selection}

Differences in patient selection may affect the time to recovery and the length of stay. Age older than 65 years, creation of a stoma and emergency procedures are well known traditional variables that significantly affect length of stay after colonic surgery ${ }^{6}$. Initial experiences with the implementation of the ERAS protocol in the five ERAS centres demonstrated that age above 60 years, ASA class above I, and complexity of surgery significantly influenced the time to recovery and the length of stay.

In-and exclusion criteria were similar between Kehlet's setting and the every day setting. Included were consecutive patients undergoing elective open colorectal resection above the peritoneal reflection for benign or malignant disease. Excluded were patients with age less than 18 years, patients who needed emergency surgery and patients requiring an end or diverting ileostomy or colostomy.

Before implementation of the ERAS programme conventionally treated patients were compared to patients that enrolled the fast track programme in Kehlet's centre. It was demonstrated that there were no differences in age, $\mathrm{BMI}$, and gender ${ }^{10}$. After implementation of the ERAS programme a comparison of demographics demonstrated again that patients of Kehlet's centre were comparable to the other centres. There were no significant differences with regard to age, distribution of sex, ASA classification, types of operation, and malignancy rates.

The lack of differences in case mix weakened the argument that patients in Kehlet's centre were highly selected.

\section{Actual exposure to the intervention, fidelity.}

Fidelity refers to the degree to which an intervention or programme is delivered as intended by the programme developers. By measuring whether an intervention has been implemented with fidelity it can be determined whether lack of impact is due to poor implementation.

Standardisation of an intervention is an important prerequisite to test the efficacy of that intervention. One of the differences between a research setting and an every day setting might be the higher level of heterogeneity of treatment in the every day setting. In every day practice interventions are much more customised and due to the nature of a guideline practitioners may decide for several reasons that a deviation from the guideline is desirable.

Kehlet showed an extremely high protocol compliance in all phases of perioperative care. The average adherence to the various protocol care elements was 87 percent. In the other centres overall compliance rates ranged between 42 and 70 per cent. It was remarkable that in all centres preoperative care elements were more successfully implemented than postoperative care elements. Protocol care elements that consider early nutrition and enforced mobilisation had a compliance 
score of less than 50 per cent. It seems reasonable to conclude that the poorer protocol compliance in every day practice might have had significant implications for the programme effect on recovery and length of stay.

Any surgical procedure causes a stress response, a complex interplay of immunologic, endocrine, inflammatory and metabolic pathways resulting in an increase in heart rate, blood pressure, blood glucose, adipose tissue mobilisation and protein brake down. The surgical stress response is related to the magnitude of surgical trauma and has a major impact on the recovery profile of patients. It has been demonstrated that diminished tissue injury (shorter incision length or minimal invasive surgery) led to an earlier recovery and a shorter length of hospitalisation ${ }^{11}$. Magnitude of surgery was compared using the P-Possum score, a method for standardizing patient data ${ }^{12}$. This P-Possum score includes an operative severity score, an addition sum of six operative factors: total blood loss, peritoneal soiling, presence of malignancy, mode of surgery, operative severity and number of procedures. It was demonstrated that the P-Possum operative severity scores did not differ between the ERAS centres.

However, this P-Possum operative score does not take into account differences between surgeons, deciding to do a smaller or more extended resection and using a short or a less short incision. It is thus not impossible that Kehlet's' patients underwent less invasive surgery than the patients in the other centres. However, it seems not reasonable to explain the differences in recovery and hospitalisation rates by the differences in magnitude of surgery. A subgroup analysis of patients that underwent the least invasive surgery ( i.e. straightforward right hemicolectomies) showed that even in this patient group a recovery and length of stay of two days was not achieved.

\section{Organisation of perioperative care.}

Kehlet documented the prerequisites for a successful implementation of the multimodal rehabilitation programme: a multidisciplinary collaboration between the expert surgeon, anaesthetist and surgical nurse, a postoperative nursing map that provides detailed information of every postoperative side effect that preclude early recovery and discharge, multidisciplinary ward rounds twice a day for the purpose of making timely corrections in treatment of postoperative side effects, direction of patients to a specialized rehabilitation care unit with a focus on early mobilisation and nutrition, the provision of a system for telephone follow-up and a database to audit success of implementation ${ }^{13} 14$.

In every day practice, the organisation of care deviated considerably from Kehlet's setting. Ward rounds twice a day, the expansion of the role of the anaesthetist beyond the post anaesthesia care unit, nursing care maps focussed on rehabilitation and specialised rehabilitation units were not realised. There is no doubt that 
the organisation of care in Kehlet's centre being totally directed to early rehabilitation, had a major influence on the time of recovery and length of hospitalisation.

\section{Organisation of discharge}

Traditionally, the discharge of clinical patients is guided by a subjective global assessment of a patient's well being. Threatening situations, close medical monitoring and observation of any complication that may occur, administration of iv fluids or medications and specialised nursing care are considered as appropriate reasons for a patient's stay in an acute hospital bed ${ }^{15}$. Usually, consultants discuss during ward rounds the appropriateness of the hospital stay and if it is felt that a longer stay if no longer appropriate, arrangements are made for the discharge of patients within a few days.

This traditional discharge process was challenged by Kehlet. He adopted the discharge scoring system of ambulatory surgery, a system developed to guide a physician's assessment of the safety of discharge on the day of surgery. Kehlet defined criteria to assess the safety of discharge 48 hours after colonic surgery. Most essential was that the discharge was planned on the second day after surgery and that criteria defined the conditions that preclude the early discharge: organ function not restored and pain not under control with oral analgesia. Based on these criteria 53 percent of the patients included in Kehlet's study could be sent home forty eight hours after surgery ${ }^{5}$.

The ERAS group tried to regulate the discharge process by defining four discharge criteria that guide the assessment of a patient's home readiness after colonic surgery $^{8}$. These discharge criteria defined the condition of the patient that no longer required the level of an acute hospital bed. It was demonstrated that indeed 70 per cent of the patients had no medically appropriate reason to stay in hospital after the discharge criteria were met.

Unfortunately, the definition of discharge criteria failed to change the traditional discharge process in every day practice. Initial experiences showed that only 26 percent of patients were sent home on the day that discharge criteria were met. The better organisation of the discharge process may thus partly explain the differences in length of stay between the research centre of Kehlet and the other centres.

\section{Expertise of practitioners}

\section{The expert surgeon}

It has been demonstrated that minimal invasive procedures significantly reduce the time to recovery ${ }^{11}$, that the length of hospital stay is shorter when patients are cared for by surgeons experienced in using fast track protocols ${ }^{16}$ and that the presence of a key leader is important for a successful change of practice ${ }^{17}$. An expert 
surgeon may be defined as some one who is specialised in minimal invasive techniques in colorectal surgery, experienced in using fast track protocols and is a strong leader with skills in consensus development and knowledge in process engineering.

\section{The expert anaesthetist}

An expert anaesthetist is trained to perform epidural and other neural block techniques, is specialized in optimizing perioperative fluid regimes and is experienced in treating postoperative pain, nausea and vomiting. The ideal anaesthetist takes an active role in the later postoperative period in facilitating early recovery and must be motivated to play a central role in coordinating and stimulating the project.

\section{The expert surgical nurse}

Changing long-standing surgical nursing care principles is a major component of the total enhanced recovery package. An expert nurse is specialised in patient education, trained to maintain patients pain free for the early postoperative period and is experienced in mobilisation of the patient in the early postoperative phase. The ideal nurse is willing to reconsider and revise traditional care principles.

\section{Clinical leadership}

In Kehlet's research setting, one surgeon (Kehlet himself) operated all patients, one anaesthetist was involved in fast track surgery and one nurse played an important role in the execution of the protocol. In every day practice, clinical leadership was present in all hospitals that implemented the ERAS programme. Some hospitals had surgeons who played a major role in the implementation process, other hospitals had anaesthetist or nurses as clinical champions. Unfortunately, there was not one hospital that had all three: an expert surgeon and an expert anaesthetist and an expert surgical nurse.

The lack of expert practitioners who carefully executed the protocol and were experienced in enhanced recovery after surgery programmes seemed to have played a major role in the success of programme implementation in every day practice.

\section{Closing the gap between research and every day practice}

The departure point for the development of an enhanced recovery after surgery programme was the availability of convincing scientific evidence that the outcome of colonic surgery could be dramatically improved by introducing a multimodal rehabilitation programme. It was obvious that a median length of stay of two days following elective colonic resection was such a huge reduction in conventional length of stay that it would be unethical not to consider the possibilities to introduce such a programme in every day practice. A postoperative stay of 8 days fol- 
lowing elective colonic surgery was difficult to defend after Kehlets' publication of a hospital stay of 2 days.

The introduction of the ERAS guideline in every day practice resulted in a reduction of length of stay to a median of 5 days, which was considered as an acceptable improvement of effectiveness of care, all the more because it coincided with an improvement of appropriateness of care. However, there remained a gnawing sorrow that the intended results were by far not achieved.

The previous evaluation of possible explanations for the reduced effectiveness in every day practice highlighted that there is still room for improvement. The effectiveness of the ERAS programme might increase by an improvement of protocol adherence, a better organisation of perioperative care and discharge and an increased experience with enhanced recovery after surgery programmes.

\section{Improving fidelity, actual exposure to the intervention/protocol adherence.}

It was demonstrated that the recommendations of the ERAS guideline were frequently not applied in every day practice. A prospective process evaluation showed that especially in the postoperative phase there were many reasons not to adhere to the protocol. Patients were perceived as being too sick and miserable and in too much pain to drink or eat, to sit out of bed or walk around. Practitioners and surgical nurses experienced difficulties with determining when departure from the protocol was desirable.

Most importantly, a shorter postoperative recovery period and a shorter length of stay were poorly accepted as reasons for changing routines. Perioperative care remained driven by the assessment of morbidity and mortality, nurses on the ward perceived no benefits of a short hospital stay and patients considered early recovery and short hospital stay as not so important

\section{Improving the motivation to change perioperative care routines.}

The lack of motivation to enhance recovery and reduce length of stay was identified as one of the most important barriers to change practice. Gaining internal support appeared to be one of the greatest challenges in implementing the ERAS guideline in every day practice. It is important to recognise that different target groups may have different reasons to change (or not to change) and that the motivation to change should thus be addressed to each group of participants. The question "why should we change?" requires an almost individualised answer, tailored to the specific professions.

\section{Surgeons}

The most important reason for surgeons to implement the ERAS protocol is the improvement of quality of care. Traditionally, quality of care has been defined primarily in terms of safety of care, as "freedom from incidental injury"18. Prevent- 
ing deaths and leakages have always been the frontline concerns of colorectal surgeons. A decade ago quality of care moved beyond the safety of care and was defined as "the degree to which health services for individuals and populations increase the likelihood of desired health outcomes and are consistent with current professional knowledge"19. Effectiveness, the impact of health care on desired patient outcomes, and appropriateness, the degree to which health care adheres to evidence based processes, became important elements of quality of care.

To improve surgeons' compliance to the protocol the importance of these elements of quality of care needs to be elucidated and it should be emphasized that evidence based guidelines act as an important mechanism to improve effectiveness and appropriateness of care. Guidelines provide an overview of recent scientific literature, summarise potential benefits or limitations of interventions and present professional consensus of good medical practice.

\section{Anaesthetists}

In the past, anaesthetists were primarily concerned with providing the best possible intra-operative surgical conditions and prevention of anaesthetic related complications with emphasis on cardiovascular and pulmonary morbidity that arises in the intra-operative and immediate post-anaesthetic period. This emphasis on the immediate postoperative phase played a major role in the lack of motivation to change perioperative care in accordance with the ERAS protocol. The recommendations regarding anaesthesia and analgesia in the ERAS protocol aim at improvements in the later postoperative phase that were not seen by the anaesthetists.

Anaesthetists play a key role in improving effectiveness of surgery through their choice of preoperative medication, anaesthetics and techniques and the administration of prophylactic and adjective drugs that maintain organ system function and minimise side effects.

The absence of an anaesthetist in the development of the guideline was frequently mentioned as another important reason that negatively influenced the motivation to change. The use of experience and expertise of the target group is an attribute of a guideline that helps the target group to consider the innovation as their own and encourages them to take responsibility for $i^{20}{ }^{2}$. Medical specialists, for example, seldom use guidelines for General Practitioners ${ }^{21}$ and attribute much more value to guidelines developed by their own group.

Nurses

Nurses primary commitment is to help patients and provide care, comfort and nurture $^{22}$. The ERAS programme was disseminated as a programme that aimed at a reduction in length of stay. Motivational problems arose because nurses felt that the change of practice was economically driven and comprised patients' welfare. Nurses were concerned about the medical appropriateness of early discharge, reduced welfare of patients and increased domiciliary support. 
To persuade nurses to change every day practice the effects of early mobilisation and early nutrition on better patient outcomes should be emphasised. Early mobilisation not only decreases the well known risk of thrombo-embolic complications, but also decreases pulmonary complications ${ }^{23}$ and improves wound healing. A structured recovery programme leads to less fatigue and need for sleep and an earlier regain of functional capacities ${ }^{24}$. It is important to emphasize that discharge criteria are the same as those of traditional care. Patients treated according to an ERAS programme achieve these criteria sooner and can therefore be discharged earlier. There is no increased need for support after discharge in patients who are sent home earlier ${ }^{24} 25$.

The absence of a relation between longer stay and greater patient satisfaction is reassuring. Reducing length of stay and increasing patients' satisfaction are therefore not conflicting goals. Patients who have longer hospital stay (after controlling for severity of illness) actually are less satisfied than patients with shorter stay ${ }^{26}$. Ninety percent of patients that were treated according to an ERAS protocol and that were sent home early were highly satisfied with the entire perioperative course with no complaints about the timing of postoperative discharge ${ }^{27}$.

Improving a patient's postoperative condition.

Postoperative nausea and vomiting, pain, sickness, dizziness, grogginess and fatigue were identified as most important reasons for a poor protocol compliance in the postoperative phase. Patients were perceived as being too miserable to eat and drink, to sit out of bed and walk around. As a consequence, intra venous fluids could not be stopped, the epidural and urinary catheter were left in place and discharge criteria were not met on the second day after surgery. To improve protocol compliance in the postoperative phase these side effects of surgery need to be prevented or treated effectively.

Preventing and treating postoperative side effects starts with the perception that side effects are a clinical relevant problem. In traditional surgery, postoperative side effects are accepted as a normal response to surgery and anaesthesia that resolve spontaneous within a few days. Side effects are rarely fatal and efforts to reduce side effects are mainly driven by the high levels of patient discomfort and dissatisfaction associated with side effects ${ }^{28}$.

Changing this traditional thinking is essential within an enhanced recovery programme. Side effects need to be recognised as important limiting factors of early nutrition, mobilisation and restoration of function. Increased attention should result in optimisation of prevention and treatment of side effects including a combined effort of surgeons, anaesthetists and nurses in a multimodal approach.

Surgeons play an important role in treating side effects by the use of minimally invasive techniques that reduce the degree of tissue trauma. Anaesthetists have a key role in minimising side effects through their choice of perioperative medication, anaesthetic and analgesic techniques. Surgical nurses are of great importance 
because they contribute to the timely corrections of treatment by feeding back detailed information of every postoperative side effect that precludes early recovery.

The pathogenesis of side effects is multifactorial and effective treatment requires a multimodal modification of all mechanisms that lead to side effects. The ERAS protocol recommends more than twenty interventions that may affect the incidence of side effects ${ }^{8}$. This multimodality of the ERAS programme is an important limiting factor in optimising the treatment of side effects. It is very difficult to relate the occurrence of side effects to deficiencies in perioperative treatment. An experienced multidisciplinary team is for that reason an important prerequisite for the treatment of side effects. A multidisciplinary team, that evaluates the incidence of side effects in the individual patient in relation to the performances of surgeon, anaesthetist and surgical nurse may find explanations for the failure of in principle effective treatment and may suggest interventions to optimise the treatment of side effects.

\section{Facilitating early mobilisation}

Facilitating the early mobilisation of the patient may further improve the protocol adherence. In 1991 Maastricht University Medical Centre moved to a newly build hospital. Nursing wards underwent revolutionary changes due to the re-evaluation of the role of the acute hospital bed ${ }^{15}$. The new patient rooms were fully directed to the expected higher severity of illness of the patient as a consequence of reduction of inappropriate hospital stay, shifts from inpatient to day surgery and changing demographics. Every patient room had a toilet and shower facilitation and was equipped with telephone, television and food facilities at bedside.

A decade later, when introducing the ERAS protocol, this environment appeared to be one of the structural problems that hindered the successful rehabilitation. The surgical ward had no facilities that encourages mobilisation like main rooms where patients could spent time out of bed, having diner and watching television. Rebuilding a part of the surgical ward to a rehabilitation unit, characterised by separation of acutely admitted patients from elective patients and a ward design which encourages rehabilitation was suggested several times, but this plan was not realised due to the low number of patients that would benefit of such a unit. Admission of enhanced recovery after surgery patients to the elective-only unit may be a good alternative. There are some preliminary data which suggest that patients may recover more quickly in an elective-only unit ${ }^{29}$. But as it is not the operation, but the patient that is suitable for the elective-only ward, a careful selection of patients, taking into account social, medical (co-morbidity) and surgical criteria is of great importance. 


\section{Improving the discharge process}

During the implementation of the ERAS protocol several surgeons stated that a delay in discharge should not be experienced as trouble-some. An ERAS programme primarily aims at an enhanced recovery and the implementation is successful if patients recover faster after surgery.

However, the rationale of the implementation of such a protocol is founded in the premise that an enhanced recovery will reduce length of stay and that reducing the time spent in hospital will reduce costs. As stated in the introduction of the current discussion, evaluation of a healthcare improvement should also take into account the efficiency of the programme: "Is it worth it? ". There is no doubt that the efficiency of the ERAS programme is low when a subsequent reduction in length of stay can not be demonstrated.

How to close the gap between recovery and discharge? Patients not willing to go home, nurses who doubt the appropriateness of discharge, consultants who delay discharge because of increased workload as a result of speeding the discharge process, patients staying over in the weekend; whatever the reason is for delay in discharge, they all come down to a bad organisation of the discharge process.

A well organised discharge process starts before admission. A specialised nurse gains patients' support for a short hospital stay by translating early recovery and short hospital stay in patient centred outcomes and in positive lifestyle events such as an earlier capability to do all hobbies, to go to social events, to travel and to return to work. The expected length of hospitalisation is discussed and patient and family are informed about the discharge criteria and the readiness to go home when discharge criteria are fulfilled. The specialised nurse reviews whether the patient lives alone and has any special needs and the role of the home help in personal care is explained. Problems that may delay discharge are thus addressed before admission and not on the moment of discharge.

During hospital stay it is important to avoid sending conflicting messages about the discharge. It is important that patients do not feel that they are rushed into leaving the hospital. A daily round of a case manager that updates patients and family on the status of discharge and on all that needs to be done before discharge may help to improve the patient's satisfaction of the entire discharge process. It has been demonstrated that general practitioners and nurses underestimate the need for information by patients and their family.

A consultation at discharge should not only provide specific information regarding the monitoring of symptoms and emergency management, but also information about care of the wound, medication, diet, resuming activity and returning to work. Within an enhanced recovery programme, the discharge process does not end at discharge. A phone call within 48 hours after discharge checking the patient's progress and clarifying the instructions, an easy access to medical and nursing advise 
and the prompt readmission of a patient who experiences a major complication at home needs to be structured into the post discharge process to ensure safety after early discharge.

\section{Improving experiences with enhanced recovery after}

\section{surgery programmes}

Lack of experience in deciding when to act according to the protocol and when to deviate from the protocol was identified as an important factor that hindered the implementation of the protocol. This problem relates to the nature of a guideline. A guideline usually takes a hypothetical standard patient as a point of reference and does not address the individual patient in every day practice ${ }^{30}$. All target groups experienced difficulties with applying the protocol in complex patients. Surgeons decided not to remove the nasogastric tube, not to start with fluids and food and to cancel the early mobilisation because surgery turned out to be more complex than expected. Anaesthetists decided not to place an epidural catheter in high risk patients because they felt more comfortable with traditional anaesthesia and analgesia. Nurses decided that patients who underwent complex surgery deserved bed rest and fell back to traditional step-up schedules of nutrition.

A commonly mentioned limitation of guidelines is the too rigid application of recommendations without appropriate deliberation (cookbook medicine). Our experiences tend to the opposite. The guideline was not rigidly enough applied as many deviations of the guideline were judged to be unnecessary. A strategy that might be effective in finding the appropriate balance between application and deviation of the guideline is the use of local opinion leaders ${ }^{31}$. Local opinion leaders are respected persons, with great influence within the domain of their leadership. They have a high credibility within the hospital, knowledge about the organizational structure and culture and a high personal commitment to the programme. Opinion leaders may act as the "clinical champions" and may play a major role in influencing the attitudes of individual practitioners and their decisions to act on new information. Opinion leaders may promote the protocol, support the try out of the protocol, provide expert clinical consultation and monitor and feedback performance to the individual care givers.

\section{Some considerations}

A programme is likely to be worthwhile for wide spread dissemination if it is proven to be efficacious, effective and efficient. The efficacy of the ERAS programme has been demonstrated by Kehlet ${ }^{4,5}$ and has been confirmed by other controlled 
trials $^{16,32-35}$. A multimodal rehabilitation programme works under optimal conditions.

The present thesis demonstrated the effectiveness of the ERAS programme. The multimodal rehabilitation programme of the ERAS group works in real world conditions. The first international study demonstrated that the ERAS programme was effective when implemented in every day practice. The other studies, performed in the Maastricht centre of the ERAS group and in the breakthrough hospitals in the Netherlands confirmed that the ERAS programme was still effective when the developer of the programme, Kehlet, was not involved. For broad dissemination of a programme it is desirable to have effectiveness studies that do not involve the developer $^{36}$.

The efficiency of the ERAS programme is not well documented. Only one single centre study compared costs of patients before and after the implementation of a clinical pathway for patients undergoing an elective total colectomy ${ }^{37}$. The mean hospital bills decreased in the pathway group, but it was not clear whether costs were transferred from the hospital to the post discharge environment. In general, reductions of hospital stay may have minimal effect on the costs of hospital admissions and may even increase overall costs if bed occupancy is kept at a normal level $^{38}$.

More interesting is the recently demonstrated reduction in rate of postoperative complications in patients that were treated in accordance with a multimodal rehabilitation programme ${ }^{39}$. The economic impact of a rehabilitation programme may be more explicit when not only hospital stay as single factor is modified, but when the reduction in length of stay is accompanied by a reduction of postoperative morbidity.

An economic evaluation of a programme focuses not only on the amount of benefit achieved by correcting inefficiency, but also on the required investment to realise these benefits. Thus, to answer the question whether the ERAS programme is cost effective not only the reduced need and demand for medical services needs to be taken into consideration but also the implementation costs, including costs for developing and executing the ERAS programme. The development of the programme by an international working group, the appointment of a programme coordinator to guide the execution of the protocol and the chosen implementation strategy may surely influence the efficiency of the ERAS programme. In the effectiveness studies described in the present thesis two different methods of implementation were used. In the ERAS centres the programme was implemented in a traditional and intuitive way; implementation strategies were mainly focused on local dissemination of information to involved professionals. In the 26 Dutch hospitals the programme was implemented via the breakthrough methodology. There is no doubt that the breakthrough methodology represented substantial investments of time and funding. Every participating centre paid to attend the breakthrough 
project and the five learning sessions together with the local project team at a central location in the Netherlands generated supplementary costs. Unfortunately, it is not possible on this moment to conclude whether the investment in the participation of the breakthrough project was worth the improvement in outcomes. The evaluation of the breakthrough project "Perioperative Care" is still ongoing and data are not yet available for publication.

A recent systematic review of collaboratives ${ }^{40,41}$ concluded that the evidence underlying quality improvement collaboratives is positive but still limited. Most of the studies included in this systematic review showed an effect on some of the selected parameters. The huge variation in the topics and settings addressed in the different collaboratives made it impossible to draw any conclusions regarding the question of whether collaboratives are especially effective for specific topics or in specific settings. The effects of collaboratives cannot be predicted with great certainty and it is unclear when to apply a collaborative. More insight is needed into the factors that make collaboratives work, so that future collaboratives can be tailored to those factors.

A sophisticated economic analysis is needed to demonstrate the efficiency of the ERAS programme and this systemic review of collaboratives emphasises the necessity to take into consideration the value of the breakthrough methodology in relation to the ERAS programme.

\section{Recommendations for practice}

The ERAS programme did not produce the intended effects and to improve effectiveness of the programme an improvement of protocol adherence, organisation of perioperative care, and experience with enhanced recovery after surgery programmes is suggested and a second cycle of improvement is recommended.

\section{A re-introduction of the ERAS protocol}

In 2008 the ERAS guideline was updated ${ }^{42}$ and this updating of the ERAS guideline motivates a re-introduction of the protocol. In the new version of the ERAS guideline an anaesthetist was involved as co-author. This involvement of the anaesthetist needs to be underlined when re-introducing the ERAS protocol to the group of anaesthetists. The re-introduction of the programme needs to emphasise the importance of integrating evidence in every day practice. The ERAS programme should be launched as an international well developed multidisciplinary guideline, published by a respected overarching institute, showing that the provision of such care is consistent with current professional knowledge. 


\section{A search for three clinical champions}

Clinical opinion leaders are considered key elements of successful change of practice. The identified lack of clinical leadership as important reason of reduced effectiveness of the ERAS protocol, motivates the renewed search for three clinical leaders (a surgeon, an anaesthetist and a surgical nurse) that will guide the consolidation of appropriate clinical care.

\section{A structural evaluation of process and outcomes of perioperative care}

The necessity to improve the quality of care and to start a second cycle of improvement may be illustrated by an up to date measurement of process and outcome of every day practice showing that practice is not as appropriate and not as effective as it should be. Many care givers overestimate their performance and demonstrating the discrepancy between actual practice and ideal practice may act as an important motivator to change. Additionally, an ongoing process and outcome evaluation is needed not only to demonstrate the effect of a second cycle of improvement, but also to evaluate the sustainability of the programme in the long term. Sustainability of a programme is the ultimate success criterion for an implementation process.

The ERAS group developed a database to audit perioperative care within an ERAS programme. This database is localised on a password and firewall protected secure internet server. Each patient's data field contains approximately 140 different variables including case mix determinants and elements of process as well as outcome of perioperative care. The programme provides users with reports on perioperative care and recovery, hospitalisation and complication rates. These reports per hospital and in comparison with other hospitals generate benchmarks of perioperative care and guide users to improving their performance. The ERAS database is a very suitable instrument to facilitate quality improvement initiatives

\section{Recommendations for further research}

To improve effectiveness of the ERAS programme, several research issues remain to be solved. These issues relate to the possibility to reduce inappropriate delayed discharge, the value of the anaesthetist employed beyond the post anaesthesia care unit and the exploration of innovative approaches. The efficiency of the programme and the expansion of the programme to rectal surgery and acute procedures are other important research issues that need to be solved. 


\section{The hospital admission coach.}

In a previous section of the current discussion is described what needs to be realised to ensure a well organised discharge process. How to realise that is still not evident. Maastricht University Medical Centre starts a trial that explores the role of a hospital admission coach, a case manager/specialised nurse that coordinates the organisation of care before, during and after admission, thus including the organisation of discharge. One of the aims of this study is to evaluate whether a better organisation of discharge process reduces inappropriate delay in discharge and results in a reduction in length of hospital stay.

\section{The anaesthetist as perioperative physician.}

Maastricht University Medical Centre is preparing a clinical trial that evaluates the effects of an optimised haemodynamic management guided by an anaesthetist participating in the early and late postoperative phase. This study includes a more active collaboration between anaesthesia staff and personnel in the surgical ward and may generate evidence of the added value of the cooperation of an anaesthetist beyond the post anaesthesia care unit.

\section{Fluid management.}

Traditionally, perioperative fluid management has been liberal, but recently several studies have shown that a fluid excess may have detrimental effects on the cardiopulmonary system, may prolong recovery of gut function and may impair wound healing including healing of the anatomoses ${ }^{43,44,45}$. Moreover, avoiding postoperative fluid excess may be crucial to enhance recovery, reduce length of hospital stay and reduce morbidity ${ }^{463}$. Maastricht University Medical Centre starts a trial to test the effect of goal directed fluid therapy guided by oesophageal Doppler on a patient's recovery.

\section{Enhanced Recovery After Surgery: Fact or Fiction?}

It is a fact that colorectal surgery patients that are treated according to an enhanced recovery after surgery programme recover faster and stay shorter in hospital than patients traditionally treated. The introduction of the ERAS programme in every day practice resulted in a decrease of recovery time by two days and a decrease of length of stay by three days. In addition, the implementation of the ERAS programme resulted in significant improvements of perioperative care.

A recovery that fast that patients can be discharged within two days after surgery is still fiction, although there is no doubt that the bridge to a very fast recovery after major surgery will be build the next decade. 
It is for sure that colorectal surgery will become short stay or even day-case surgery. The majority of colorectal procedures will be performed laparoscopically, surgical wards will have separate units for high and low care patients, anaesthetists will become perioperative physicians, the perioperative care process will be guided by nurse practitioners specialised in colon care and postoperative recovery will become the most important indicator of quality of perioperative care. 


\section{References}

1. Cochrane A. Effectiveness and efficiency: random reflection on health services. London: Nuffield Provincial Hospitals Trust 1972.

2. Haynes B, Haynes B. Can it work? Does it work? Is it worth it? The testing of health care interventions is evolving. BMJ 1999;319(7211):652-653.

3. Bausewein C, Higginson IJ. Appropriate methods to assess the effectiveness and efficacy of treatments or interventions to control cancer pain. Journal of Palliative Medicine 2004;7(3):423-430.

4. Kehlet $\mathrm{H}$, Mogensen T. Hospital stay of 2 days after open sigmoidectomy with a multimodal rehabilitation programme. Br J Surg 1999;86(2):227-230.

5. Basse L, Hjort Jakobsen D, Billesbolle $P$, Werner $M$, Kehlet $H$. A clinical pathway to accelerate recovery after colonic resection. Ann Surg 2000;232(1):51-57.

6. Schoetz DJ, Jr., Bockler M, Rosenblatt MS, Malhotra S, Roberts PL, Murray JJ, et al. "Ideal" length of stay after colectomy: whose ideal? Dis Colon Rectum 1997;40(7):806-810.

7. Marley. Efficacy, effectiveness, efficiency. Australian Perscriber 2000;23:114.

8. Fearon KC, Ljungqvist $\mathrm{O}$, Von Meyenfeldt $\mathrm{M}$, Revhaug $\mathrm{A}$, Dejong $\mathrm{CH}$, Lassen $\mathrm{K}$, et al. Enhanced recovery after surgery: a consensus review of clinical care for patients undergoing colonic resection. Clin Nutr 2005;24(3):466-477.

9. Brian. Standards of evidence: criteria for efficacy, effectiveness and dissemination. Prevention Science 2005.

10. Nygren J, Hausel J, Kehlet H, Revhaug A, Lassen K, Dejong C, et al. A comparison in five European Centres of case mix, clinical management and outcomes following either conventional or fasttrack perioperative care in colorectal surgery. Clin Nutr 2005;24(3):455-461.

11. Abraham NS, Young JM, Solomon MJ, Abraham NS, Young JM, Solomon MJ. Meta-analysis of short-term outcomes after laparoscopic resection for colorectal cancer. Br J Surg 2004;91(9) :1111-1124.

12. Copeland GP, Jones D, Walters M. POSSUM: a scoring system for surgical audit. Br J Surg $1991 ; 78(3): 355-360$.

13. Kehlet $\mathrm{H}$. Multimodal approach to control postoperative pathophysiology and rehabilitation. $\mathrm{Br} \mathrm{J}$ Anaesth 1997;78(5):606-617.

14. Kehlet $\mathrm{H}$, Wilmore DW. Multimodal strategies to improve surgical outcome. Am J Surg 2002;183(6):630-641.

15. Panis $L$, Verheggen FW, Pop P, Panis LGG, Verheggen FWSM, Pop P. To stay or not to stay. The assessment of appropriate hospital stay: a Dutch report. International Journal for Quality in Health Care 2002;14(1):55-67.

16. Delaney CP, Zutshi M, Senagore AJ, Remzi FH, Hammel J, Fazio VW. Prospective, randomized, controlled trial between a pathway of controlled rehabilitation with early ambulation and diet and traditional postoperative care after laparotomy and intestinal resection. Dis Colon Rectum 2003;46(7):851-859.

17. Donaldson L, Donaldson L. Conflict, power, negotiation. BMJ 1995;310(6972):104-107.

18. Medicine lo. To err is human:building a better health system. National Academy Press 2000.

19. Medicine lo. Crossing the quality chasm: the IOM health care quality initiative. available at: http://www.iom.edu/focuson.asp/id=8089 2003.

20. NHMRC. a guide to the development, implementation and evaluation of clinical practice guidelines. Canberra: Commonwealth of Australia 1999.

21. Everdingen J. Van consensus naar CBO richtlijn. NTVG 1999;143:2086.

22. Nettina SM. The lippincott manual of nursing practice. $2005 ; 8^{\text {th }}$ edition: Philadelphia:Lippincott.

23. Harper. Physiology and complications after bed rest. Journal of American Geriatric Society 1988;36:1047. 
24. Jakobsen $\mathrm{DH}$, Sonne E, Andreasen J, Kehlet $\mathrm{H}$, Convalescence after colonic surgery with fast-track vs conventional care. Colorectal Disease 2006;8(8):683-687.

25. Scott A, Shiell A, Farnworth MG. The value of early discharge: Dispelling some myths. Health Policy 1993;26(2):81-91.

26. Clark PA. Increase patient satisfaction by improving your discharge process. Hospitalist Management Advisor 2006.

27. Andersen J, Hjort-Jakobsen D, Christiansen PS, Kehlet $\mathrm{H}$, Readmission rates after a planned hospital stay of 2 versus 3 days in fast-track colonic surgery. British Journal of Surgery 2007;94(7):890-893.

28. van Wijk MG, Smalhout B, A postoperative analysis of the patient's view of anaesthesia in a Netherlands' teaching hospital. Anaesthesia 1990;45(8):679-682.

29. Vather R, Zargar-Shoshtari K, Metcalf P, Hill AG, The influence of hospital environment on postoperative length of stay following major colorectal surgery. New Zealand Medical Journal 2007;120(1266):U2828.

30. Tonelli MR, Tonelli MR. The philosophical limits of evidence-based medicine. Academic Medicine 1998;73(12):1234-1240.

31. Rogers E. Lessons for guidelines from the diffusion of innovation. Jt Comm J Qual Improv 1995;21:324-328.

32. Anderson AD, McNaught CE, MacFie J, Tring I, Barker P, Mitchell CJ. Randomized clinical trial of multimodal optimization and standard perioperative surgical care. Br J Surg 2003;90(12):14971504.

33. Bradshaw BG, Liu SS, Thirlby RC. Standardized perioperative care protocols and reduced length of stay after colon surgery. J Am Coll Surg 1998;186(5):501-506.

34. Raue W, Haase O, Junghans T, Scharfenberg M, Muller JM, Schwenk W. 'Fast-track' multimodal rehabilitation program improves outcome after laparoscopic sigmoidectomy: a controlled prospective evaluation. Surgical Endoscopy 2004;18(10):1463-1468.

35. Basse L, Thorbol JE, Lossl K, Kehlet H. Colonic surgery with accelerated rehabilitation or conventional care. Diseases of the Colon \& Rectum 2004;47(3):271-277;

36. Flay BR, Biglan A, Boruch RF, Castro FG, Gottfredson D, Kellam S, et al. Standards of evidence: criteria for efficacy, effectiveness and dissemination. Prevention Science 2005;6(3):151-175.

37. Stephen AE, Berger DL. Shortened length of stay and hospital cost reduction with implementation of an accelerated clinical care pathway after elective colon resection. Surgery 2003;133(3):277282.

38. Taheri PA, Butz DA, Greenfield LJ. Length of stay has minimal impact on the cost of hospital admission. Journal of the American College of Surgeons 2000;191(2):123-130.

39. Muller S, Zalunardo MP, Hubner M, Clavien PA, Demartines N, Zurich Fast Track Study Group. A fast-track program reduces complications and length of hospital stay after open colonic surgery. Gastroenterology 2009;136(3):842-847.

40. Schouten LM, Hulscher ME, van Everdingen JJ, Huijsman R, Grol RP. Evidence for the impact of quality improvement collaboratives: systematic review. BMJ 2008;336(7659):1491-1494.

41. Hulscher M, Schouten L, Grol R. Collaboratives. London, The Health Foundation, 2009.

42. Lassen K, Soop M, Nygren J, Cox B, Hendry P, Spies C, et al. Enhanced Recovery after Surgery: A consensus review of optimal perioperative care in colorectal surgery. submitted 2009.

43. Grocott MP, Mythen MG, Gan TJ. Perioperative fluid management and clinical outcomes in adults. . Anesthesia \& Analgesia 2005;100(4):1093-1106.

44. Lang K, Boldt J, Suttner S, Haisch G. Colloids versus crystalloids and tissue oxygen tension in patients undergoing major abdominal surgery. Anesthesia \& Analgesia;93(2):405-409.

45. Holte $\mathrm{K}$, Kehlet $\mathrm{H}$. Compensatory fluid administration for preoperative dehydration. Does it improve outcome? Acta Anaesthesiologica Scandinavica 2002;46(9):1089-1093.

46. Rahbari NN, Zimmermann JB, Schmidt T, Koch M, Weigand MA, Weitz J. Meta-analysis of standard, restrictive and supplemental fluid administration in colorectal surgery. $\mathrm{Br} J$ Surg 2009;96(4):331-341. 



\section{Chapter 11}

Summary

Samenvatting

Dankwoord

Over de auteur

Appendix 


\section{Summary}

With traditional perioperative care, hospital stay after colorectal resection has ranged between 1-2 weeks. A decade ago, Henrik Kehlet demonstrated at the Hvidovre University Hospital in Denmark a dramatic reduction of postoperative stay by changing traditional perioperative care routines to a "fast track" clinical pathway. Kehlet's fast track programme combined a series of interventions that addressed traditional factors leading to prolonged hospital stay such as stress induced organ dysfunction, pain, nausea and vomiting, ileus, and fatigue. Modern concepts of patient education were combined with minimal invasive surgical techniques, optimization of anaesthetic and analgesic regimens and enforced postoperative nutrition and mobilisation. Treating colorectal surgery patients according to this multimodal rehabilitation programme resulted in an improved postoperative recovery and a reduction of postoperative hospital stay to a median of 2 days.

Other single centre groups have subsequently confirmed that multimodal perioperative care programmes lead to a reduced length of hospital stay, less morbidity, improved pulmonary function, reduced postoperative ileus, less pain and less fatigue.

In 2000 the Enhanced Recovery After Surgery (ERAS) group was established, a collaboration of five university or specialised departments of surgery in Northern Europe. As there appeared to be a wide variation in the application of perioperative care elements in multimodal rehabilitation programmes, the ERAS group considered the evidence base for individual components of perioperative care and developed a new multimodal perioperative care programme for patients undergoing colorectal resections, the ERAS programme. Based on the best available scientific evidence the guideline presented the consensus on how surgical patients undergoing a colonic resection should be cared for. Using a multidisciplinary team approach, with a focus on stress reduction and early return of function, the ERAS protocol aims to allow patients to recover more quickly from major surgery.

\section{Aim of the thesis}

Evidence that a multimodal rehabilitation programme was superior to traditional perioperative care was already generated in various randomised controlled trials. Randomised controlled trials are the gold standard for establishing the efficacy of new interventions. Participants are highly selected, have no health problems other than the condition being investigated, are not treated with concomitant medications, are likely to cooperate fully with the medical advice and receive special at- 
tention from expert practitioners who supplement or replace those employed in the usual clinical setting.

However, results of randomised controlled trials are often not reproducible in real life clinical practice comprising less controlled circumstances with usual practitioners treating real patients. A protocol that works well in a controlled environment may thus not work well in every day practice.

The present thesis aimed to evaluate prospectively the effectiveness of a multimodal rehabilitation programme implemented in every day practice, including all patients that are scheduled for a colon resection and all practitioners involved in colonic surgery with varying experience and acceptance of the principles of the enhanced recovery after surgery program.

Besides effectiveness, the present thesis evaluated the feasibility of the change of traditional practice en the difficulties that arise when introducing the ERAS programme in daily care.

Part 1 discusses multimodal recovery programmes and describes the initial experiences with implementing the ERAS programme in the five ERAS centres.

Part 2 evaluates the implementation of the ERAS programme in the patient population of the Maastricht University Medical Centre.

Part 3 reports of the implementation of the ERAS programme in 26 hospitals in the Netherlands that participated to the breakthrough project "Perioperative Care".

\section{Part 1. Initial international experiences}

Chapter 2 presents a review of fast track programmes in colonic surgery. Fast track programmes in colonic surgery include extensive preadmission counselling, no bowel preparation, no preoperative fasting, carbohydrate loading until two hours before surgery, no sedative pre-medication, thoracic epidural anaesthesia and short acting anaesthetics, minimal incisions, warm air body heating during operation, non-opioid pain management, avoiding of fluid overload, no routine use of nasogastric tubes and drains, early postoperative nutrition and mobilisation, standard laxatives and early removal of bladder catheters.

The relative contribution of each of the single elements in the fast track programme remains uncertain. For some care elements there is solid evidence that its implementation as a single modality results in less morbidity and/or an enhanced recovery. For other elements the evidence is less robust and the recommendations were based on consensus interpretation of the best available scientific evidence.

To guarantee patients' safety after early discharge, fast track programmes define clear criteria to be fulfilled before discharge. These discharge criteria include tolerance of solid foods, passage of flatus and/or stool, adequate pain control on oral analgesics and mobilisation and self support as to preoperative level. There is no 
increased need of domiciliary support because patients are discharged in the same condition as in a traditional setting. Fast track programmes recommend to discharge patients "under supervision". Patients should be contacted by phone within 48 hours after discharge to ensure that there are no complications at home. Facilities should be created for the prompt readmission of patients who do experience complications at home.

An analysis of five fast track studies, two randomised and three controlled clinical trials, published between 1999 and 2004, demonstrated that the overall hospital stay of patients treated according to a fast track programme was significantly shorter than the hospital stay of patients that were traditionally treated. Length of stay of fast track patients varied between three and six days. The early discharge of fast track patients had no influence on morbidity and mortality rates. Increased readmission rates after early discharge, as reported in Kehlet's studies, were not confirmed.

In 2001 the perioperative care guideline of the enhanced recovery after surgery programme was introduced in the five centres of the ERAS group: Kehlet's fast track center in Denmark and the four other Northern European surgery centres that were, up to this introduction, adhering to a more traditional pattern of care. Chapter 3 describes initial experiences with the implementation of the ERAS guideline within the centres of the ERAS collaboration.

Between 2001 and 2004 four hundred and twenty five patients from the five centres of the ERAS group fulfilled the study criteria and entered into the ERAS programme. The mean age of these patients was 67, almost a quarter had ASA grade III/IV. Two third of the patients had colorectal cancer and 16 percent of the patients underwent a complex multiple organ resection. Median length of postoperative stay was five days. Total length of stay, including readmissions within 30 days after surgery, was a median of 6 days. There appeared to be a discrepancy between the moment that patients were recovered to the level of being ready to go home and the moment of actual discharge. Patients did leave hospital only a median of two days after fulfilling the preset recovery criteria for hospital discharge.

The study demonstrated a significant difference in proportion of patients with a delay in discharge between the centre of Kehlet and the other traditional care centres. In Denmark 66 per cent of the patients left the hospital on the day of discharge compared to 26 per cent of the patients in the other centres.

A multivariate analysis of factors that might influence length of stay demonstrated that the ability to discharge patients when they had reached functional recovery and previous experience with rehabilitation programmes were strongly associated with reduced length of stay. The development of major complications was strongly associated with a prolonged length of hospitalisation.

The study also showed that changing traditional perioperative routines was troublesome. Protocol adherence was high before and during the operation but fell 
considerably in the immediate postoperative phase. The postoperative goals of mobilisation, nutritional supplements and intravenous fluids were achieved in less than half of the patients.

The main conclusion was that to achieve a dramatic reduction in length of hospitalisation after colonic surgery a more complete protocol compliance, more experience and a better organisation of care may be required.

\section{Part 2. Experiences at Maastricht University Medical Centre}

Between 2003 and 2006 one hundred and thirty two elective colorectal surgery patients entered into the ERAS protocol in the Maastricht site of the ERAS collaboration. A prospective case series implementation study was performed, comparing ERAS patients to a historical control group of fifty five consecutive patients traditionally treated in 2001, the year that the ERAS programme was not heard of yet. The pre-ERAS patients were evaluated by a retrospective review of medical and nursing charts.

In chapter 4 the discrepancy between recovery and discharge, observed in the multicentre study of the ERAS group, was studied. It was demonstrated that this discrepancy existed to the same extend before as after the introduction of the ERAS programme. Only 10 per cent of patients were discharged on the day that recovery indicators were fulfilled. It was remarkable that the extent of the delay was significantly shorter in the ERAS group. ERAS patients were discharged a median of 1 day after recovery criteria were fulfilled where as pre-ERAS patients were discharged a median of 2 days after fulfilling recovery criteria. A reduction in length of stay of a median of one day after institution of the ERAS programme was thus not achieved by an enhanced recovery, but by a reduced delay of discharge.

The additional stay after recovery was evaluated using the Dutch Appropriateness Evaluation Protocol, a validated instrument to assess the appropriateness of the hospital stay. According to this instrument fifty nine per cent of the traditionally treated patients and sixty nine percent of the patients treated according to the ERAS programme had no medical reason to stay in hospital after discharge criteria were fulfilled.

The ultimate aim of an enhanced recovery after surgery programme is "to allow patients to recover more quickly from major surgery", thus facilitating earlier discharge and reducing length of stay. The study demonstrated that discharging patients on the day of recovery may result in a reduction in length of hospitalisation of a median of two days, independent of the success of the guideline on shortening the postoperative recovery period. 
In chapter 5 the effect of the ERAS programme on recovery per se was evaluated. Clinical recovery was defined as the first day after surgery that a patient fulfilled the four discharge criteria: tolerance of food, defecation, pain control on oral analgesics and nursed back to ADL independency.

It was demonstrated that patients treated according to an ERAS programme were eating three days earlier, were ADL independent two days earlier and had pain control on oral analgesics one day earlier than traditionally treated patients. Recovery time significantly decreased from a median of six days to a median of four days.

A recovery in two days as demonstrated by Kehlet could by far not be achieved in daily practice and appeared to be a too ambitious implementation goal. Not achieving preset implementation goals will leave a poor impression of the programme not only on caregivers but also on patients and may have a detrimental effect on motivation to change. For hospitals that are adhering to a traditional pattern of care and that view the challenge to change perioperative care routines, a clinical recovery in three days in non complex colorectal surgery patients is suggested as a feasible, but still ambitious implementation goal.

As was shown in the multicentre study of the ERAS group, the implementation of the protocol in every day practice was troublesome. In chapter 6 a prospective process evaluation is described that identified reasons for non compliance to the ERAS protocol. An expert panel translated identified reasons into barriers and facilitators to change practice. Understanding factors that hinder or facilitate the implementation of the ERAS programme may be helpful for other hospitals that are planning the introduction of the ERAS protocol into their clinical practice. The process evaluation confirmed that it was not difficult to change routines before and during surgery. Compliance before surgery was high because there were hardly any reasons for protocol violation, no doubts about the value of the recommendations and few contra-indications in patients. Change of postoperative care principles was much more problematic. Early nutrition and mobilisation as to the prescheduled care plan were realised in less than half of the patients. Limits in staff and time, restrictions in patients that felt miserable after surgery and motivational factors in care givers were identified as most important reasons for failure of implementation.

The reduced discomfort of patients because of cancellation of unpleasant traditional practices, the appointment of a nurse coordinator and the high level of evidence supporting key-elements of the programme were defined as important facilitators of implementation. Most important barriers of the implementation were the lack of patients' well being postoperatively, lack of experience in new routines, lack of robust evidence behind some of the recommendations and a poor focus on recovery as important outcome of care. 
The lack of motivation to enhance recovery and reduce length of hospital stay was considered the most unforeseen and probably most important barrier to change traditional care. Unforeseen, as in the perspectives of health workers "one leaves a hospital as soon as possible". Important, because this barrier operated at the level of patients as well as nurses, anaesthetists and surgeons. To promote the adoption of the ERAS programme in every day practice strategies that address this motivational problem are suggested, such as the dissemination of the protocol as an international well-developed multidisciplinary guideline, published by a respected overarching institution, the buy in of local opinion leaders and the purposeful selection of the first patients.

\section{Part 3. Experiences in the Netherlands}

In 2005 and 2006 the CBO, the Dutch institute for quality in healthcare organised a breakthrough project, concerning the synchronous implementation of the multimodal care programme of the Enhanced Recovery After Surgery group. All Dutch hospitals were invited to participate and within a short timeframe twenty six hospitals in the Netherlands (one quarter of all Dutch hospitals) signed up for the Breakthrough Series "Perioperative Care" . Prior to the start of the project, all hospitals gathered data for a baseline measurement. A consecutive series of approximately 50 colorectal surgery patients per hospital, operated in 2004, was analysed. Data of 1265 patients were entered in an Excel database.

In chapter 7 results of the baseline measurement of contemporary perioperative care in the Netherlands are presented. The study showed a median length of stay after colorectal surgery in the Netherlands of nine days. Based on best available evidence bowel preparation and nasogastric decompression tubes are not indicated, normal food should be re-started within 24 hours after surgery and thoracic epidural analgesia is recommended in colonic surgery.

The baseline measurement demonstrated that mechanical bowel preparation was still used in all hospitals. One centre had the policy to remove the nasogastric decompression tube at the end of surgery. All other centres routinely used postoperative nasogastric decompression tubes. The nasogastric tube was removed after a median of 2.5 days and fluid intake was resumed after a median of two days. Solid foods were resumed a median of five days after surgery and i.v. fluids were discontinued on a median of 6 days. Eleven hospitals used thoracic epidural analgesia routinely, five hospitals in less than one third of the cases.

This study confirmed the lack of adherence to the best available evidence in perioperative care in colorectal surgery in the Netherlands. Effective implementation strategies are urgently needed to bridge the gap between what we know and what we do. 
In chapter 8 the effect of the implementation of the ERAS programme via the breakthrough project "Perioperative Care" on the use of nasogastric tubes was described. Although there is abundant evidence that the routine use of nasogastric decompression following elective abdominal surgery is ineffective in achieving any goals it is intended for, the baseline measurement of contemporary care in one quarter of the Dutch hospitals demonstrated that 88.3 per cent of colorectal surgery patients still had a nasogastric tube that was removed after a median of 2.5 days.

The Breakthrough Series covers a period of 12 month. Within this period 827 patients had been treated according to the ERAS programme. It was demonstrated that the routine use of nasogastric decompression tubes dropped to below 10 percent. Within a year's time the inappropriate use of nasogastric decompression tubes was eradicated in one quarter of Dutch hospitals.

In chapter 9 the influence of the structured implementation of the ERAS guideline via the Breakthrough Series on the early start of oral nutrition is described. There is a high level of evidence that early re-establishment of oral nutrition after abdominal surgery does not increase complication rates, is tolerated by over 70 per cent of the patients and that early nutrition can help to decrease the negative impact of the metabolic response to surgery.

However, in spite of a large body of evidence that early nutrition after abdominal surgery is safe, feasible and beneficial, the baseline measurement of conventional care in the Netherlands showed that the new insights regarding postoperative nutrition were not implemented in daily practice. In 2004 less than 10 per cent of colonic surgery patients were eating within 2 days after surgery. The majority of patients were subjected to a period of starvation that lasted five days.

One year after the start of the breakthrough project "Perioperative Care" the median time to resumption of normal food decreased significantly from 5 days to 2 days. In 2004 seven percent of colonic surgery patients were eating normal food within two days after surgery compared to 65 per cent of the patients entered in the ERAS programme via the breakthrough project "Perioperative Care".

Thus, the synchronous implementation of the ERAS guideline in 26 hospitals in the Netherlands was successful in realizing early oral nutrition after abdominal surgery.

\section{Enhanced Recovery After Surgery: Fact or Fiction?}

It is a fact that colorectal surgery patients that are treated according to an Enhanced Recovery After Surgery programme recover faster and stay shorter in hospital than patients traditionally managed. The introduction of an Enhanced Recovery After Surgery programme in daily practice resulted in a reduction of recovery time of two days en a reduction of length of stay of three days. Additionally, the 
implementation of the ERAS programme resulted in significant improvements of perioperative care.

A recovery in two days, as shown in randomised clinical trials, is still fiction, although there is no doubt that the bridge to a very short recovery will be build the next decade. 


\section{Samenvatting}

De traditionele opnameduur na colorectale resecties varieert tussen de 1 en 2 weken. Einde jaren negentig toonde Henrik Kehlet, een Deense chirurg, aan dat de opnameduur drastisch kon worden gereduceerd door een "snelherstel" programma in te voeren. Dit snelherstel programma bestond uit een serie interventies die gericht waren op traditionele factoren die leiden tot verlengde opnameduur zoals stress geïnduceerd orgaan falen, pijn, misselijkheid en braken, ileus en vermoeidheid. Intensieve patiëntenvoorlichting werd gecombineerd met minimaal invasieve chirurgie, optimale anesthesie, adequate pijnstilling en geforceerde vroege voeding en mobilisatie. Het behandelen van colorectale chirurgiepatiënten volgens dit multimodaal herstel programma resulteerde in een versneld postoperatief herstel en een afname van de postoperatieve ligduur tot een mediaan van 2 dagen.

Andere groepen bevestigden nadien dat multimodale herstelprogramma's niet alleen leiden tot een reductie in opnameduur maar ook tot minder morbiditeit, verbeterde longfunctie, afname van postoperatieve ileus, minder pijn en minder vermoeidheid.

In 2001 werd de "Enhanced Recovery After Surgery (ERAS) " groep opgericht, een samenwerkingsverband tussen vijf universitaire/gespecialiseerde chirurgische centra in het noorden van Europa. Aangezien er een grote variatie bestond in de toepassing van zorgelementen binnen de multimodale herstelprogramma's van de diverse onderzoeksgroepen, evalueerde de ERAS groep de wetenschappelijke basis van herstelprogramma's en ontwikkelde op basis van het best beschikbare wetenschappelijk bewijs een nieuw perioperatief zorgprotocol voor patiënten die colorectale chirurgie ondergaan, het ERAS programma. Het ERAS programma focust op een sneller herstel na darmchirurgie door reductie van de chirurgische stress respons en stmulering van vroeg herstel van functies.

\section{Inhoud van dit proefschrift}

Wetenschappelijk bewijs dat een multimodaal herstelprogramma superieur is aan traditionele zorg is geleverd in diverse gerandomiseerde klinische onderzoeken.

Gerandomiseerde klinische onderzoeken zijn de gouden standaard om de effectiviteit van nieuwe behandelingen aan te tonen. De behandeling wordt namelijk toegepast bij geselecteerde patiënten die geen andere ziekten hebben dan de ziekte die onderzocht wordt, die geen met de behandeling interfererende medicijnen gebruiken en die het medisch advies correct opvolgen. Bovendien worden deze 
patiënten door klinische experts behandeld die het onderzoeksprotocol zorgvuldig uitvoeren.

Echter, de resultaten van gerandomiseerde klinische onderzoeken zijn vaak niet reproduceerbaar in de dagdagelijkse klinische praktijk, waar patiënten bijkomende ziekten hebben, medicijnen gebruiken die de interventie beinvloeden, minder coöperatief zijn in de opvolging van medische voorschriften en waar vele zorgverleners betrokken zijn bij de uitvoering van de zorg. Een protocol dat effectief is onder ideale onderzoeksomstandigheden is dus niet noodzakelijkerwijs effectief in de dagdagelijkse praktijk.

Het huidig proefschrift evalueert prospectief het effect van de implementatie van het multimodale herstelprogramma van de ERAS groep in de dagdagelijkse praktijk. Hierbij worden alle patiënten betrokken die in aanmerking komen voor een colorectale resectie en alle zorgverleners rondom colorectale chirurgie met wisselende ervaring en acceptatie van de principes van een snelherstelprogramma.

Centraal in het huidige proefschrift staan naast het effect van het ERAS programma in de dagdagelijkse praktijk en de haalbaarheid van de verandering van traditionele zorg, ook de problemen die zich voordoen bij het veranderen van de traditionele praktijkvoering.

In deel 1 worden snelherstelprogramma's geëvalueerd en worden de eerste ervaringen met de implementatie van het ERAS programma in de vijf ERAS centra beschreven. Deel 2 analyseert de implementatie van het ERAS programma in het Maastricht Universitair Medisch Centrum. Deel 3 rapporteert over de implementatie van het ERAS programma in 26 Nederlandse ziekenhuizen die deelgenomen hebben aan het doorbraakproject "Perioperatieve Zorg".

\section{Deel 1. Eerste internationale ervaringen}

Hoofdstuk 2 beschrijft de toepassing van snelherstelprogramma's in colon chirurgie. Sleutelelementen van snelherstelprogramma's zijn minimaal invasieve chirurgie, adequate pijnbestrijding en geforceerde rehabilitatie, die vertaald zijn in een aantal zorgelementen: uitvoerige patiënteninformatie, geen darmvoorbereiding, koolhydraatload 2 uur voor operatie, geen premedicatie, thoracale epidurale anesthesie, kort werkende anesthesie middelen, minimale incisies, preventie van hypothermie tijdens operatie, pijnbestrijding zonder opiaten, voorkomen van overvulling, geen routinematig gebruik van maagsondes en drains, vroege postoperatieve voeding en vroege mobilisatie, standaard gebruik van laxantia en vroege verwijdering van blaaskatheters.

De relatieve bijdrage van de diverse zorgelementen aan een versneld herstel en een korter verblijf blijft onduidelijk. Voor sommige zorgelementen is er solide bewijs dat de implementatie van het element als op zichzelf staand element resul- 
teert in minder morbiditeit en/of in een versneld herstel. Voor andere elementen is het bewijs minder robuust en is de aanbeveling meer gebaseerd op interpretatie van het best beschikbare bewijs.

Om de veiligheid van de patiënt te garanderen bij een vroeg ontslag, definiëren snelherstelprogramma's duidelijke criteria die moeten zijn vervuld voordat de patient ontslagen kan worden. Deze ontslagcriteria zijn: tolerantie van normale voeding, defaecatie of flatus, adequate pijnbestrijding op basis van orale pijnmedicatie en mobilisatie op preoperatief niveau. Deze criteria wijken niet af van de traditionele setting en patiënten worden dus in dezelfde conditie ontslagen als voor de introductie van het snelherstelprogramma. Het vroege ontslag heeft dan ook geen toename van thuiszorg tot gevolg, maar er wordt aanbevolen om patiënten binnen 48 uur na ontslag te bellen en te checken of er geen complicaties thuis zijn en om faciliteiten te creëren die een snelle opname van de patiënt mogelijk maken als complicaties zich zouden voordoen.

Vijf klinische onderzoeken (twee gerandomiseerde en drie gecontroleerde klinische trials, gepubliceerd tussen 1999 en 2004) zijn geanalyseerd. Aangetoond wordt dat de ligduur van patiënten die behandeld worden volgens een snelherstelprogramma significant korter is dan de ligduur van patiënten die traditioneel behandeld worden. De opnameduur varieert tussen de drie en zes dagen en het vroege ontslag van patiënten heeft geen invloed op morbiditeit en mortaliteit. De in Kehlet's studies gerapporteerde toename in heropnames wordt in andere studies niet bevestigd.

In 2001 werd het ERAS programma geïntroduceerd in de vijf ERAS centra: in Kehlet's "snelherstel" centrum in Kopenhagen en in vier andere Noord-Europese chirurgische centra, die een meer traditioneel zorgpad bewandelden.

Hoofdstuk 3 beschrijft de eerste ervaringen met de implementatie van het ERAS programma in deze vijf centra. Tussen 2001 en 2004 werden 425 patiënten behandeld volgens het ERAS programma. De gemiddelde leeftijd van de patiënten was 67 jaar, bijna een kwart van de patiënten had ASA classificatie III/IV, tweederde van de patiënten had colorectaal kanker en 16 procent van de patiënten onderging een complexe multi-orgaan resectie.

De mediane ligduur van de ERAS patiënten bedroeg vijf dagen. De totale mediane ligduur, inclusief de heropnames binnen 30 dagen na chirurgie, bedroeg 6 dagen. Er bleek een discrepantie te bestaan tussen de dag dat de patiënten hersteld waren om naar huis te gaan (volgens de ontslagcriteria) en het uiteindelijke ontslag. Patienten gingen pas 2 dagen nadat ze hersteld waren naar huis. Deze vertraging in ontslag was significant minder aanwezig in Kehlets centrum, waar 66 procent van de patiënten naar huis ging op de dag van herstel tegenover 26 procent van de patiënten in de overige centra.

Een analyse van factoren die van invloed waren op de ligduur toonde aan dat het ontslaan van patiënten op de dag van functioneel herstel en het hebben van erva- 
ring met snelherstel programma's sterk geassocieerd was met een kortere opnameduur. De ontwikkeling van complicaties was sterk geassocieerd met een langere opnameduur.

Het veranderen van traditionele zorgpatronen bleek moeilijk te zijn. De opvolging van het protocol leverde vooral in de fase na de operatie veel problemen op. De postoperatieve hersteldoelen van mobilisatie, voeding en intraveneuze vochttoediening werden in minder dan 50 procent van de patiënten gehaald.

Belangrijkste conclusie was dat voor een drastische reductie in ligduur niet alleen een goede protocol opvolging nodig is maar ook een goede organisatie van zorg en veel ervaring met snelherstelprogramma's.

\section{Deel 2. Ervaringen in het Maastricht Universitair Medisch Centrum}

Tussen 2003 en 2006 werden in het Maastricht Universitair Medisch Centrum 132 colorectale chirurgie patiënten behandeld volgens het ERAS protocol. Om de effecten van het protocol te kunnen beoordelen werden ERAS patiënten vergeleken met een historische controle groep, bestaande uit een groep van 55 patiënten die in 2001 een colorectale resectie ondergingen, de pre-ERAS groep. De pre-ERAS patienten werden retrospectief geëvalueerd door gegevens van proces en uitkomsten van zorg te verzamelen uit medische en verpleegkundige statussen.

In hoofdstuk 4 wordt de geconstateerde discrepantie tussen herstel en ontslag nader onderzocht. In het Maastricht Universitair Medisch Centrum bleek zowel voor als na de introductie van het ERAS protocol slechts 10 procent van de patiënten naar huis te gaan op de dag van functioneel herstel. De vertraging van ontslag was echter significant korter in de ERAS groep. Patiënten die volgens het ERAS programma behandeld werden, werden 1 dag na herstel ontslagen, de traditioneel behandelde patienten werden 2 dagen na herstel ontslagen.

De redenen voor verblijf nadat de ontslagcritieria waren vervuld, werden geëvalueerd. Met behulp van het Dutch Appropriateness Evaluation Protocol (DAEP), een gevalideerd instrument om de noodzakelijkheid van het verblijf in het ziekenhuis te evalueren, werden de redenen voor vertraging van ontslag geclassificeerd als noodzakelijk of niet noodzakelijk ziekenhuis verblijf. Volgens de DAEP was het verblijf van 59 procent van de traditioneel behandelde patiënten en van 69 procent van de ERAS patiënten niet noodzakelijk. Het ontslaan van deze patiënten op de dag van herstel zou tot een reductie in opnameduur van1 tot 2 dagen kunnen leiden.

De meeste studies die het effect van snelherstelprogramma's evalueren rapporteren als belangrijkste uitkomstmaat de lengte van de ziekenhuisopname. Aangezien 
echter reducties in ligduur ook door een betere organisatie van ontslag gerealiseerd kunnen worden, wordt in hoofdstuk 5 het effect van het ERAS programma op herstel per se onderzocht.

Herstel is gedefinieerd als de eerste dag dat de patiënt alle vier de ontslagcriteria heeft vervuld, dus de dag dat de patiënt normaal kan eten én defaecatie heeft gehad én de pijn onder controle heeft met orale pijnstillers én weer zelfstandig is in algemeen dagelijkse levensbehoeften (ADL).

De studie toonde aan dat patiënten die volgens het ERAS programma behandeld werden 2 dagen eerder hersteld waren dan traditioneel behandelde patiënten. De dag van herstel daalde van dag 6 naar dag 4 postoperatief. De ERAS patiënten aten drie dagen eerder, waren 2 dagen eerder ADL zelfstandig en hadden 1 dag eerder ontlasting en adequate pijnstilling met orale medicatie.

Belangrijkste conclusie van dit onderzoek was dat een herstel in twee dagen, zoals gerapporteerd in Kehlet's studies, niet meteen haalbaar is in de dagdagelijkse praktijk en dat een herstel in 3 dagen een reëler en toch voldoende ambitieus doel is voor ziekenhuizen die een traditioneel zorgpad bewandelen en de uitdaging aangaan om het ERAS programma te implementeren.

Aangezien in de multicentre studie van de ERAS groep de opvolging van het protocol moeizaam verliep, zijn de problemen die de implementatie van het ERAS protocol in de dagdagelijkse praktijk met zich meebrachten in het Maastricht Universitair Medisch Centrum nader onderzocht.

In hoofdstuk 6 wordt een procesevaluatie van het ERAS programma beschreven. Deze evaluatie bevestigde de eerdere bevindingen dat de protocolopvolging in de pre- en peri-operatieve fase weinig problemen oplevert. In de pre en perioperative fase zijn er nauwelijks redenen om af te wijken van het protocol, geen twijfels over de waarde van de aanbevelingen en weinig medische contra-indicaties. Dit in tegenstelling tot de postoperatieve fase, waar te weinig staf en tijd, beperkingen in patiënten die beroerd zijn na operatie en gebrek aan motivatie onder zorgverleners werden gedefinieerd als belangrijkste redenen voor het falen van de implementatie.

De redenen voor het niet opvolgen van de protocol elementen werden door een panel van experts, zorgverleners die direct betrokken waren bij de implementatie van het protocol, vertaald in belemmerende en bevorderende factoren van implementatie.

Als belangrijkste bevorderende factoren voor een succesvolle implementatie werden de reductie van discomfort bij patiënten vanwege het opheffen van onplezierige traditionele praktijken, de aanstelling van een verpleegkundig coördinator en het hoge niveau van wetenschappelijk bewijs voor sleutelelementen van het programma geïdentificeerd.

De belangrijkste belemmerende factoren waren het gebrek aan welbevinden van de patiënt postoperatief, gebrek aan ervaring in nieuwe routines, gebrek aan ro- 
buust wetenschappelijk bewijs achter sommige aanbevelingen en een gebrekkige focus op herstel als belangrijke uitkomst van zorg. Het gebrek aan motivatie om het herstel te bevorderen en de opnameduur te reduceren was de meest onverwachte en wellicht meest belangrijke belemmerende factor. Onverwacht, omdat vanuit het perspectief van de zorgverlener een verblijf in het ziekenhuis niet kort genoeg kan zijn. Belangrijk, omdat niet alleen zorgverleners maar ook patiënten niet gemotiveerd waren om het ontslag te versnellen.

Om tot een betere acceptatie van het ERAS protocol te komen wordt onder andere aanbevolen het protocol te promoten als een kwalitatief zeer goede richtlijn die ontwikkeld is door een gerespecteerde onderzoeksgroep, om sleutelfiguren in het implementatieproces te benoemen en om te starten met zorgvuldig geselecteerde patiënten.

\section{Deel 3. Ervaringen in Nederland}

In 2005 gaven 26 ziekenhuizen in Nederland te kennen deel te willen nemen aan het doorbraakproject "Peri-operatieve Zorg" Het doorbraakproject peri-operatieve zorg betrof de synchrone implementatie van het ERAS programma in de Nederlandse ziekenhuizen. Voordat het protocol in deze ziekenhuizen geïntroduceerd werd, werd een nulmeting verricht. Alle ziekenhuizen verzamelden gegevens van een opeenvolgende serie van ongeveer 50 patiënten die in 2004 colorectale chirurgie ondergingen. Deze gegevens werden ingevoerd in een centrale database.

Hoofdstuk 7 beschrijft de resultaten van de nulmeting peri-operatieve zorg bij 1265 patiënten in 26 Nederlandse ziekenhuizen. De ligduur van traditioneel behandelde colorectale chirurgie patiënten bedroeg in 20049 dagen en de peri-operatieve zorg bleek niet gebaseerd te zijn op het best beschikbare wetenschappelijk bewijs. Op basis van een hoog niveau van wetenschappelijk bewijs beveelt het ERAS programma aan om geen darmlavage te gebruiken, standaard geen maagsonde te gebruiken postoperatief, snel te starten met normale voeding en bij voorkeur thoracale epidurale analgesie toe te passen.

Uit de nulmeting bleek dat darmlavage nog standaard toegepast werd in alle ziekenhuizen. De maagsonde werd postoperatief nog in alle behalve één ziekenhuis gebruikt. Deze maagsonde werd na 2,5 dag verwijderd. Na 2 dagen werd gestart met drinken en na 5 dagen met normale voeding. Het infuus werd gestopt na 6 dagen en standaard thoracale epidurale anaesthesie werd in minder dan de helft van de ziekenhuizen gebruikt.

De chirurgische praktijkvoering bleek in Nederland in 2004 niet gebaseerd te zijn op het best beschikbare wetenschappelijk bewijs en geconcludeerd werd dat implementatie strategieën dringend nodig zijn om wetenschappelijk bewijs te introduce- 
ren in de praktijk en het gat tussen wat we zouden moeten doen volgens best evidence en wat we werkelijk doen in de dagdagelijkse praktijk te dichten.

Hoofdstuk 8 evalueert het effect van het ERAS programma op het gebruik van maagsondes postoperatief. De nulmeting gaf aan dat 88 procent van de traditioneel behandelde patiënten in de 26 Nederlandse ziekenhuizen in 2004 nog een maagsonde had bij terugkomst op de chirurgische afdeling. Deze maagsonde werd na 2,5 dag verwijderd. De doorbraakmethodologie bestrijkt een periode van 12 maanden. Binnen deze periode werden in de 26 doorbraakziekenhuizen 827 patienten volgens het ERAS programma behandeld. Het gebruik van maagsondes daalde naar minder dan 10 procent; de maagsonde bleek succesvol geëlimineerd uit de chirurgische praktijkvoering.

Hoofdstuk 9 beschrijft de invloed van het doorbraakproject op de start van normale voeding. Vroege voeding is een belangrijk element van snel herstel programma's. $\mathrm{Er}$ is een hoog niveau van wetenschappelijk bewijs dat normale voeding na darmchirurgie niet leidt tot een toename van complicaties, getolereerd wordt door meer dan 70 procent van de patiënten en zinvol is om de negatieve invloed van de chirurgische stressresponse te verminderen.

Ondanks de grote hoeveelheid wetenschappelijk bewijs dat vroege voeding na darmchirurgie veilig, haalbaar en nuttig is, blijken deze inzichten volgens de nulmeting niet geïmplementeerd in de Nederlandse ziekenhuizen. In 2004 at minder dan 10 procent van de colonchirurgie patiënten normale voeding binnen 2 dagen na chirurgie en duurde het vijf dagen voordat normale voeding herstart werd.

Volgens het ERAS programma mag de patiënt 4 uur na operatie starten met drinken en, als drinken geen problemen geeft, mag de dag na operatie gestart worden met normale voeding. Uit de evaluatie van het doorbraakproject bleek dat de startdag normale voeding vervroegd kon worden van dag 5 naar dag 2. In 2004 kreeg 7 procent van de traditioneel behandelde patiënten normale voeding binnen twee dagen na operatie tegenover 65 procent van de patiënten die volgens het ERAS programma werden behandeld binnen het doorbraakproject peri-operatieve zorg. De implementatie van het ERAS programma in 26 ziekenhuizen in Nederland was dus succesvol in het realiseren van een vroege start van normale voeding na colorectale chirurgie.

\section{Versneld hersteld na darmchirurgie: feit of fictie?}

Uit dit poefschrift is gebleken dat het een feit is dat darmchirurgie patiënten die behandeld worden volgens een snelherstelprogramma sneller herstellen en korter in het ziekenhuis verblijven dan patiënten die traditioneel behandeld worden. Door een snelherstelprogramma in te voeren in de dagdagelijkse praktijk kan het herstel na darmchirurgie met 2 dagen vervroegd worden en het verblijf met 3 dagen be- 
kort worden. Daarnaast leidt de implementatie van een snelherstelprogramma tot een duidelijke verbetering van de peri-operatieve zorg, doordat de uitvoering van de zorg meer berust op de resultaten van wetenschappelijk onderzoek.

Een herstel in 2 dagen, zoals in wetenschappelijk onderzoek is aangetoond, is op dit moment in de dagdagelijkse praktijk nog fictie. Er is echter geen twijfel dat in de nabije toekomst het herstel zodanig bekort kan worden dat na een darmoperatie slechts een korte opname of alleen nog een dagopname nodig is. 


\section{Dankwoord}

Het is verbazingwekkend hoeveel personen betrokken zijn geweest bij de tot stand koming van dit proefschift. Velen hebben geholpen bij de implementatie van het ERAS project in het Maastricht Universitair Medisch Centrum, bij de implementatie in de ziekenhuizen die meegedaan hebben aan het doorbraakproject Perioperatieve Zorg, bij het verzamelen en verwerken van gegevens, bij het schrijven en beoordelen van de manuscripten en bij de afronding van het proefschrift. Daarnaast heb ik veel steun gehad van familie, vrienden en collega's. Graag wil ik allen bedanken. De volgende pesonen wil ik in het bijzonder bedanken:

\section{Maarten von Meyenfeldt}

Ik kan mijn dankwoord niet anders beginnen dan met mijn dank uit te spreken aan jou, Maarten. In 1995 bood jij mij een buitengewone job aan als onderzoeksassistent van de "Abbott visolie studie". Gedurende vier jaar heb ik heel Limburg en Brabant doorkruist om terminale kankerpatienten thuis te bezoeken, waarbij ik altijd bij jou terecht kon als er vragen of problemen waren bij de patiënt thuis. Een half jaar na afronden van dit onderzoek, bood jij mij wederom een fantastische baan aan, nu als coöordinator van het ERAS programma, weliswaar op voorwaarde dat ik "een boekje" schreef over het project. Welnu, het boekje is eindelijk klaar en ik wil je bij deze van harte bedanken voor het vertrouwen dat je mij schonk en voor het geduldig wachten op het boekje. Maarten, het hele traject was geweldig.

Kees Dejong

Kees, jij bent de tweede in rij die ik graag wil bedanken. Met jou heb ik heel Nederland doorkruist op weg naar doorbraakconferenties, symposia en audits. "Maak dich neet drök, ut stelt allemaol niks veur" zei je altijd en meestal was dat ook zo, met de nadruk op meestal. Londen was gewoon een klein vergissinkje.

"Een artikel schrijf je in één avond"zei je vaak. Het toppunt van optimisme voor een beginnende promovenda. Ik dank je omdat het aantal avonden dankzij jouw hulp wat beperkt zijn gebleven. Jouw beoordeling van artikelen was altijd heel bijzonder. Je kon door één woord of regel toe te voegen een heel artikel verhelderen.

Trudy van der Weijden

Trudy, bedankt voor je hulp. Jij was zeer concenscieus, manuscripten spitte jij van voor tot achter door. Als jij het geschrevene beoordeeld en gecorrigeerd had, wist ik dat het in orde was. Ik heb veel geleerd van jouw zeer gestructureerde manier van schrijven.

\section{De beoordelingscommssie}

De beoordelingscommissie onder leiding van Prof. Dr. Van Kleef wil ik hartelijk bedanken voor het kritisch lezen van het proefschrift. 


\section{Phil Geerlings}

Phil, jij regelde dat ik de geboden kansen met beide handen kon aannemen.

Bedankt voor het vertrouwen en de steun, je belangstelling en betrokkenheid.

\section{Henriette Willigers}

Henriette, jij was als anaesthesist vanaf het eerste uur betrokken bij het ERAS programma en die eerste consulten van jou op de afdeling chirurgie hebben mij overtuigd van de toegevoegde waarde van de anaesthesist op de afdeling. Ik vond het geweldig (en de patient ook) als je naar de afdeling kwam, anti-emetica regelde, de pijnstilling optimaliseerde en afspraken maakte over het vochtbeleid. Ik heb veel geleerd van jouw uitleg over de anaesthesie en de rol van de anaesthesist rondom de operatie. Jouw blik op de patiënt en de zorg rondom de patient was zeer vernieuwend.

\section{Marina Hauben}

Marina, als unithoofd van A4, de afdeling waar de meeste colonchirurgie patiënten werden opgenomen, heb jij een grote rol gespeeld bij de implementatie van het ERAS programma. Je zorgde ervoor dat assistenten en verpleegkundigen op de hoogte waren van het protocol en dat er volgens protocol gehandeld werd. Als er afgeweken was van het protocol, wist jij altijd waarom. Bedankt voor je hulp, ik heb veel van jou geleerd en ik vind het een enorm gemis dat je niet meer op de afdeling bent.

\section{Margriet Rouflart}

Niemand anders kon zo goed uitleggen waarom de patient boerde, hikte, een gespannen buik had en niet kon eten. Je leerde mij hoe ik naar "de patient met een darmoperatie" moest kijken, een vaardigheid die je als oud-verpleegkundige van het voedingsteam zeer goed beheerste. Als pijnverpleegkundige heb je me niet alleen veel geleerd over postoperatieve pijnbestrijding, maar heb je ook bijgedragen aan een goede opvolging van het ERAS programma. Bedankt voor de vele "schouderklopjes".

\section{Bedankt:}

Elise en Boris, anaesthesisten, omdat ik altijd bij jullie terecht kon als ik vragen had over de anesthesie, postoperatieve pijnbestrijding of postoperatieve misselijkheid Jacqueline, hoofd verpleegafdeling A4 en alle verpleegkundigen van de afdeling chirurgie, omdat julie meehielpen de zorg volgens protocol te laten verlopen.

Bernadette, Annemarie, Christel, IIma, Marion, Mylene, Petra, Tanja en Claudia, medewerkers van poliliniek chirurgie, omdat jullie meewerkten aan de preoperatieve screening door een chirurg en meehielpen met het inplannen van spoedconsulten voor patienten met complicaties thuis.

Ria en Carina van bureau opname, omdat jullie ervoor zorgden dat alle patiënten die ingeschreven werden voor een darmoperatie, bij mij bekend waren 
Gertie, Emilienne, Claire, Jetty, Angele en Lucy, medewerkers poliliniek anesthesiologie, omdat jullie meewerkten aan het regelen van de preoperatieve screening door een anesthesist

Mariet, Denise en Olga, medewerkers van de Transmurale Apotheek Service Maastricht, omdat jullie ten behoeve van de preoperatieve screening de medicatie overzichten van de patiënten aanleverden.

Sylvia, anaesthesie-medewerker, omdat je je studie afrondde met een scriptie over het ERAS project en bijgedragen hebt aan de scholing van de anaesthesiemedewerkers.

Fons Kessels, statisticus, omdat je meehielp met de statistische verwerking van data en met het schrijven van methoden en resultaten. Fons, ik geloof dat jou af en toe de moed in de schoenen zonk, als je me een statistische bewerking moest uitleggen. Maar met behulp van vele kleine "consultjes" en een goed handboek is het uiteindelijk allemaal in orde gekomen.

Joyce Haas, secretaresse heelkunde, omdat je zovele afspraken bij Maarten inplande en meehielp bij de afronding van het proefschrift. Yoyce, je bent een geweldige secretaresse, zeer goed georganiseerd en nooit te beroerd om iets te doen wat eigenlijk niet jouw taak is. Zonder jou was ik niet op 6 november 2009 gepromoveerd.

Riette en Carla, mijn paranimfen, bedankt voor jullie vriendschap. Met jullie kom ik in het Guiness boek of Records. We zijn samen meer dan 150 jaar oud, meer dan 75 jaar werkzaam in het azM en meer dan 75 jaar getrouwd. Riette, bedankt voor je nuchterheid. Als ik weer eens klaagde over het vele werk maakte je me terecht duidelijk dat ik er zelf voor gekozen had. . Carla, bedankt voor de belangstelling. Ondanks dat je al ettelijke jaren niet meer mijn directe collega bent, ben jij nog altijd van de stand van zaken op de hoogte.

Nel en Sandra, lotgenoten, jullie waren geweldig. Nel, je bent een echte wetenschapper. "Het zoeken naar antwoorden is het spannendste, het schrijven van een artikel is het gemakkelijkste en de discussie is het leukste". Sandra, je hebt me veel "tips and tricks" gegeven. Al die jaren was je net iets verder met je proefschrift en maakte ik dankbaar gebruik van alles wat jij al wist.

Mieke, Liesbeth, Esther, Linda, Corrie, Nicole, Marjan, Anke, Levonne,Sjerty, Jenny, Marielle, Wilmy en Anita, collega's dietetiek, bedankt voor jullie tolerantie. Ik maak gebruik van een werkplek dietetiek, maak veel lawaai als ik op het toetsenbord zit te rammen, blokkeer de printer regelmatig en ontvang al dan niet storend bezoek op mijn werkplek. Jullie belangstelling voor mijn proefschrift was groot. Ik hoop dat iedereen die de kans krijgt te promoveren deze kans met beide handen aanneemt. Een promotie traject is een geweldig traject.

Jitske, Erica, Jeroen, Heleen, medewerkers CBO, leden van het kernteam perioperatieve zorg, voor het faciliteren van mijn proefschrift. Jullie waren echte im- 
plementatie deskundigen, ik heb veel van jullie geleerd. Het was goed toeven in Utrecht, op een enkel "stormpje" na.

Ken Fearon, Olle Ljungqvist, Arthur Revhaug, Jonas Nygren, Jonathan Haussel, Kristoffer Lassen, Mattias Soop, members of the ERAS collaboration, Thank you very much for your ever friendly support. Ken, I really enjoyed our discussions about quality of care and though your have a great power of persuasion, soup is still no normal food. Olle, you were very convinced of "spreading the message". So I spread: I gave more than 70 presentations of the ERAS programme since the start of the project. Arthur, it was a great pleasure to visit the wonderful Trømso. I thank you for your kind hospitality. Jonas, thanks for your friendship. Jonathan, I admire your enormous patience. Year after year you changed the ERAS data base, I would have given it up years ago. Mattias, wherever you were, you were always involved in the international ERAS project. I think you owe this your Apple computer. Kristoffer, I thank you for joining the opposition during the defending of my thesis.

Dorhte Hjort, Kirsti Fosland, Erika Fränden and Rachel Luff , nurse coordinators of the ERAS sites, Thank you for sharing experiences and being honest about the problems each of you experienced with the implementation of the ERAS project. It was very reassuring that we all had problems to change perioperative care.

Francois, Elke en Maud,

Francois, bedankt voor je nuchterheid. Het woord stress komt in jouw woordenboek niet voor; een dag heeft immers 24 uur en in 24 uur kun je veel doen. Bovendien moet je alleen doen wat echt nodig is. Het huishouden kun je gewoon laten liggen of uitbesteden. Fast food is ook eten en een boterham is nog gemakkelijker. Een keertje om 5 uur opstaan doet ook wonderen.

Jij was de belangrijkste "facilitator" van dit proefschrift. Zonder jou was er geen promotie geweest.Bedankt voor de hulp en de steun, ondanks dat je er met je zakelijk verstand nog altijd niet bij kunt waarom het schrijven van een proefschrift zoveel tijd kost en zo weinig opbrengt.

Elke en Maud, excuses voor het verwaarlozen van het huishouden (weer geen tijd gehad om chips en koekjes te halen), voor de gemiste koffie uurtjes op zondagmorgen bij oma Buchten (iedereen is er, behalve wij), voor de niet op tijd gewassen sportkleren en voor het lange wachten op tijd voor de kapper (al meer dan een half jaar geleden). Na 6 november ga ik weer "gezond koken", mee naar de volleybal wedstrijden, gaan we weer veel shoppen en iedere zondag bij oma koffiedrinken. 


\section{Over de auteur}

Jose Maessen werd geboren op 20 augustus 1959 in Born. Na het behalen van het diploma gymnasium ß aan de scholengemeenschap "Serviam" te Sittard in 1977, volotooide zij de opleiding Diëtetiek aan de scholengemeenschap "Wachtendonck" te Heerlen in 1981.

In september 1981 werd zij benoemd als diëtist in het St.Laurentius ziekenhuis te Roermond en in januari 1985 als diëtist in het toenmalige ziekenhuis St. Annadal te Maastricht.

Vanaf 1995 voerde ze als research assistent het door Abbott gesponsorde onderzoek naar "het effect van een met visolie verrijkte drinkvoeding op gewichtsverlies bij inoperable pancreaskopcarcinoom patiënten" uit.

Vanaf maart 2001 was zij werkzaam bij de afdeling epidemiologie van de universiteit Maastricht, alwaar zij betrokken was bij de opzet van het onderzoek "ATP infusies in de palliatieve thuiszorg".

In september 2001 werd ze benoemd als een van de "nurse coördinators" van de internationale ERAS groep en coördineerde ze de implementatie van het ERAS programma in het academisch ziekenhuis Maastricht. Vanaf januari 2006 tot september 2009 was ze als lid van het expertteam van het doorbraakproject "perioperatieve zorg" betrokken bij de begeleiding van programme in 36 Nederlandse ziekenhuizen.

De werkzaamheden ten behoeve van de internationale ERAS groep, ten behoeve van de coördinatie van het ERAS programma in het academisch ziekenhuis Maastricht en ten behoeve van het doorbraakproject Perioperatieve Zorg, hebben geleid tot het huidige proefschrift.

Jose is getrouwd met François Maessen en heeft twee dochters, Elke en Maud. 


\section{List of publications}

Draaijer $\mathrm{P}$, de Leeuw $\mathrm{P}$, Maessen J, van Hooff J, Leunissen K. Salt-sensitivity testing in patients with borderline hypertension: reproducibility and potential mechanisms. J Hum Hypertens. 1995 Apr;9(4):263-9.

Draaijer P, Kool MJ, Maessen JM, van Bortel LM, de Leeuw PW, van Hooff JP, Leunissen KM. Vascular distensibility and compliance in salt-sensitive and saltresistant borderline hypertension. J Hypertens. 1993 Nov;11(11):1199-207.

Wind J, Maessen J, Polle SW, Bemelman WA, von Meyenfeldt MF, Dejong $\mathrm{CH}$. Elective colon surgery according to a 'fast-track' programme Ned Tijdschr Geneeskd. 2006 Feb 11;150(6):299-304. Review

Maessen JMC, Dejong CH, Hausel J, Nygren J, Lassen K, Andersen J, Kessels AG, Revhaug $A$, Kehlet $H$, Ljungqvist $O$, Fearon $K C$, von Meyenfeldt MF. A protocol is not enough to implement an enhanced recovery programme for colorectal resection.Br J Surg. 2007 Feb;94(2):224-31.

Maessen JMC, Dejong CH, Kessels AG, von Meyenfeldt MF; Enhanced Recovery After Surgery (ERAS) Group. Length of stay: an inappropriate readout of the success of enhanced recovery programs. World J Surg. 2008 Jun;32(6):971-5.

Jottard K, Hoff C, Maessen J, van Ramshorst B, van Berlo CL, Logeman F, Dejong CH; Dutch Perioperative Breakthrough Project; ERAS Group.Life and death of the nasogastric tube in elective colonic surgery in the Netherlands. Clin Nutr. 2009 Feb;28(1):26-8

Maessen JMC, Hoff C, Jottard K, Kessels AG, Bremers AJ, Havenga K, Oostenbroek $\mathrm{RJ}$, von Meyenfeldt MF, Dejong $\mathrm{CH}$; Dutch Breakthrough Project Perioperative Care; ERAS Group. To eat or not to eat: facilitating early oral intake after elective colonic surgery in the Netherlands. Clin Nutr. 2009 Feb;28(1):29-33.

P.B.W. (Boris) Cox, Cornelis H.C. Dejong, Josephina M.C. Maessen, Jitske H.F.A. Teeuwen, Heleen Tijink en Marco A.E. Marcus. Sneller beter na een electieve colonoperatie, anesthesiologische aspecten van het 'sneltraject '-programma. Ned Tijdschr Geneeskd. 2009;153:B377

Maessen JMC, Dejong CHC, Willigers HMM, Kessels AGH, von Meyenfeldt MF. Enhanced recovery after surgery, fact of fiction. Submitted 
Maessen JMC, van der Weijden T, Willigers HMM, Dejong CHC, von Meyenfeldt MF, ERAS group, Reasons for poor adoption of evidence based recommendations for postoperative recovery in colonic surgery. Submitted

Hoff C, Jottard K, Maessen J, Tijink H, Wien J, van der Hagen S, Houdijk A, Rosman $C$, Dejong $C$. Perioperative care in elective colonic surgery in the Netherlands in the new millenium: are we doing what we should do? Submitted 


\title{
Enhanced recovery after surgery: A consensus review of clinical care for patients undergoing colonic resection
}

\author{
K.C.H. Fearon ${ }^{a, *}$, O. Ljungqvist ${ }^{b}$, M. Von Meyenfeldt ${ }^{c}$, A. Revhaug ${ }^{d}$, \\ C.H.C. Dejong ${ }^{c}$, K. Lassen ${ }^{d}$, J. Nygren ${ }^{b}$, J. Hausel ${ }^{b}$, M. Soop $^{b}$, \\ J. Andersen ${ }^{e}, H$. Kehlet ${ }^{e, f}$
}

${ }^{a}$ Clinical and Surgical Sciences (Surgery), School of Clinical Sciences and Community Health, The University of Edinburgh, Royal Infirmary, 51 Little France Crescent, Edinburgh EH16 4SA, UK

${ }^{\mathrm{b}}$ Centre of Gastrointestinal Disease, Ersta Hospital, PO Box 4622, 11691 Stockholm \& Karolinska Institutet, Centre for Surgical Sciences, Karolinska University Hospital, Huddinge, 14186 Stockholm, Sweden, 'Department of Surgery, University Hospital Maastricht, PO Box 5800, Maastricht 6202 AZ, The Netherlands ${ }^{\mathrm{d}}$ Department of Surgery, Tromso University Hospital, Tromso, Norway

'Department of Surgical Gastroenterology, 435 Hvidovre University Hospital, Kettegard Alle 30, nbsp; Hvidovre 2650, Denmark

fSection for Surgical Pathophysiology 4074, The Juliane Marie Centre, Rigshospitalet, Blegdamsvej 9, 2100 Copenhagen, Denmark

Received 26 January 2005; accepted 8 February 2005

\section{KEYWORDS}

Perioperative care; Colorectal; Enhanced recovery

\begin{abstract}
Summary
Background \& Aims: Clinical care of patients undergoing colonic surgery differs between hospitals and countries. In addition, there is considerable variation in rates of recovery and length of hospital stay following major abdominal surgery. There is a need to develop a consensus on key elements of perioperative care for inclusion in enhanced recovery programmes so that these can be widely adopted and refined further in future clinical trials.

Methods: Medline database was searched for all clinical studies/trials relating to enhanced recovery after colorectal resection. Relevant papers from the reference lists of these articles and from the authors' personal collections were also reviewed. A combination of evidence-based and consensus methodology was used to develop the resulting enhanced recovery after surgery (ERAS) clinical care protocol.

Results and Conclusions: Within traditional perioperative practice there is considerable evidence supporting a range of manoeuvres which, in isolation, may
\end{abstract}

\footnotetext{
*Corresponding author. Tel.: +44131242 3615; fax: +441312423617.

E-mail address: k.fearon@ed.ac.uk (K.C.H. Fearon).
} 
improve individual aspects of recovery after colonic surgery. The present manuscript reviews these issues in detail. There is also growing evidence that an integrated multimodal approach to perioperative care can result in an overall enhancement of recovery. However, effects on major morbidity and mortality remain to be determined. A protocol is presented which is in current use by the ERAS Group and may provide a standard of care against which either current or future novel elements of an enhanced recovery approach can be tested for their effect on outcome.

(c) 2005 Elsevier Ltd. All rights reserved.

\section{Introduction}

The key factors that keep a patient in hospital after uncomplicated major abdominal surgery include the need for parenteral analgesia (persistent pain), intravenous fluids (persistent gut dysfunction), and bed rest (persistent lack of mobility). These factors often overlap and interact to delay return of function. Obviously, postoperative complications will also prolong the time until recovery and ultimately length of stay. Interestingly, recent findings suggest that the rate of complications can be unaltered or even reduced when actions are taken that support faster return of normal function. ${ }^{1}$ A clinical pathway to accelerate recovery after colonic resection based on a multimodal programme with optimal pain relief, stress reduction with regional anaesthesia, early enteral nutrition and early mobilisation has demonstrated improvements in physical performance, pulmonary function, body composition and a marked reduction of length of stay. ${ }^{2-4} \mathrm{~A}$ subsequent randomised trial using a similar protocol has demonstrated a significant reduction in median length of stay from 7 to 3 days. ${ }^{5}$ However, different surgical groups proclaim wide variation in the nature of their optimal 'fast-track' or enhanced recovery programmes. For example, apparently similar outcomes can be achieved with ${ }^{3-5}$ or without epidural anaesthesia/analgesia. ${ }^{6}$ This suggests that it is the combination of each of the different elements of an enhanced recovery programme that goes to make an effective regimen rather than any single element on its own. At present, the evidence on which to base a multimodal programme is taken in isolation from traditional care pathways and little evidence is available concerning the importance of each element when considered within the context of an enhanced recovery pathway. The aim of this review is to consider the evidence-base for individual components of enhanced recovery programmes and to present the consensus of the The European Society of Clinical Nutrition and Metabolism (ESPEN) special interest group on management of patients undergoing such a programme (Fig. 1). The content of the consensus protocol refers to colonic surgery, but similar protocols have and can be developed for other surgical procedures.

\section{Methods}

The ERAS group was established in 2001 as a collaborative of five university or specialised Departments of Surgery from five Northern European Countries (Scotland, Sweden, Denmark, Norway and The Netherlands). Using the Medline database, an electronic search on 'fast-track' or 'multimodal' recovery was undertaken. Relevant papers from the reference lists of these articles and from group members' personal collections were also reviewed. The committee met on several occasions to reach a consensus on a protocol, which was then documented by the present authors.

\section{Results}

\section{Principles of the ERAS protocol}

Conventional perioperative metabolic care has accepted that a stress response to major surgery is inevitable. This concept has recently been challenged with the view that a substantial element of the stress response can be avoided with the appropriate application of modern anaesthetic, analgesic and metabolic support techniques. Conventional postoperative care has also emphasised prolonged rest for both the patient and their gastrointestinal tract. Similarly, this concept has recently been challenged. In the catabolic patient, medium-term functional decline will ensue if active steps are not taken to return the patient to full function as soon as possible. These two concepts have been combined to produce a new view of how 


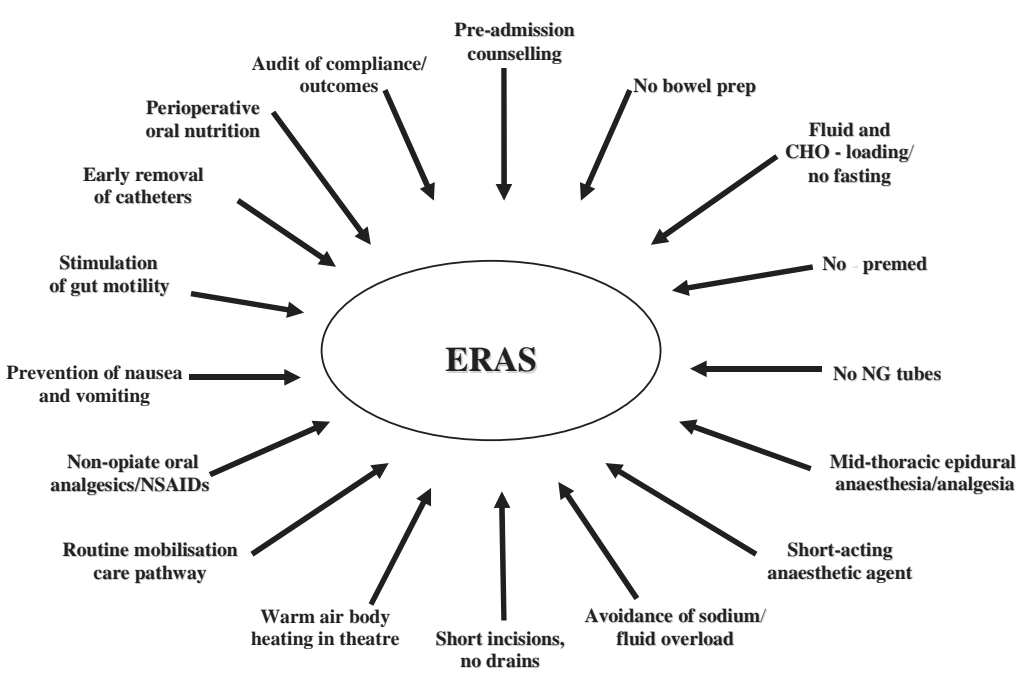

Figure 1 Main elements of the ERAS protocol.

surgical patients should be cared for (the ERAS protocol). Using a multidisciplinary team approach with a focus on stress reduction and promotion of return to function, the ERAS protocol aims to allow patients to recover more quickly from major surgery, avoid medium-term sequelae of conventional postoperative care (e.g. decline in nutritional status and fatigue) and reduce health care costs by reducing hospital stay.

\section{Preadmission information and counselling}

It is well established that intensive preoperative patient information can facilitate postoperative recovery and pain relief, particularly in patients who exhibit most denial and the highest levels of anxiety. ${ }^{7,8}$ A clear explanation of what is to happen during a patient's hospital stay can also facilitate adherence to the care pathway and allow timely recovery to allow early discharge. In addition and importantly, at this first meeting with the patient, he or she should also be given a clear role with specific tasks to perform during the postoperative period. ${ }^{9}$ These include targets for intakes of food and oral nutritional supplements (ONS) and targets for staying out of bed.

Consensus: A patient should receive oral and written preadmission information describing what will happen during their hospital stay, what they have to expect, and what their role is in their recovery.

\section{Preoperative bowel preparation}

Many regimens have been used, with oral sodium phosphate probably being the most convenient method. ${ }^{10}$ Mechanical bowel preparation is stressful for the patient and can result in significant dehydration/fluid and electrolyte abnormalities (particularly in the elderly). ${ }^{11} \mathrm{~A}$ recent metaanalysis of all available data ${ }^{12}$ confirms earlier meta-analyses ${ }^{13,14}$ showing that bowel preparation has no benefit in colonic surgery. Furthermore, this most recent meta-analysis suggests that bowel preparation increases the risk for anastomotic leak. Bowel preparation may be essential in selected patients who require intraoperative colonoscopy.

Consensus: Patients undergoing colonic resection should not receive routine oral bowel preparation.

\section{Preoperative fasting}

To avoid pulmonary aspiration, fasting after midnight has been the standard in elective surgery. However, a review of recent studies has found no scientific support for this practice. ${ }^{15}$ Several National Anaesthesia Societies now recommend intake of clear fluids up until $2 \mathrm{~h}$ before initiation of anaesthesia and a 6-h fast for solid food. ${ }^{16-18}$ It has been proposed that patients should be in the fed state rather than fasted when they go to theatre. Provision of a clear carbohydrate-rich beverage $(12.6 \%)$ at a dose of $800 \mathrm{mt}^{7}$ Before 
midnight and $400 \mathrm{ml} 2-3 \mathrm{~h}$ before surgery reduces preoperative thirst, hunger and anxiety ${ }^{19}$ and significantly reduces postoperative insulin resistance. ${ }^{20}$ Thus, patients are in a more anabolic state to benefit from postoperative nutrition ${ }^{21}$ and with less risk of hyperglycaemia. ${ }^{22}$ Patients should have access to normal food on the day before surgery.

Consensus: Patients should only be fasted for liquids for $2 \mathrm{~h}$ and for solids for $6 \mathrm{~h}$ preoperatively. Patients should receive oral preoperative fluids and carbohydrate loading.

\section{Preanaesthetic medication}

Beneficial effects of preanaesthetic medication on anxiety have not been established and preanaesthetic provision of anxiolytics increases postoperative sedation. ${ }^{23}$ Furthermore, a recent metaanalysis has demonstrated no effect on postoperative pain relief by starting analgesic treatment before the operation (so-called preemptive analgesia). ${ }^{24}$ Short-acting anxiolytics may be helpful in worried patients during placement of an epidural. In addition, the use of oral carbohydrate loading has been shown to reduce the level of preoperative anxiety. ${ }^{19}$ Patients who receive sleeping medication at home can continue in hospital.

Consensus: Patients should not receive preanaesthetic anxioloytic or analgesic medication.

\section{Anti-thrombotic prophylaxis}

In colorectal surgery, there is a clear indication for anti-thrombotic prophylaxis, where unfractionated and fractionated low-dose heparin regimens are effective. ${ }^{25}$ Low molecular weight heparin (LMWH) (fractionated) is preferable due to compliance (once daily administration). ${ }^{26}$ Low dose (20 mg enoxaprim daily) is about as effective as higher doses in general surgery and higher doses should be avoided because of the risk of potential bleeding complications when using concomitant epidural analgesia. Treatment is usually initiated $2-12 \mathrm{~h}$ before the operation and continued until fully mobilised. There is no further advantage in general surgery by continued treatment for 4 weeks (in contrast to major orthopaedic surgery). ${ }^{27}$

Concomitant use of LMWH and continuous epidural analgesia is debatable, due to reported cases of epidural haematoma in the USA, where double doses of thromboembolic prophylaxis have been used. ${ }^{28-31}$ Recommendations from USA authorities are: delayed administration until $1-2 \mathrm{~h}$ after epidural catheterisation and that the epidural catheter is removed $8-2 \mathrm{~h}$ after previous $\mathrm{LMWH}$ administra- tion. Concomitant administration of acetaminophen (paracetamol) does not add additional risk, while the risk of concomitant administration of nonsteroidal anti-inflammatory drugs (NSAID) and LMWH is considered safe, although debated. It should be emphasised that epidural analgesia per se reduces thromboembolic complications by $50 \%$ in lower body procedures, but this has not been demonstrated after abdominal procedures.

The use of graded compression elastic stocking is recommended and should be used to provide an additional advantage when combined with LMWH and epidural analgesia and mobilisation (combined effect unknown). Intermittent pneumatic compression is effective, but costly and may hinder early mobilisation and is therefore not recommended.

Consensus: Patients should receive antithrombotic prophylaxis according to the local peer-reviewed protocol.

\section{Anti-microbial prophylaxis}

It is well established that anti-microbial prophylaxis is effective in reducing infectious complications in colorectal surgery. ${ }^{32}$ Key elements include (1) that prophylaxis should be active against both aerobic and anaerobic bacteria, (2) that administration should be before skin incision and (3) that single-dose prophylaxis is as effective as multidose regimens (although a repeat dose intraoperatively may be justifiable in case of prolonged $(>3 \mathrm{~h})$ operations). The optimal anti-biotic combination regimen has not been established, but single-dose Metronidazole and Cefuroxime is suggested based upon cost considerations and avoidance of newer generations of antibiotics, which have not been demonstrated to be more effective than primary prophylaxis, and therefore may be used if secondary infectious complications occur.

Consensus: Patients should receive single-dose antibiotic prophylaxis against both aerobic and anaerobic pathogens.

\section{Standard anaesthetic protocol}

There is no evidence as to the choice of the optimal anaesthetic method based on morbidity or recovery data from colorectal procedures. However, it is rational to use agents with short pharmacodynamic duration (propofol, remifentanil) ${ }^{33}$ thereby allowing pro-active recovery to start on the day of surgery. Thus, opioids with longer-lasting effect (morphine, fentanyl) should be avoided. Shortacting inhalation anaesthesia is a reasonable alternative to total intravenous anaesthesia. There is no 
evidence that intraoperative epidural analgesia improves postoperative outcome in colorectal procedures, but its use will reduce the dosage of general anaesthetic agents. Also, a mid-thoracic epidural activated before the onset of surgery also blocks stress hormone release and attenuates postoperative insulin resistance. ${ }^{34}$ Epidural analgesia has been suggested for routine postoperative analgesia on the basis that it provides optimal pain relief and based on a meta-analysis may reduce postoperative mortality and morbidity. ${ }^{35} \mathrm{~A}$ recent large single study ${ }^{36}$ has questioned the benefits of epidural analgesia in terms of postoperative morbidity and mortality. One also has to consider the very small but significant risks of epidural haematoma or abscess or neurological damage $(0.01-0.6 \%)$. There is, however, clear evidence that a thoracic epidural can block many of the components of the stress response to injury ${ }^{37}$ and has been proven to reduce the duration of postoperative ileus. ${ }^{38}$ The catheter is best placed in the midthoracic level at T7/8 for colonic surgery to achieve both analgesic block and sympathetic block preventing gut paralysis. ${ }^{39}$ The catheter is sited in the awake patient to establish the effectiveness of the block. During surgery the block can be maintained by continuous infusion of local anaesthetic (e.g. bupivacaine $0.1 \%$ ) plus a low-dose opiate (e.g. $2 \mu \mathrm{g} / \mathrm{ml}$ fentanyl) at $4-10 \mathrm{ml} / \mathrm{h}$. Epidural opioids in small doses have been shown to act in synergy with epidural local anaesthetics in providing analgesia, allowing reduced dosages of both agents. ${ }^{40}$ Furthermore, low-dose epidural opioids improve the analgesic effects without major systemic effects. ${ }^{40}$ Finally, addition of a small amount of adrenaline to the epidural infusion of local anaesthetic and opioid has been shown to markedly improve analgesia and decrease systemic opioidrelated side-effects. ${ }^{41-43}$

Consensus: Patients should undergo anaesthesia avoiding long-acting opioids. Patients should receive a mid-thoracic epidural commenced preoperatively and containing local anaesthetic in combination with a low-dose opioid.

\section{Surgical incisions}

It remains unclear if transverse or longitudinal incisions are to be preferred. There is evidence from some randomised trials that transverse or curved incisions reduce pain and pulmonary dysfunction following abdominal procedures, ${ }^{44,45}$ while other trials have found no advantage of transverse incisions. ${ }^{46,47}$ The fact that some Departments always use transverse or curved incision while other Departments always use midline incisions provides evidence that sufficient access to the surgical site can be obtained by either type of incision. However, it is clear that incision length affects patient recovery. ${ }^{48}$

Consensus: Patients should undergo laparotomy using an abdominal incision of minimum length.

\section{Nasogastric intubation}

There is good evidence from a meta-analysis ${ }^{49}$ that routine nasogastric decompression should be avoided after colorectal surgery since fever, atelectases and pneumonia are reduced. There is no clear rationale for routine insertion of nasogastric tube during surgery, except to evacuate air that may have been pushed down in the stomach during intubation for ventilation. If a tube is placed during surgery, it should be removed before the patient wakes up from anaesthesia.

Consensus: Nasogastric decompression tubes should not be used as a routine in the postoperative period.

\section{Prevention of intraoperative hypothermia}

Prevention of intraoperative hypothermia reduces endocrine-metabolic responses and sympathetic reflexes, and changes the fibrinolytic-coagulatory balance resulting in reduced bleeding. Subsequently, several randomised trials have demonstrated that preservation of normothermia by infusion of warmed fluids and using an upper-body forced-air heating cover reduces wound infections, ${ }^{50}$ cardiac complications ${ }^{51}$ and bleeding and transfusion requirements. ${ }^{52}$

Consensus: Intraoperative maintenance of normothermia with infusion of warmed fluids and an upper-body forced-air heating cover should be used routinely.

\section{Perioperative fluid management}

A proportion of patients who undergo bowel preparation with purgative laxatives and who are subject to conventional preoperative fasting protocols are subject to dehydration and electrolyte imbalance. ${ }^{53-55}$ Avoidance of bowel preparation, the use of preoperative oral carbohydrate loading and free access to fluids until $2 \mathrm{~h}$ before induction of anaesthsia are potential methods to reduce this problem. There is good evidence to support the safety of allowing access to fluids up to $2 \mathrm{~h}$ before surgery. ${ }^{15}$
175 
With reference to intraoperative and postoperative intravenous fluids, modern resuscitation methodology has emphasised the concept that 'wet is best' and a patient therefore cannot be given too much intravenous fluid. With traditional care patients currently receive $3.5-5 \mathrm{l}$ of intravenous fluids on the day of surgery and 2 l/day for the next 3-4 days with a resultant weight gain of $3-6 \mathrm{~kg}$ over the perioperative period. ${ }^{56,57}$ Recently, however, evidence has suggested that a policy of providing no more intravenous infusions than necessary to maintain fluid balance (i.e. body weight), may significantly reduce postoperative complications $^{58}$ and shorten postoperative hospital stay. ${ }^{57}$ Clearly, the best way to limit postoperative intravenous fluid administration is to take the intravenous drip down. This can usually be achieved routinely on the first or second postoperative day. ${ }^{3}$

Patients with an epidural can experience vasodilation leading to relative intravascular volume depletion and hypotension. Intraoperative and postoperative management of hypotension may include fluid loading. Alternatively, the judicious use of vasopressors can avoid excessive fluid administration. ${ }^{59}$

There is increasing evidence that excess administration of salt solutions can delay the return of normal gastrointestinal function ${ }^{57}$ and can be associated with increased postoperative complications and prolonged hospital stay. ${ }^{56,58}$ Equally, for high-risk patients there is evidence that goaldirected preoperative conditioning (including fluid loading) can reduce postoperative complications. ${ }^{60}$ Clearly, there must be a balance between achieving adequate tissue perfusion versus overloading the patient with sodium and/or water. Trans-oesophageal Doppler ultrasonography during surgery offers a method of titrating fluids in relation to cardiac output and may be particularly useful in the high risk patient and may even result in reduced length of stay. ${ }^{61,62}$

Consensus: Patients should commence oral fluids $2 \mathrm{~h}$ post surgery on day 0 . Target intake should be $>800 \mathrm{ml}$ oral fluids on the day of operation. Patients should have IV fluids discontinued as soon as adequate oral intake is established. The target should be during day 1 .

Vasopressors should be considered for the intraand postoperative management of epidural-related hypotension. A reduction in epidural infusion rate should also be considered. Target levels for blood pressure should be moderated. Intraoperative monitoring of fluid replacement with Doppler ultrasonography may help in the management of high-risk patients.

\section{Drainage of peritoneal cavity following colonic anastomoses}

The presence of an abdominal drain represents a significant impediment to achieving early and appropriate levels of mobilisation. Meta-analyses $^{63,64}$ have demonstrated that use of drains after colonic anastomoses does not reduce the incidence or the severity of an anastomotic leak or other complications.

Consensus: Drains are not recommended following routine colonic resection.

\section{Urinary drainage}

Several randomised trials report that suprapubic bladder drainage as compared with urethral catheterisation is associated with lower urinary tract infection rates and/or lower discomfort in patients undergoing abdominal surgery ${ }^{65-67}$ while another showed no such benefits. ${ }^{68}$ Most trials have been undertaken in patients requiring prolonged periods of urinary drainage (i.e. 4-7 days). The risk of urinary retention after only $24 \mathrm{~h}$ urinary bladder catheterisation has been reported to be low after colonic resection during epidural analgesia. ${ }^{69}$ The presence of urinary drainage represents a significant impediment to achieving early and appropriate levels of mobilisation.

Consensus: It is recommended to use urinary bladder drainage for the duration of thoracic epidural analgesia. Earlier removal of urinary drainage may be considered before the epidural is stopped.

\section{Postoperative nausea and vomiting}

In order to attain the objective of early and sustained oral food intake it is important to have a defined strategy for the management of postoperative nausea and vomiting (PONV). Risk factors should be minimised including the avoidance of emetogenic drugs (neostigmine, opioids, certain gaseous anaesthetic agents, etc) with the substitution of agents that are less so. Patients at risk for PONV (e.g. non-smoking women with a history of motion sickness) should receive prophylactic treatment (e.g. ondansetron, dexamethasone or droperidol).$^{70}$ If patients develop nausea and vomiting, treatment should be with a combination of such agents.

Consensus: Antiemetics should be used selectively and in a structured manner to diminish PONV and promote an early return of oral intake. 
lleus prophylaxis and promotion of gastrointestinal motility Patients' pattern of postoperative care should be integrated to try to prevent postoperative gut dysfunction. Strategies should include epidural analgesia, ${ }^{38}$ avoidance of opiates, avoidance of fluid overload ${ }^{57}$ and use of oral magnesium oxide (1 $\mathrm{g}$ twice daily commenced on the evening of surgery and used until discharge). ${ }^{3}$

Consensus: Patients should undergo a structured pattern of care to avoid postoperative ileus and promote early oral intake.

\section{Postoperative analgesia}

It is well established from several controlled trials and a Cochrane Review ${ }^{38}$ that optimal analgesia allowing early mobilisation is best achieved by continuous epidural local anaesthetic or local anaesthetic-opioid techniques. Patient-controlled analgesia (PCA) using intravenous opioids does not provide the same efficient analgesia and has less beneficial physiological effects on surgical stress responses compared with epidural local anaesthetic techniques. Whilst it is possible to achieve almost the same pain scores with PCA at rest compared with epidural analgesia, this is done at the expense of the patient remaining sedated and at rest in bed. Randomised trials have demonstrated that continuous epidural local anaesthetic techniques reduce pulmonary morbidity, but not other types of morbidity or hospital stay or convalescence. ${ }^{71}$ The explanation hereto is probably that unimodal intervention does not take advantage of the efficient analgesia and positive effect on paralytic ileus provided by an epidural on its own. NSAIDs may provide some additional analgesia, but probably less than in minor procedures. $^{72}$ The combination of paracetamol and NSAIDs provides superior analgesia in minor procedures but has not been demonstrated to be synergistic/additive in major (colorectal) procedures. ${ }^{73}$ The main principle for analgesia is opioid sparing thereby avoiding opioid-related side effects and enhancing recovery. ${ }^{74}$ The optimal duration of continuous postoperative mid-thoracic epidural analgesia has not been established in well-designed randomised trials, but large-case series suggest that two days may be sufficient in colonic resection. ${ }^{3}$ NSAIDs should not be given during a wellfunctioning epidural since there is no evidence that this improves analgesia.

Consensus: Patients should receive continuous epidural mid-thoracic low-dose local-anaesthetic/ opioid combinations for 2 days after colonic resection. Paracetamol should be given as a baseline analgesic ( $4 \mathrm{~g}$ daily) throughout the postoperative course. For break-through pain NSAIDs and bolus epidural bupivacaine should be given whilst the epidural is running. NSAIDs should be started just before removal of the epidural and continued until and/or after discharge.

\section{Postoperative nutritional care}

For normally nourished patients, restoration of normal GI function to allow adequate food intake and rapid recovery is one of the primary objectives of postoperative care. A meta-analysis of controlled trials of early enteral or oral feeding versus 'nil by mouth' after Gl surgery concluded there is no clear advantage to keeping patients fasting after elective $\mathrm{GI}$ resection. ${ }^{75}$ Early feeding reduced both the risk of any type of infection and the mean length of stay in hospital. Furthermore, early feeding was not associated with an increased risk of dehiscence of an anastomosis distal to the site of feeding. However, the risk of vomiting increased in patients fed early and, in the absence of multimodal anti-ileus therapy, early enteral feeding was associated with intestinal bloating and impairment of mobilisation and pulmonary function. ${ }^{76}$

For malnourished patients undergoing abdominal surgery, there is a clear advantage for the prescription of ONS in the postoperative period and for 8 weeks thereafter in terms of recovery of nutritional status, protein economy and quality of life. ${ }^{77}$ Positive clinical outcomes from oral nutrition supplements have also been documented in studies of elective surgical patients who were not screened specifically for malnutrition. ${ }^{78,79}$ However, oral supplementation in such studies (using traditional perioperative care) was commenced some 4-5 days after the day of surgery. In enhanced recovery programmes, ONS have been used successfully on the day prior to operation and for at least the first four post operative days to achieve recommended intakes of energy and protein. $3,80,81$

When used in combination, preoperative oral carbohydrate loading, epidural analgesia and early enteral nutrition have been shown to result in nitrogen equilibrium without concomitant hyperglycaemia. ${ }^{22}$ This emphasises the importance of multimodal therapy in the maintenance of nutritional status following surgery.

Consensus: Patients should be encouraged to commence oral food intake $4 \mathrm{~h}$ after surgery. ONS should be taken (approx $400 \mathrm{ml}$ energy dense ONS) from the day of surgery until a normal level of food intake is achieved. Continuation of ONS at 
home is recommended for nutritionally depleted patients.

\section{Early mobilisation}

Bed rest not only increases insulin resistance and muscle loss but also decreases muscle strength, pulmonary function and tissue oxygenation. ${ }^{82}$ Moreover patients are exposed to an increased risk of thromboembolism. Effective pain relief using ambulatory thoracic epidural analgesia is a key adjuvant measure to encourage postoperative mobilisation. Organisation is essential, and a prescheduled care plan should be drawn up with goals for mobilisation listed each day. It is essential that the patient be nursed in an environment which encourages early mobilisation. In particular, whilst the patient has an epidural running it is helpful if patients are nursed in an ordinary ward or level 1 facility rather than a high dependency unit (level 2 ). The latter leads to suppression of the patient's independence. If possible, food and television facilities should be separate from the patient's bedside to encourage mobilisation. Another useful measure may be using a patient diary where patients document the time out of bed on a daily basis. The aim is that patients are out of bed $2 \mathrm{~h}$ on the day of surgery, and $6 \mathrm{~h}$ per day until discharge.

Consensus: Patients should be nursed in an environment that encourages independence and mobilisation. A care plan that facilitates patients being out of bed for $2 \mathrm{~h}$ on the day of surgery and $6 \mathrm{~h}$ thereafter is recommended.

\section{Discharge criteria}

Patients can be discharged when they meet the following criteria:

(a) good pain control with oral analgesia;

(b) taking solid food, no intravenous fluids;

(c) independently mobile or same level as prior to admission;

(d) all of the above and willing to go home.

The discharge process starts at the preadmission counselling session when it is determined if the patient lives alone and has any special needs (e g transport, social support etc). Problems that will delay discharge must be addressed at this time rather than once the patient has been admitted.

Consensus: Planning the discharge process should begin when the patient attends for preadmission counselling. Defined discharge criteria should be followed?

\section{Follow-up}

Patients entering an enhanced recovery programme will inevitably require more active supervision when they get home. In general, if length of stay is reduced to $2-3$ days approximately $10-20 \%$ may require readmission or a few hours of observation and treatment as outpatients. ${ }^{3,82}$ Readmission in itself does not imply an overnight stay. Often patients can re-attend the hospital as an outpatient, receive treatment (e.g. anti-emetics/ analgesia/fluids) and go home the same day. Ready access to medical and nursing advice either on the phone or on the ward must be structured into the Unit's working practice. Patients' general practitioners should be alerted to their patients' participation in an enhanced recovery programme and to their increased needs in the community. It is essential that there is a clear pathway for the prompt and safe readmission of the 1-3\% of patients who will experience an anastomotic leak at home.

Once at home, patients should be contacted by phone within $24-48 \mathrm{~h}$ to ensure all is well and to provide advice. Many Units organise out-patient clinic review at 7-10 days following surgery when the wound can be checked, staples/stitches removed, pathology results discussed and, if necessary, future oncology therapy organised. A further clinical or telephone review at 30 days after surgery is recommended for patient reassurance and audit purposes.

Consensus: Surgical units undertaking an enhanced recovery programme must be restructured to provide adequate follow-up and continuity of care. An enhanced recovery programme should only be initiated once there is a clear pathway established for the prompt and safe readmission of the $1-3 \%$ of patients who will experience an anastomotic leak (or other major complications) at home.

\section{Audit}

All good surgical practice is based on ongoing audit of clinical outcomes. It is essential that outcomes be documented during the introduction of an enhanced recovery programme. This not only ensures that morbidity and mortality are optimal but that feedback is provided on aspects of the programme that may need further development of infrastructure/staff education.

Consensus: Audit is an inherent and essential component of every enhanced recovery programme. 


\section{Summary of core protocol elements}

- Patient information: Essential before admission for surgery.

- Preoperative bowel preparation: No routine oral preparation for colon resections.

- Preanaesthetic medication: Not recommended.

- Preoperative fasting and fluids: Patients should be allowed to drink clear fluids up to $2 \mathrm{~h}$ prior to initiation of anaesthesia and should receive preoperative oral carbohydrate loading.

- Standard anaesthetic protocol: Intraoperative mid-thoracic epidural analgesia (local anaesthetic+low-dose opioid). Short-acting intravenous or inhalational anaesthetic agents, according to local traditions.

- Prevention of intraoperative hypothermia: Warmed IV fluids and upper body air-warming device.

- Thromboembolic prophylaxis: Low-dose LMWH started about $2 \mathrm{~h}$ after placement of epidural catheter and continued until full mobilisation.

- Nasogastric decompression tubes: Not recommended.

- Prophylactic antibiotics: Indicated with two drugs (anaerobic and aerobic prophylaxis) given before skin incision and single dose, may be repeated when surgery $>3 \mathrm{~h}$.

- Incision: Short midline or transverse incisions recommended.

- Drainage: Drains should not be used routinely in colonic surgery.

- Urinary bladder catheterisation: Suprapubic or urethral catheterisation. Removal of catheter 24-48 h after surgery recommended.

- Fluid therapy: Avoid excessive intravenous fluids. Vasopressors recommended for treatment of epidural-related hypotension. Discontinuation of IV fluids on postoperative day 1.

- Ileus prophylaxis and promotion of GI motility: Continuous thoracic epidural analgesia for first 2 postoperative days (low-dose epidural local anaesthetic-opioid): Use of magnesium oxide twice daily recommended.

- Postoperative analgesia: Continuous thoracic epidural analgesia for 2 days postoperatively (low-dose epidural local anaesthetic-opioid), paracetamol as routine oral analgesic and epidural top up as rescue. Commence NSAIDs at end of epidural. Additional opioid only if other efforts fail.

- Nutrition: Postoperative nutrition includes ONS from the day of operation in addition to normal food. Malnourished patients should continue ONS at home.
- Early Mobilisation: A care plan that facilitates patients being out of bed for $2 \mathrm{~h}$ on the day of surgery and $6 \mathrm{~h}$ thereafter is recommended.

- Discharge Criteria: Good pain control with oral analgesics, taking solid food and no intravenous fluids, independently mobile, willing to go home.

- Follow-up and audit: Patients should be contacted 1-2 days after discharge, reviewed clinically at 7-10 days postoperatively and reviewed finally at 30 days postoperatively. Audit of results/endpoints/adverse events and protocol compliance is essential.

\section{Acknowledgement}

The ERAS group would like to thank Nutricia Healthcare for their generous financial support via an unrestricted grant.

\section{References}

1. Kehlet H, Dahl JB. Anaesthesia, surgery, and challenges in postoperative recovery. Lancet 2003;362(9399):1921-8.

2. Basse L, Raskov HH, Hjort Jakobsen D, Sonne E, Billesbolle P, Hendel HW, et al. Accelerated postoperative recovery programme after colonic resection improves physical performance, pulmonary function and body composition. Br J Surg 2002;89(4):446-53.

3. Basse L, Hjort Jakobsen D, Billesbolle P, Werner M, Kehlet H. A clinical pathway to accelerate recovery after colonic resection. Ann Surg 2000;232(1):51-7.

4. Basse L, Thorbol JE, Lossl K, Kehlet H. Colonic surgery with accelerated rehabilitation or conventional care. Dis Colon Rectum 2004;47(3):271-7 (Discussion 277-8).

5. Anderson $\mathrm{AD}$, McNaught CE, MacFie J, Tring I, Barker P, Mitchell CJ. Randomized clinical trial of multimodal optimization and standard perioperative surgical care. Br J Surg 2003;90(12):1497-504.

6. Delaney CP, Fazio VW, Senagore AJ, Robinson B, Halverson $\mathrm{AL}$, Remzi $\mathrm{FH}$. 'Fast track' postoperative management protocol for patients with high co-morbidity undergoing complex abdominal and pelvic colorectal surgery. Br J Surg 2001;88(11):1533-8.

7. Egbert LD, Battit GE, Welch CE, Bartlett MK. Reduction of postoperative pain by encouragement and instruction of patients. A study of doctor-patient rapport. N Engl J Med 1964;270:825-7.

8. Kiecolt-Glaser JK, Page GG, Marucha PT, MacCallum RC, Glaser R. Psychological influences on surgical recovery. Perspectives from psychoneuroimmunology. Am Psychol 1998;53(11):1209-18.

9. Disbrow EA, Bennett HL, Owings JT. Effect of preoperative suggestion on postoperative gastrointestinal motility. West $J$ Med 1993;158(5):488-92.

10. Toledo TK, DiPalma JA. Review article: colon cleansing preparation for gastrointestinal procedures. Aliment Pharmacol Ther 2001;15(5):605-11.

11. Holte K, Nielsen KG, Madsen JL, Kehlet H. Physiologic effects of bowel preparation. Dis Colon Rectum 2004; 47(8):1397-402. 
12. Slim K, Vicaut E, Panis Y, Chipponi J. Meta-analysis of randomized clinical trials of colorectal surgery with or without mechanical bowel preparation. Br J Surg 2004; 91(9):1125-30.

13. Wille-Jorgensen P, Guenaga KF, Castro AA, Matos D. Clinical value of preoperative mechanical bowel cleansing in elective colorectal surgery: a systematic review. Dis Colon Rectum 2003;46(8):1013-20.

14. Platell $C$, Hall J. What is the role of mechanical bowel preparation in patients undergoing colorectal surgery? Dis Colon Rectum 1998;41(7):875-82 (discussion 882-3).

15. Ljungqvist $\mathrm{O}$, Soreide $\mathrm{E}$. Preoperative fasting. $\mathrm{Br} J$ Surg 2003;90(4):400-6.

16. Eriksson LI, Sandin R. Fasting guidelines in different countries. Acta Anaesthesiol Scand 1996;40(8 Part 2):971-4.

17. Soreide E, Fasting S, Raeder J. New preoperative fasting guidelines in Norway. Acta Anaesthesiol Scand 1997; 41(6):799.

18. Practice guidelines for preoperative fasting and the use of pharmacologic agents to reduce the risk of pulmonary aspiration: application to healthy patients undergoing elective procedures: a report by the American Society of Anesthesiologist Task Force on Preoperative Fasting. Anesthesiology 1999;90(3):896-905.

19. Hausel J, Nygren J, Lagerkranser M, Hellstrom PM, Hammarqvist $F$, Almstrom $C$, et al. A carbohydrate-rich drink reduces preoperative discomfort in elective surgery patients. Anesth Analg 2001;93(5):1344-50.

20. Soop M, Nygren J, Myrenfors P, Thorell A, Ljungqvist 0 . Preoperative oral carbohydrate treatment attenuates im mediate postoperative insulin resistance. Am J Physiol Endocrinol Metab 2001;280(4):E576-83.

21. Yuill KA, Richardson RA, Davidson HI, Garden OJ, Parks RW. The administration of an oral carbohydrate-containing fluid prior to major elective upper-gastrointestinal surgery preserves skeletal muscle mass postoperatievely - a randomised clinical trial. Clinical Nutrition 2005;24(1):32-7.

22. Soop M, Carlson GL, Hopkinson J, Clarke S, Thorell A, Nygren $\mathrm{J}$, et al. Randomized clinical trial of the effects of immediate enteral nutrition on metabolic responses to major colorectal surgery in an enhanced recovery protocol. Br J Surg 2004;91(9):1138-45.

23. Caumo W, Hidalgo MP, Schmidt AP, Iwamoto CW, Adamatt LC, Bergmann J, et al. Effect of pre-operative anxiolysis on postoperative pain response in patients undergoing total abdominal hysterectomy. Anaesthesia 2002;57(8):740-6.

24. Moiniche $\mathrm{S}$, Kehlet $\mathrm{H}$, Dahl JB. A qualitative and quantitative systematic review of preemptive analgesia for postoperative pain relief: the role of timing of analgesia. Anesthesiology 2002;96(3):725-41.

25. Clagett GP, Anderson Jr FA, Geerts W, Heit JA, Knudson M, Lieberman JR, et al. Prevention of venous thromboembolism. Chest 1998;114(Suppl. 5):531S-60S.

26. Koch A, Bouges S, Ziegler S, Dinkel H, Daures JP, Victor N. Low molecular weight heparin and unfractionated heparin in thrombosis prophylaxis after major surgical intervention: update of previous meta-analyses. Br J Surg 1997;84(6): 750-9.

27. Lausen I, Jensen R, Jorgensen LN, Rasmussen MS, Lyng KM, Andersen $M$, et al. Incidence and prevention of deep venous thrombosis occurring late after general surgery: randomised controlled study of prolonged thromboprophylaxis. Eur $J$ Surg 1998;164(9):657-63.

28. Horlocker TT, Wedel DJ. Spinal and epidural blockade and perioperative low molecular weight heparin: smooth sailing on the Titanic. Anesth Analg 1998;86(6):1153-6.
29. Liu SS, Mulroy MF. Neuraxial anesthesia and analgesia in the presence of standard heparin. Reg Anesth Pain Med 1998;23(6 Suppl 2):157-63.

30. Horlocker TT, Wedel DJ. Neuraxial block and low-molecularweight heparin: balancing perioperative analgesia and thromboprophylaxis. Reg Anesth Pain Med 1998;23(6 Suppl 2):164-77.

31. Tryba M. European practice guidelines: thromboembolism prophylaxis and regional anesthesia. Reg Anesth Pain Med 1998;23(6 Suppl 2):178-82.

32. Song F, Glenny AM. Antimicrobial prophylaxis in colorectal surgery: a systematic review of randomized controlled trials. Br J Surg 1998;85(9):1232-41.

33. British National Formulary Oxford. UK: Pharmaceutical Press; 2003.

34. Uchida I, Asoh T, Shirasaka C, Tsuji H. Effect of epidural analgesia on postoperative insulin resistance as evaluated by insulin clamp technique. Br J Surg 1988;75(6):557-62.

35. Rodgers A, Walker N, Schug S, McKee A, Kehlet $H$, van Zundert A, et al. Reduction of postoperative mortality and morbidity with epidural or spinal anaesthesia: results from overview of randomised trials. Br Med J 2000;321(7275): 1493.

36. Rigg JR, Jamrozik K, Myles PS, Silbert BS, Peyton PJ, Parsons RW, et al. Epidural anaesthesia and analgesia and outcome of major surgery: a randomised trial. Lancet 2002;359 (9314):1276-82.

37. Holte K, Kehlet H. Epidural anaesthesia and analgesia-effects on surgical stress responses and implications for postoperative nutrition. Clin Nutr 2002;21(3):199-206.

38. Jorgensen $\mathrm{H}$, Wetterslev J, Moiniche S, Dahl JB. Epidural local anaesthetics versus opioid-based analgesic regimens on postoperative gastrointestinal paralysis, PONV and pain after abdominal surgery. Cochrane Database Syst Rev 2000(4):CD001893.

39. Miedema BW, Johnson JO. Methods for decreasing postoperative gut dysmotility. Lancet Oncol 2003;4(6):365-72.

40. Liu SS, Carpenter RL, Mackey DC, Thirlby RC, Rupp SM, Shine TS, et al. Effects of perioperative analgesic technique on rate of recovery after colon surgery. Anesthesiology 1995; 83(4):757-65.

41. Niemi G, Breivik H. Adrenaline markedly improves thoracic epidural analgesia produced by a low-dose infusion of bupivacaine, fentanyl and adrenaline after major surgery. A randomised, double-blind, cross-over study with and without adrenaline. Acta Anaesthesiol Scand 1998;42(8): 897-909.

42. Niemi G, Breivik H. Epinephrine markedly improves thoracic epidural analgesia produced by a small-dose infusion of ropivacaine, fentanyl, and epinephrine after major thoracic or abdominal surgery: a randomized, double-blinded crossover study with and without epinephrine. Anesth Analg 2002;94(6):1598-605 (table of contents).

43. Niemi G, Breivik $\mathrm{H}$. The minimally effective concentration of adrenaline in a low-concentration thoracic epidural analgesic infusion of bupivacaine, fentanyl and adrenaline after major surgery. A randomized, double-blind, dose-finding study. Acta Anaesthesiol Scand 2003;47(4):439-50.

44. Grantcharov TP, Rosenberg J. Vertical compared with transverse incisions in abdominal surgery. Eur J Surg 2001; 167(4):260-7.

45. Lindgren PG, Nordgren SR, Oresland T, Hulten L. Midline or transverse abdominal incision for right-sided colon cancer-a randomized trial. Colorectal Dis 2001;3(1):46-50.

46. Brown SR, Goodfellow PJ, Adam IJ, Shorthouse AJ. A randomised controlled trial of transverse skin crease vs. 
vertical midline incision for right hemicolectomy. Tech Coloproctol 2004;8(1):15-8.

47. Greenall MJ, Evans M, Pollock AV. Midline or transverse laparotomy? A random controlled clinical trial. Part I: Influence on healing. Br J Surg 1980;67(3):188-90.

48. O'Dwyer PJ, McGregor JR, McDermott EW, Murphy JJ, O'Higgins NJ. Patient recovery following cholecystectomy through a $6 \mathrm{~cm}$ or $15 \mathrm{~cm}$ transverse subcostal incision: a prospective randomized clinical trial. Postgrad Med J 1992; 68(804):817-9.

49. Cheatham ML, Chapman WC, Key SP, Sawyers JL. A metaanalysis of selective versus routine nasogastric decompression after elective laparotomy. Ann Surg 1995;221(5): 469-76 (discussion 476-8).

50. Kurz A, Sessler DI, Lenhardt R. Perioperative normothermia to reduce the incidence of surgical-wound infection and shorten hospitalization. Study of Wound Infection and Temperature Group. N Engl J Med 1996;334(19): 1209-15.

51. Frank SM, Fleisher LA, Breslow MJ, Higgins MS, Olson KF, Kelly $\mathrm{S}$, et al. Perioperative maintenance of normothermia reduces the incidence of morbid cardiac events. A randomized clinical trial. J Am Med Assoc 1997;277(14):1127-34.

52. Schmied H, Kurz A, Sessler DI, Kozek S, Reiter A. Mild hypothermia increases blood loss and transfusion requirements during total hip arthroplasty. Lancet 1996;347(8997):289-92.

53. Barker P, Trotter T, Hanning C. A study of the effect of Picolax on body weight, cardiovascular variables and haemoglobin concentration. Ann R Coll Surg Engl 1992; 74(5):318-9.

54. Sanders G, Mercer SJ, Saeb-Parsey K, Akhavani MA, Hosie $\mathrm{KB}$, Lambert AW. Randomized clinical trial of intravenous fluid replacement during bowel preparation for surgery. Br J Surg 2001;88(10):1363-5.

55. Hill AG, Teo W, Still A, Parry BR, Plank LD, Hill GL. Cellular potassium depletion predisposes to hypokalaemia after oral sodium phosphate. Aust N Z J Surg 1998;68(12):856-8.

56. Tambyraja AL, Sengupta F, MacGregor AB, Bartolo DC, Fearon KC. Patterns and clinical outcomes associated with routine intravenous sodium and fluid administration after colorectal resection. World J Surg 2004;28(10):1046-51 (discussion 1051-2).

57. Lobo DN, Bostock KA, Neal KR, Perkins AC, Rowlands BJ, Allison SP. Effect of salt and water balance on recovery of gastrointestinal function after elective colonic resection: a randomised controlled trial. Lancet 2002;359(9320): 1812-8.

58. Brandstrup B, Tonnesen H, Beier-Holgersen R, Hjortso E, Ording $\mathrm{H}$, Lindorff-Larsen $\mathrm{K}$, et al. Effects of intravenous fluid restriction on postoperative complications: comparison of two perioperative fluid regimens: a randomized assessorblinded multicenter trial. Ann Surg 2003;238(5):641-8.

59. Holte K, Foss NB, Svensen C, Lund C, Madsen JL, Kehlet H. Epidural anesthesia, hypotension, and changes in intravascular volume. Anesthesiology 2004;100(2):281-6.

60. Wilson J, Woods I, Fawcett J, Whall R, Dibb W, Morris C, et al. Reducing the risk of major elective surgery: randomised controlled trial of preoperative optimisation of oxygen delivery. Br Med J 1999;318(7191):1099-103.

61. Sinclair $S$, James $S$, Singer $M$. Intraoperative intravascular volume optimisation and length of hospital stay after repair of proximal femoral fracture: randomised controlled trial. Br Med J 1997;315(7113):909-12.

62. Venn R, Steele A, Richardson P, Poloniecki J, Grounds M, Newman P. Randomized controlled trial to investigate influence of the fluid challenge on duration of hospital stay and perioperative morbidity in patients with hip fractures. Br J Anaesth 2002;88(1):65-71.

63. Urbach DR, Kennedy ED, Cohen MM. Colon and rectal anastomoses do not require routine drainage: a systematic review and meta-analysis. Ann Surg 1999;229(2): 174-80.

64. Jesus E, Karliczek A, Matos D, Castro A, Atallah A. Prophylactic anastomotic drainage for colorectal surgery. Cochrane Database Syst Rev 2004(4):CD002100.

65. Sethia KK, Selkon JB, Berry AR, Turner CM, Kettlewell MG, Gough $\mathrm{MH}$. Prospective randomized controlled trial of urethral versus suprapubic catheterization. Br J Surg 1987; 74(7):624-5.

66. O'Kelly TJ, Mathew A, Ross S, Munro A. Optimum method for urinary drainage in major abdominal surgery: a prospective randomized trial of suprapubic versus urethral catheterization. Br J Surg 1995;82(10):1367-8.

67. Ratnaval CD, Renwick P, Farouk R, Monson JR, Lee PW. Suprapubic versus transurethral catheterisation of males undergoing pelvic colorectal surgery. Int J Colorectal Dis 1996;11(4):177-9.

68. Baan $\mathrm{AH}$, Vermeulen $\mathrm{H}$, van der Meulen J, Bossuyt $\mathrm{P}$, Olszyna D, Gouma DJ. The effect of suprapubic catheterization versus transurethral catheterization after abdominal surgery on urinary tract infection: a randomized controlled trial. Dig Surg 2003;20(4):290-5.

69. Basse $L$, Werner $M$, Kehlet $\mathrm{H}$. Is urinary drainage necessary during continuous epidural analgesia after colonic resection? Reg Anesth Pain Med 2000;25(5):498-501.

70. Gan TJ, Meyer T, Apfel CC, Chung F, Davis PJ, Eubanks S, et al. Consensus guidelines for managing postoperative nausea and vomiting. Anesth Analg 2003;97(1):62-71.

71. Ballantyne JC, Carr DB, deFerranti S, Suarez T, Lau J, Chalmers TC, et al. The comparative effects of post operative analgesic therapies on pulmonary outcome: cumulative meta-analyses of randomized, controlled trials. Anesth Analg 1998;86(3):598-612.

72. Power I, Barratt S. Analgesic agents for the postoperative period. Nonopioids. Surg Clin North Am 1999;79(2) 275-95.

73. Hyllested M, Jones S, Pedersen JL, Kehlet H. Comparative effect of paracetamol, NSAIDs or their combination in postoperative pain management: a qualitative review. $\mathrm{Br} J$ Anaesth 2002;88(2):199-214.

74. Kehlet $\mathrm{H}$, Holte $\mathrm{K}$. Effect of postoperative analgesia on surgical outcome. Br J Anaesth 2001;87(1):62-72.

75. Lewis SJ, Egger M, Sylvester PA, Thomas S. Early enteral feeding versus "nil by mouth" after gastrointestinal surgery: systematic review and meta-analysis of controlled trials. Br Med J 2001;323(7316):773-6.

76. Watters JM, Kirkpatrick SM, Norris SB, Shamji FM, Wells GA. Immediate postoperative enteral feeding results in impaired respiratory mechanics and decreased mobility. Ann Surg 1997;226(3):369-77 (discussion 377-80).

77. Beattie AH, Prach AT, Baxter JP, Pennington CR. A randomised controlled trial evaluating the use of enteral nutritional supplements postoperatively in malnourished surgical patients. Gut 2000;46(6):813-8.

78. Keele AM, Bray MJ, Emery PW, Duncan HD, Silk DB. Two phase randomised controlled clinical trial of postoperative oral dietary supplements in surgical patients. Gut 1997; 40(3):393-9.

79. Smedley F, Bowling T, James M, Stokes E, Goodger C, O'Connor $\mathrm{O}$, et al. Randomized clinical trial of the effects of preoperative and postoperative oral nutritional supptements 
on clinical course and cost of care. $\mathrm{Br} J$ Surg 2004; 91(8):983-90.

80. Fearon KC, Luff R. The nutritional management of surgical patients: enhanced recovery after surgery. Proc Nutr Soc 2003;62(4):807-11.
81. Henriksen MG, Hansen HV, Hessov I. Early oral nutrition after elective colorectal surgery: influence of balanced analgesia and enforced mobilization. Nutrition 2002;18(3):263-7.

82. Kehlet H, Wilmore DW. Multimodal strategies to improve surgical outcome. Am J Surg 2002;183(6):630-41.

Available online at www.sciencedirect.com

science@directo 